\title{
Male migration and alpha male takeovers in crested macaques, Macaca nigra
}

\author{
Dissertation \\ for the award of the degree \\ "Doctor rerum naturalium" (Dr.rer.nat.) \\ of the Georg-August-Universität Göttingen \\ within the doctoral program Biology \\ of the Georg-August University School of Science (GAUSS) \\ Submitted by \\ Pascal Marty \\ from Uitikon, Switzerland \\ Göttingen, 2015
}


Thesis committee

Prof. Dr. Julia Fischer

Cognitive Ethology Lab,

German Primate Center \& Georg-August University Göttingen

Prof. Dr. Keith Hodges

Senior Professor,

German Primate Center

Dr. Antje Engelhardt

Jr. Research Group Primate Sexual Selection,

German Primate Center

Members of the examination board:

Reviewers:

Prof. Dr. Julia Fischer

Cognitive Ethology Lab,

German Primate Center \& Georg-August University Göttingen

Prof. Dr. Keith Hodges

Senior Professor,

German Primate Center

Further members of the examination board:

Dr. Antje Engelhardt

Jr. Research Group Primate Sexual Selection,

German Primate Center \& Georg-August University Göttingen

Prof. Prof. Dr. Michael Mühlenberg

Conservation Biology, Workgroup on Endangered Species

Georg-August-University Göttingen

Prof. Dr. Julia Ostner

Department of Behavioral Ecology

Georg-August-University Göttingen

Dr. Bernhard Fink

Emmy-Noether-Research Group, Department of Psychology \& Courant Research Center 'Evolution of Social Behavior'

Georg-August-University Göttingen

Day of the oral examination: 24.04 .2015 




\section{Table of Contents}

Summary _ 1

Zusammenfassung __ 5

Chapter 1: General introduction ___ 9

1.1. Dispersal ___ 12

1.1.1. Benefits of dispersal ___ 12

1.1.2. Costs of dispersal ___ 14

1.1.3. Migration strategies based on the cost-benefit trade-off __ 17

1.2. Crested macaques as a model species ___ 20

1.3. Aims of this thesis ___ 21

Chapter 2: Cost and benefit dependent migration strategies in male crested macaques

(Macaca nigra)

Chapter 3: Experience rather than external factors predict the physiological stress

response upon immigration in male crested macaques (Macaca nigra) 41

Chapter 4: Alpha male replacements and delayed dispersal in crested macaques

(Macaca nigra) 55

Chapter 5: General discussion 67

5.1. Migrating strategies 69

5.1.1. Cost and benefit trade-off of dispersal for males of high fighting ability (pioneers) 70

5.1.2. Cost and benefit trade-off of dispersal for males of low fighting ability (followers) 76

5.2 Implication for other mammal species 78

5.3 Conclusion and outlook 80

References 83

Acknowledgements 97

Curriculum Vitae 99 



\section{Summary}

In gregarious living mammals, males are often forced to leave their natal group as a consequence of selective pressures from within group competition and inbreeding avoidance. A successful natal dispersal increases a male's chance to get access to unrelated mating partners and therefore enhances his reproductive success. Males may further increase their mating success by consecutive migrations into groups with more favourable conditions, allowing better access to fertile females. In socially living mammals, however, access to fertile females is often restricted to high ranking males such that the top dominant male reaps the highest benefits. Dispersal and the subsequent achievement of a high dominance rank are therefore essential events for a male to achieve high reproductive success and ultimately increase his fitness. During their dispersal and the attempt to achieve top dominance, males face various threats and often have to bear high costs. During the transition period between two social groups, males often face an increased predation risk and aggressive acts from conspecifics, potentially leading to severe injuries or death. During the process of immigrating into a group, males often get injured as a consequence of challenges for higher ranking positions. Both the transition period and the immigration itself are assumed to be very stressful events for dispersing males. Short-term elevated stress hormone levels are expected to be adaptive, a prolonged physiological stress response however, might be detrimental and would add additional costs to the dispersal event. As a consequence of the combined costs, male dispersal and intrasexual competition are considered to be the main causes of the higher mortality observed in male than in female animals. As a result, males often face a trade-off between the reproductive benefits of dispersal and the achievement of the alpha position in a group on the one hand, and the corresponding costs on the other hand. Selection would favour males who can shift this trade-off in a more favourable direction by strategically increasing benefits and reducing costs. Condition-dependent plasticity would be expected in such strategies, assuming that males migrate under different physical conditions.

Despite the importance for a male's fitness, surprisingly little is known about dispersal, dispersal strategies, and the achievement of the alpha male position. The aim of this thesis was therefore to shed light on strategies utilised by males to disperse and to achieve top dominance. I predicted that males would use condition-dependent strategies to migrate and achieve the top 
dominant position with minimal costs and maximum reproductive benefits. A second aim of this study was to investigate the impact of an often neglected potential cost: an elongated stress response. The dispersal from one group to another is likely to represent the most profound shift in social life and environment in an animal's life. I therefore expected males to show an adaptive stress response during the transition period between two groups, and during the following immigration process. If this stress response is prolonged over an extended time period, physiological costs for the dispersing males would be expected. I studied crested macaques (Macaca nigra), an ideal study species to investigate cost- and benefit-dependent migrating strategies, as all males disperse from their natal group and are known to subsequently migrate between groups. As a result of a high male reproductive skew, inter-individual differences in reproductive benefits were expected between males whereby the alpha male reaps the greatest benefits by siring most infants.

I found immigrations in crested macaques to occur in clusters, with several males immigrating into a group around the same time. Males used two specific strategies to immigrate according to their physical condition. Males who immigrated into a group first (pioneers) were most often males with substantial fighting ability, regularly achieving the alpha male position in the new group. The majority of pioneers who achieved the alpha male position were young males who had just emigrated out of their natal group. They either challenged the resident alpha male, or opportunistically took over the alpha male position after the resident alpha male previously emigrated or was injured. These males delayed their natal dispersal in order to reach their maximal physical prime, giving them the best chance to win an upcoming challenge. By doing so, natal males were expected to avoid costs of dispersal as a sub-adult male, and at the same time, increased their reproductive benefits by achieving the alpha male position upon natal emigration.

After the arrival of a pioneer, males of lower fighting ability (followers) subsequently immigrated into the group, usually achieving a low rank. By following a male of high fighting ability, these males reduced costs by taking advantage of instabilities in the male hierarchy. Males of low fighting ability therefore used a low-risk, low-benefit strategy. In contrast, males of high fighting ability, who immigrated into a group as pioneers, were more likely to get injured upon immigration and therefore used a high-risk, high-benefit strategy.

Surprisingly, males did not show a stress response during the transition period between two social groups. During immigration, however, a stress response was detectable in which the variation between males was extensive. Differences in the magnitude were most pronounced 
between natal emigrating males and males who already experienced dispersal. More experienced males showed lower stress hormone levels. The stress response was generally short and assumed to be only adaptive. Thus, physiological costs according to stress are not expected for dispersing male crested macaques.

The observed dispersal strategies in crested macaques are directly linked to alpha male replacements and the attributes of the social system of this species in general. I predicted the migrating strategies of males with high fighting ability to be part of a positive feedback loop: as a result of a delayed natal dispersal, all alpha male takeovers were conducted from extra-group males. As a consequence, females are unable to prevent infanticide by using strategies such as paternity confusion. Females are then expected to favour the alpha male which is most likely to protect their future infants against other extra-group males. Male-male competition is intense as a consequence of the high reproductive skew, whereby selection would favour males with more pronounced weaponry. Weaponry, such as large canines, therefore then add costs to dispersal, leading to a delayed dispersal and takeovers from outside males.

In summary, this thesis provides substantial evidence for the use of condition-dependent strategies by male crested macaques to reduce the costs of dispersal and to increase their chances of obtaining maximal reproductive benefits in a new group. Condition-dependent behavioural plasticity allows males to successfully enter a social group, which is, in most mammals, a requirement to get access to unrelated females. These strategies are assumed to ultimately increase a male's fitness. Although this is the first study to systematically investigate condition-dependent strategies according to the costs and benefits of dispersal, such strategies are expected in a variety of species as a result of the high costs of dispersal. As soon as reproductive benefits of dispersal are dependent on intrinsic factors, the evolution of conditiondependent strategies is expected. Accordingly, the implications of this thesis reach far beyond primates. 


\section{Zusammenfassung}

Bei sozial lebenden Säugetierarten sind männliche Tiere häufig gezwungen, ihre natale Gruppe zu verlassen, um Inzucht und Konkurrenzkämpfe mit verwandten Tieren zu vermeiden. Durch die Migration erhält ein Männchen Anschluss an eine neue soziale Gruppe, wobei sein Zugang zu Geschlechtspartnern häufig durch den erreichten sozialen Rang limitiert ist. Erst durch das Erreichen eines hohen Ranges, im besten Falle des höchsten Ranges, ist dem Männchen ein hoher Reproduktionserfolg gewiss. Die Migration und das Erreichen des höchsten Ranges sind demnach mit die wichtigsten Ereignisse im Leben eines Männchens um seine Fitness zu erhöhen. Trotz der positiven Effekte die eine Migration auf den zukünftigen Reproduktionserfolg eines Männchens haben kann, ist diese meist mit substanziellen Kosten verbunden. Während der Übergangsphase, in der ein Männchen alleine zwischen zwei Gruppen unterwegs ist, ist es oft einem erhöhten Prädationsdruck ausgesetzt. Zusätzlich müssen die Männchen des Öfteren Territorien von anderen Gruppen durchqueren und sind wiederholt Aggressionen von ortsansässigen Individuen ausgesetzt. Diese Konfrontationen können zu schweren Verletzungen bis hin zum Tode des migrierenden Männchens führen. Während der anschließenden Immigration in eine neue Gruppe kommt es häufig zu Kämpfen um die Rangordnung und damit einhergehend, zu Verletzungen der Rivalen. Aufgrund der hohen Kosten werden die Migration und der Wettkampf zwischen Männchen um den Zugang zu Weibchen als Hauptursachen für die erhöhte Mortalität von Männchen im Vergleich zu Weibchen angesehen. Trotz deren Einfluss auf die Fitness eines Männchens ist bis heute erstaunlich wenig bekannt über Migration, Migrationsstrategien und Strategien, die Männchen nutzen, um den höchsten Rang in einer Gruppe zu erreichen. Da sowohl die Migration in eine neue Gruppe, als auch das Erreichen der Alpha-Position zu einem erhöhten Reproduktionserfolg führen können, jedoch auch mit essentiellen Kosten verbunden sind, müssen Männchen den optimalen Zeitpunkt abwägen, zu dem es sich lohnt zu migrieren und/oder ein anderes Männchen herauszufordern. Die evolutionäre Selektion würde Männchen bevorzugen, denen es gelänge, über spezifische Strategien die Kosten klein zu halten und den zukünftigen Reproduktionserfolg zu vergrößern.

Ziel dieser Arbeit ist es, unser bisher limitiertes Wissen über Migrationsstrategien sowie über das Erreichen der Alpha-Position mit minimalen Kosten und maximalem Reproduktionserfolg zu erweitern. Im Speziellen bin ich daran interessiert, inter-individuelle Unterschiede in den gewählten Strategien festzustellen. Ich erwartete unterschiedliche Strategien zu finden, die es 
Männchen unterschiedlicher körperlicher Verfassung erlauben, die Kosten einer Migration klein zu halten. Neben der Erforschung von Migrationsstrategien anhand der Kosten und reproduktiven Vorteile war ich zusätzlich an einer bisher vernachlässigten Komponente potentieller Kosten interessiert: chronischem Stress. Die Migration von einer Gruppe in eine andere repräsentiert die wahrscheinlich größte Veränderung im ökologischen und sozialen Umfeld eines Tieres. Daher erwartete ich, dass migrierende Tiere eine Stressreaktion zeigen, um eine solche Situation besser bewältigen zu können. Hält die Stressreaktion jedoch über geraume Zeit an, sind negative Effekte zu erwarten und würden den migrierenden Tieren zusätzlich physiologische Kosten auferlegen.

Um das Migrationsverhalten, Migrationsstrategien und die physiologischen Stressreaktionen von Männchen während der Migration zu untersuchen habe ich Schopfmakaken (Macaca nigra) studiert. Diese Art der Altweltaffen lebt, wie alle Makaken, in sozialen Gruppen, die mehrere Männchen und Weibchen umfassen. Alle Männchen verlassen ihre Geburtsgruppe und schließen sich einer anderen sozialen Gruppe an. Häufig migrieren Männchen anschließend noch mehrmals zwischen verschiedenen Gruppen. Da die Männchen am oberen Ende der Hierarchie einen deutlich höheren Reproduktionserfolg als niedriger im Rang stehende Männchen haben, sind unterschiedliche Reproduktionserfolge nach einer Migration zu erwarten.

Ich fand heraus, dass bei Schopfmakaken häufig mehrere Männchen innerhalb kurzer Zeit in eine neue Gruppe immigrieren, wobei sich zwei Strategien gezeigt haben: Männchen, die als erstes in eine Gruppe immigrierten (Pioniere), waren meist kampfstarke Männchen, die einen hohen sozialen Rang in der neuen Gruppe erreichten, häufig denjenigen des Alpha-Männchens. Diejenigen, die nach ihrer Immigration den Alpha-Männchen Status erreichten, waren meist junge Männchen, die vor kurzem aus ihrer natalen Gruppe emigrierten. Durch eine verzögerte Emigration und das Warten bis sie ihre höchste Kampfkraft erreichten, erhöhten diese Männchen ihre Chancen, erfolgreich ein Alpha-Männchen einer anderen Gruppe herauszufordern. Trotz ihrer hohen Kampfkraft waren Verletzungen bei diesen Männchen häufiger als bei anderen. Nach der Ankunft von einem Pionier immigrierten oft andere Männchen mit einer weniger hohen Kampfkraft in dieselbe Gruppe, wobei diese meist einen niedrigen sozialen Rang erreichten. Diese Männchen nutzten die Instabilität in der männlichen Hierarchie aus, um mit geringeren Kosten in die Gruppe zu immigrieren. Folglich werden zwei Strategien deutlich: Männchen mit hoher Kampfkraft nutzen eine Strategie, die sehr großen Erfolg auf zukünftige Fortpflanzungschancen verspricht, aber auch eine hohe Verletzungsgefahr birgt. Männchen mit geringer Kampfkraft nutzen eine Strategie, die wenig Erfolg verspricht, aber auch geringe Kosten mit sich trägt. 
Überraschenderweise zeigten die untersuchten Männchen keine Stressreaktion, während sie sich zwischen zwei Gruppen aufhielten. Im Gegensatz dazu konnte ich eine Stressreaktion während der Immigration in eine neue Gruppe feststellen, wobei die Variation zwischen den Männchen bemerkenswert war. Ob ein Männchen schon einmal migriert ist, hatte wesentlichen Einfluss auf die Stressreaktion. Männchen, die schon Erfahrung im Immigrieren hatten, zeigten eine deutlich verminderte Stressreaktion im Vergleich zu Männchen, die zum ersten Mal immigrierten. Die Stressreaktion der neu eingewanderten Männchen beschränkte sich jedoch nur auf einen kurzen Zeitraum weniger Tage nach der Immigration, wodurch negative Effekte durch eine verlängerte Stressreaktion unwahrscheinlich sind.

Die gefundenen Migrationsstrategien stehen im direkten Zusammenhang mit spezifischen Eigenschaften des Sozialsystems von Schopfmakaken. Ich schlage hier einen positiven Zirkelschluss vor, bei dem sich verschiedene Faktoren gegenseitig positiv beeinflussen. Das Infantizid-Risiko in Schopfmakaken ist durch die starken Unterschiede im Reproduktionserfolg von Männchen sehr hoch, wobei die Weibchen keine Möglichkeit haben Infantizid zu vermeiden da alle neuen Alpha-Männchen von ausserhalb der Gruppe immigrieren. Dies führt dazu, dass Weibchen das Alpha-Männchen bevorzugen, da er der Kandidat ist, der am ehesten in der Lage ist, ihre Nachkommen gegen Männchen von ausserhalb der Gruppe zu verteidigen. Infolge dessen erhöht sich der Wettkampf unter den Männchen um die Alpha-Position, was wiederum die Evolution von größeren sekundären Sexualmerkmalen, die im Kampf von Vorteil sind (z. B. Eckzähne), begünstigt. Diese wiederum erhöhen die Wahrscheinlichkeit, dass ein immigrierendes Männchen verletzt wird, wodurch es lohnenswert ist, die Migration so lange heraus zu zögern, bis es in der Lage ist, sich den Männchen in einer fremden Gruppe zu stellen.

Zusammenfassend zeigt meine Arbeit neue Einblicke in die Evolution unterschiedlicher Strategien, die Männchen sozialer Säugetiere in Abhängigkeit ihrer Kampfkraft nutzen, um sich Zugang zu einer neuen sozialen Gruppe zu sichern. Ich konnte zeigen, dass männliche Schopfmakaken spezifische Strategien verwenden, um entsprechend ihrer Kampfkraft mit möglichst kleinen Kosten von einer sozialen Gruppe in eine andere zu migrieren. Solche Strategien erhöhen die Fitness eines Männchens und sind dadurch auch bei vielen anderen sozial lebenden Säugetierarten zu erwarten. Folglich hat diese Arbeit Auswirkungen auf unser Verständnis von Migrationsstrategien, die weit über die Primatologie hinaus Anwendung finden können. 


\section{Chapter 1}

\section{General Introduction}


Sexual selection favours individuals capable of increasing their individual fitness in comparison to conspecifics [Darwin, 1859, 1871]. In sexually reproducing species, individuals strive to find suitable mating partners, outcompete same sex individuals and reproduce at a maximal rate with the least possible fitness costs. Sexual selection for mating partners occurs by selecting traits that are either attractive to individuals of the opposite sex (intersexual competition) or that enable an individual to defeat, intimidate or deter individuals of the same sex (intrasexual competition) [Darwin, 1871; Clutton-Brock, 2004]. Reproductive success is generally more variable for the sex that invests less in reproduction and parental care, leading to comparably higher intrasexual competition [Bateman, 1948; Collet et al., 2014]. As reproductive and parental investment, in general, is often lower in males than in females, male reproductive success is ultimately limited by the number of females that can be fertilized, whereas female reproductive success is limited by the number of offspring that can be produced [e.g., Trivers, 1972]. Specifically in mammals, where males often show little parental investment, male-male competition is high, and males often only have a short time during their life in which they are physically able to outcompete other males and reproduce successfully [e.g., Le Boeuf \& Reiter, 1988].

In the majority of gregarious mammalian species, females are the philopatric sex and males have to leave their natal group [Greenwood, 1980; Pusey, 1987]. A male's first necessary step to obtain access to suitable mating partners is to leave the natal territory or social group to avoid competition and breeding with close kin [e.g., Brock \& White, 1992; Pray et al., 1994]. Subsequently, males have to compete with other males for access to fertile females, to monopolize reproduction and to prevent other males from breeding. Hence, male-male competition can be very intense, and males compete fiercely for access to females. In such species, dispersal, the successful immigration into another social group, and the achievement of the top dominant position are often the most important factors leading to high reproductive success in males. As male survival is hampered by risky behaviours, such as dispersal, roaming and male-male combat [Johnson, 1990; Magnhagen, 1991; Alberts \& Altmann, 1995; Rödel et al., 2004; Kraus et al., 2008], evolution should favour males who can overcome these situations at low costs. However, due to a tendency to focus on the philopatric sex and the difficulties of following the fates of dispersing males [e.g., Jack, 2003], surprisingly little is known about the proximate mechanisms of dispersal and alpha male takeovers. Moreover, it is unknown whether males differ in their migrating strategies in terms of the expected costs and benefits of dispersal. With this thesis, I seek to shed light on the migration strategies and patterns of alpha male takeovers in crested macaques (Macaca nigra), a social species that exhibits male dispersal, in regard to the costs and benefits of dispersing and challenging males. 
On this background, the introduction will be structured as follows: In the general introduction, I will introduce the benefits of dispersal regarding inbreeding avoidance and intrasexual competition (section 1.2.1), followed by an overview of how to access females and, therefore, the reproductive benefits of migration (section 1.2.1.1). Furthermore, I will outline the current knowledge of migration costs regarding survival (section 1.2.2.), with a specific focus on costs during the transition period (section 1.2.2.1.) and the immigration process (section 1.2.2.2.). In this context, I will introduce the physiological stress response and potentially associated costs males might face during migration (section 1.2.2.3.). In the following section, I will tie the previous sections together and introduce the trade-off between the costs and benefits males face when deciding whether or when to migrate (section 1.3), and I will introduce strategies used by males to maximize benefits (e.g. achieving the alpha male position)(section 1.3.1.), or to reduce the costs of dispersal (section 1.3.2). After introducing the study species (section 1.4.), I will outline the aims of this thesis (section 1.6.).

\subsection{Dispersal}

\subsubsection{Benefits of dispersal}

The dispersal of males from a group or population is often caused by inbreeding avoidance and kin competition [Gandon, 1999; Gandon \& Michalakis, 1999; Palmqvist et al., 2000; Leturque \& Rousset, 2002; Cressman \& Křivan, 2006]. Inbreeding depression, defined as a decline in the value of a fitness-related trait as a consequence of inbreeding (e.g., the number of offspring survived) is considered to be a major force leading to the evolution of inbreedingavoidance traits, such as mating systems and dispersal [Cheptou \& Donohue, 2011]. A loss of fitness after inbreeding is a result of a number of genetic factors: increased homozygosity and/or reduced allozyme variability [e.g., Brock \& White, 1992; Pray et al., 1994], as well as the unmasking of recessive deleterious alleles [e.g., Lynch et al., 1995]. Fitness consequences for inbred populations was shown in a variety of species [Crnokrak \& Roff, 1999]. As a result, females of a certain population are known to actively avoid mating with close relatives [e.g., Liu et al., 2013; Alberts \& Altmann, 1995; including humans: Boyd \& Silk, 2009] or may even be reproductively suppressed by the presence of close kin [Saltzman et al., 1997]. As a result of the avoidance of mating with close relatives, the number of potential mating partners for a natal male in a group is limited, and can only be increased through dispersal. The dispersal of young 
males from their natal group or territory before reaching sexual maturity will prohibit mating with close relatives and provides the male with more mating opportunities in a new group [Primates: e.g., Pusey \& Packer, 1987; Birds: e.g., Krebs et al., 2007; Rodents: e.g., Anthony et al., 2013].

In addition to inbreeding avoidance, intrasexual competition has been proposed to be a main factor for natal and secondary dispersal [Dobson, 1982]. In mammals, young males are likely to be forced to compete with relatives for resources within their natal territory, while dispersal will give them the advantages of outbreeding and competing with non-relatives. Consequently, in social mammals, males generally leave their natal group around sexual maturity and join other social groups where they are more likely to encounter a greater number of potential mates and where they do not have to compete with relatives [Pusey, 1987]. Even though dispersal is often limited to a specific developmental stage [Smale et al., 1997], in some species, males subsequently migrate to other groups throughout their lives [Pusey \& Packer, 1987; Jack, 2003].

\section{Benefits depending on the reproductive skew and access to females}

Dispersing males gain benefits by not having to compete with relatives and by being surrounded by non-kin females in a new group. The dispersal itself is a necessary precondition, but it does not guarantee access to receptive females. The reproductive benefit a male gains upon immigration into a new social group is directly related to its access to receptive females and its capability to prevent other males from reproducing. The degree to which a single male is able to monopolize females and hamper other males from reproducing varies greatly within and between species. Several theoretical models have tried to explain these differences using social and ecological factors [Clutton-Brock, 1988; Keller \& Reeve, 1994; Hager \& Jones, 2009]. On a proximate level, the control a male has over reproduction in a group is often limited by the number of receptive females at a specific time. According to the priority of access model (PoA) [Altmann, 1962], originally designed to explain variations in reproductive skew in primates, the most dominant male (the alpha male) will be able to completely monopolize all receptive females and exclude other males from reproducing in species where female reproductive synchrony is zero (i.e., no more than one female is fertile at a time). If more than one female is receptive at the same time, they will be distributed among males according to the male hierarchy. The PoA model has been confirmed in several species [e.g. mandrills (Mandrillus sphinx): Setchell, 2002; yellow baboons (Papio cynocephalus): Alberts et al., 2003, 2006; chacma baboons (Papio ursinus): 
Weingrill et al., 2003; chimpanzees (Pan troglodytes); Boesch et al., 2006], although in some species deviations from the PoA model have been found, where male dominance rank does not perfectly predict the male reproductive skew [e.g. Rhesus monkeys (Macaca mulatta): Dubuc \& Muniz, 2011]. Consequently, the higher the reproductive synchrony within females, the less likely high ranking males can monopolize all females and the higher the chance for lower ranking males to sire offspring [e.g., Japanese macaques (Macaca fuscata): Soltis et al., 2001; Barbary macaques (Macaca sylvanus): Widdig et al., 2004]. In contrast, when female reproductive synchrony is low and males have a high potential to monopolize females, there is a high reproductive skew and little chance for low ranking males to reproduce [e.g., Red howler monkey (Aluatta seniculus): Pope, 1990; Gorilla (Gorilla beringeri): Bradley et al., 2005; mandrill: Setchell et al., 2005]

While the likelihood of some females to be in oestrus at the same time increases with the number of females in a group, the absolute number of females, as well as the sex ratio, affects the likelihood of a male successfully reproducing in a specific group regarding his competitive abilities. The influence of individual competitive ability on a male's access to females, however, varies between species and even within populations [reviewed in Alberts, 2012]. Nevertheless, males should be expected to move into groups with the most favourable female cohort. This is not always the case, however, which is explained by the high costs males have to bear during migration and upon immigration [e.g., Altmann, 2000].

\subsubsection{Costs of dispersal}

After leaving their social group or territory, dispersing males often spend a considerable amount of time alone. While dispersing, these individuals have to cope with fundamental needs regarding where to find food, shelter or new escape routes from predators [Smale et al., 1997]. In social species, the complete and sudden loss of all social partners due to dispersal might be even more challenging; once arriving in a new group, dispersers have to find new social partners, are often exposed to high aggression from resident conspecifics, or may even be directly physically challenged by potential competitors [Pusey \& Packer, 1987; Smale et al., 1997]. The transition between two groups, as well as the immigration into a new social group, are therefore likely to represent extremely stressful situations for migrating males. Consequently, the dispersal of an individual is often accompanied by substantial costs [e.g., Isbell \& Vuren, 1996; Bonte et al., 2012]. In primates, probably the best studied taxa regarding dispersal, there is a higher mortality 
rate for males and, consequently, a female-biased sex ratio which is often directly linked to male dispersal [e.g., Dunbar, 1987]. Although more often discussed in the context of "risky behaviour" [e.g., Kraus et al., 2008], dispersal, in combination with roaming and physical combat, decreases male survival [e.g., Greenwood, 1980; Alberts \& Altmann, 1995]. Despite their importance, little is known about the actual costs of dispersal, mainly due to difficulties following dispersing individuals and monitoring their survival [Young \& Monfort, 2009]. Theoretically, dispersal costs are composed of two components: the costs during the transition between two groups and the costs during immigration into a new group [van Noordwijk \& van Schaik, 2004].

\section{Transition costs}

During the transition period between two social groups, males often face an increased mortality risk compared with their philopatric conspecifics [Petersburg et al., 2000]. Because living in groups is at least partly explained by reduced predation risk [van Schaik, 1983; Inman \& Krebs, 1987], males leaving their group are often at a higher risk of predation than their conspecifics within the group [Dunbar, 1987; Holzenbein \& Marchinton, 1992; Isbell et al., 1993]. Accordingly, in many species, an increased mortality attributed to predation was shown [e.g., Holzenbein \& Marchinton, 1992; van Vuren \& Armitage, 1994; Alberts \& Altmann, 1995; but see Gillis \& Krebs, 2000]. In vervet monkeys (Cercopithecus aethiops), for example, moving in unfamiliar areas has been associated with an increased risk of predation by leopards (Panthera pardus) [Isbell, 1990].

In addition to predation, aggression from conspecifics is one of the most frequent reported costs for dispersing animals. While leaving, dispersing males have to pass through other individuals' or social groups' territory. During this period, dispersing males evoke more aggression from conspecifics (as strangers) than do familiar animals. This might lead to injuries or even death [reviewed in Ydenberg et al., 1988; Primates: Packer, 1979; Cheney \& Seyfarth, 1982; Berger, 1986; Rodents: Garrett \& Franklin, 1988].

While traversing through unknown habitat, males are often unaware of where to find suitable food sources, and they are expected to bear costs due to difficulties finding food [van Noordwijk \& van Schaik, 2004]. In howler monkeys, for example, dispersing males have been observed to have a poorer diet containing less protein and phosphorus and more fibre than those of non-dispersing males [Pope, 1989]. However, data on feeding costs during dispersal are rare due to the difficulties to follow single dispersing males. Additionally, while being absent from a group, males miss mating opportunities, which can directly lead to even more pronounced fitness 
costs for the dispersing male, particularly when males disperse several times during their life [Alberts \& Altmann, 1995].

\section{Immigration costs}

As the number of competitors for access to females increases with the number of males in a social group, all resident males have an interest in preventing extra-group males from entering their group [Nunn, 2000]. Consequently, immigrants often face high aggression from resident males [e.g., long-tailed macaques (Macaca fasicularis): van Noordwijk \& van Schaik, 1985; whitefaced capuchins (Cebus capucinus): Fedigan, 1993; Hanuman langurs (Semnopithecus entellus): Borries, 2000], and they are chased and sometimes severely wounded [e.g., olive baboons (Papio anubis): Packer, 1979; crested macaques, pers. observation]. Similar to the transition period, the immigration is therefore a potentially dangerous and highly stressful situation for dispersing males. For resident group males, preventing a male from entering a group can be considered as a collective benefit, but this does not often benefit all males to the same degree. High ranking males are considered to reap the greatest benefits and are expected to be the most active ones in preventing extra-group males from entering their group [Nunn, 2000]. Consequently, males trying to integrate into a new social group often face high resistance from resident males, potentially leading to high costs in terms of injuries. For a male striving to achieve access to females in a new group, a successful immigration without major injuries is crucial. As a result of the high costs of dispersal males are expected to show an adaptive physiological stress response (e.g., Sapolsky, 2002).

\subsubsection{The physiological stress response and potential physiological costs}

A physiological stress response does, amongst others, provide the dispersing individual with increased energy used to cope with a stressful situation. As soon as a stressor (e.g., a predator) is perceived by the brain, corticotropin-releasing hormones (CRHs) are released by the hypothalamus (within a few seconds). CRHs then stimulates the pituitary gland, which releases adrenocortical hormones (ACTHs) (within 15 seconds), which in turn stimulates the adrenal gland to release glucocorticoids (GCs) (within a few minutes) [Sapolsky, 2002]. The physiological stress response is unspecific, but enables the mobilization of energy for immediate use (e.g., the 'flight or fight' response) [Sapolsky, 2002]. During the physiological stress response, energy storage is inhibited, and existing forms of energy storage are broken down into simpler forms, 
which are better for immediate use, thereby leading to an increase in glucose in the bloodstream. While the body is provided with energy for immediate use, other less important functions are inhibited during the physiological stress response (e.g. digestion, growth and reproduction [Nelson, 2005]). In addition to the mobilization of energy, a physiological stress response enhances cognition, analgesia and sensory function, while decreasing pain perception. These physiological adaptations may substantially increase the chances of successfully overcoming a stressful situation, such as dispersal events [Sapolsky, 1992; Nelson, 2005].

While the physiological stress response is adaptive and provides the dispersing individual with energy required during the transition or immigration, a prolonged physiological stress response would be maladaptive for an individual [Alberts et al., 1992; Arlet et al., 2009; Bergman et al., 2005; but see: Van Belle et al., 2009]. Although the physiological stress response is an ideal system to cope with short-term stressors, it can have negative health consequences when activated for too long or too frequently (e.g., immunosuppression, decreased growth and impaired reproduction) [Sapolsky, 1992; Balm, 1999; Nelson, 2005].

Currently, the physiological stress response during the transition period, as well as upon immigration, is poorly understood. Moreover, whether a physiological stress response is always adaptive or can be elongated and therefore detrimental for a male is unknown. To evaluate the costs of migration in general, a closer look at the stress response and its duration is needed to determine the potential physiological costs.

\subsubsection{Migration strategies based on the cost-benefit trade-off}

Males face a trade-off between the costs and benefits of migrations, whereby migrations would only occur when the benefits exceed the costs. In light of the PoA [Altmann, 1962], a male's reproductive benefit upon immigration is predicted by his dominance rank (fighting ability) scaled to the number of females that are simultaneously receptive. Consequently, the payoff a male gains upon immigration is expected to vary according to his competitive ability [Clarke et al., 2008]. If payoffs for specific behaviours hinge on internal states, the evolution of condition-dependent plasticity is likely [Gross, 1996; Brockmann, 2001]. Accordingly, potentially migrating males have a specific set of preconditions, such as fighting ability, which are likely to directly influence the decision whether to migrate. If costs are too high, males are not expected to migrate, whereas a migration is expected when benefits outweigh costs. Evolution would therefore favour males who choose strategies to increase their potential reproductive benefits and/or lower the costs of dispersal. 


\section{Migration strategies to increase reproductive benefits}

Reproductive benefits of males are more or less dependent on the rank achieved in a new group. When male reproductive skew is high, the alpha male reaps the highest benefits, thus attaining the top position is highly desirable and worth fighting for [van Noordwijk \& van Schaik, 2004]. In such species, males should use strategies to increase their chances to attain a high rank, and preferentially the alpha male position, upon immigration [van Noordwijk \& van Schaik, 2004]. Therefore, males should favour groups according to the characteristics of the male cohort (e.g., the number of competitors or the tenure of alpha males) and their chances of successfully challenging these males. In long-tailed macaques, males have been found to be more successful when challenging alpha males who might have lost some strength after a long tenure [van Noordwijk \& van Schaik, 2004]. As challenges for the alpha male position are generally events in which a male acts alone [e.g., van Noordwijk \& van Schaik, 1985; Hamilton \& Bulger, 1990; Sprague, 1992; Borries, 2000], internal states, such as fighting ability, are most likely to influence the outcome of a challenge. As such, alpha male challengers are reported to be in their physical prime [reviewed in van Noordwijk \& van Schaik, 2004]. Timing a challenge according to the physiological condition, therefore, is essential for males ensure the best chances of a successful alpha male challenge. However, surprisingly little is known about timing and strategies males use to obtain the alpha position in a group. Male dispersal and alpha male takeovers are linked in some species, with immigrants often achieving the alpha male position shortly upon immigration into a new group [e.g., chacma baboons: Hamilton \& Bulger, 1990; yellow baboons: Alberts et al., 1992; mantled howler (Alouatta palliata): Glander, 1992; white-faced capucins: Jack \& Fedigan, 2004] whereas in other species challenges of the alpha male are more common from within the group [ e.g. long tailed macacques, rhesus monkeys: Clarke et al., 2009].

In species with a low reproductive skew, in which mating competition is mostly scramble based, males benefit from a relatively higher number of females in the group [van Noordwijk \& van Schaik, 2004]. Therefore, males should prefer to migrate into groups with a higher absolute or relative number of females. The scrambled mating competition leads to low male-male competition and escalated fighting over access to females is rare; thus, immigration costs are assumed to be low [e.g., Nakamichi et al., 1995]. Indeed, males have been found to base their migration decisions mainly on the number of females in a group, thus fitting the predicted migration pattern [van Noordwijk \& van Schaik, 2004]. This strategy has not only been proposed to be most important in increasing reproductive benefits upon migration in species with low reproductive skew, but also for males of lower fighting abilities in species with high reproductive 
skew. These males should switch to the strategy of species with a lower reproductive skew and should favour groups with a more favourable female cohort to increase their chances to obtain access to females [van Noordwijk \& van Schaik, 2004]. This implies the existence of alternative, condition-dependent migrating strategies. Evidence for such strategies is particularly rare because most studies either investigated species specific strategies or compared differences between species [e.g., van Noordwijk \& van Schaik, 1985, 2001, 2004; Teichroeb et al., 2011; Yao et al., 2011; Zhao et al., 2011]. Interestingly, and in contrast to the prediction of van Noordwijk \& van Schaik [2004], male chacma baboons of high fighting ability have been found to preferentially immigrate into groups with an absolute higher number of females [Clarke et al., 2008]. However, potential characteristics of the male cohort, such as alpha male tenure, were not included. Males of lower fighting ability seemed not to immigrate into groups with a specific demographic structure [Clarke et al., 2008]. As we do not have any further evidence of conditiondependent migrating strategies, further investigations on an individual level are clearly needed.

\section{Migration strategies to reduce costs}

In the absence of costs due to male-male competition and dispersal, males would be expected to go where the most receptive females are present [Altmann, 2000]. However, this is not always the case, even though a tendency for migrations towards groups with a more favourable female cohort was observed in some species [e.g. yellow baboons: Altmann, 2000]. Instead, males face a trade-off between potential reproductive benefits in a new group and the costs they have to bear to obtain access to these females.

Because the dispersal event is associated with an increased mortality [e.g., Alberts \& Altmann, 1995], dispersing males should use strategies to avoid these costs. Such strategies have now been described in a variety of primate species. To avoid a long transition period alone, in which males are exposed to predators and other stressors (potentially leading to physiological costs), dispersing males have been observed to preferentially migrate to neighbouring groups, or to avoid any time spent alone by transferring during intergroup encounters (vervet monkeys: Cheney \& Seyfarth, 1983; Henzi \& Lucas, 1980; rhesus monkeys: Melnick et al. 1984; long-tailed macaques: van Noordwijk \& van Schaik, 1985, 2001; tibetan macaques (Macaca thibetana): Zhao, 1994; see also Pope, 2000).

By migrating with a partner rather than alone, predation risk is supposed to be lowered, and a potential ally against aggressors is available [Schoof et al., 2009]. Accordingly, several different primate species have been observed to regularly migrate with peers or kin [e.g., vervet 
monkeys,: Cheney \& Seyfarth, 1983; white-faced capuchins: Jack \& Fedigan, 2004; see also Schoof et al., 2009]. Peers and kin not only help a dispersing individual reduce costs during the transition period, but also when they are already present in the target group during the immigration of a male. As potential allies, these males can support the new arrival in confrontations with the resident males [vervet monkeys: Cheney \& Seyfarth, 1983; western Gorillas: Bradley et al., 2007; but see Chancellor et al., 2011]. Because high ranking males, and specifically the alpha male, are expected to be the most effective males in preventing other males from entering the group [Nunn, 2000], group instabilities in the male hierarchy, as observed upon changes in the top dominant positions [Bergman et al., 2005; Setchell et al., 2010; Jack et al., 2011], may facilitate immigrations. In long-tailed macaques, groups with an unstable male hierarchy have indeed attracted more males than groups with a stable hierarchy [van Noordwijk \& van Schaik, 2001].

Similar to the variation in benefits of migration among males (particularly in species with a high reproductive skew), the costs of immigration are also expected to differ between males. Males of high fighting ability often challenge the resident alpha male, which leads to escalated fights and severe injuries [van Noordwijk \& van Schaik, 2004]. These immigrating males are expected to be willing to bear higher costs than males of low fighting ability due to the high reproductive benefits in the group. Hence, males of low fighting ability should use strategies to lower the immigration costs. However, whether males of various fighting abilities use different immigration strategies to reduce costs so far remains unknown.

\subsection{Crested macaques as a model species}

To investigate the timing and pattern of alpha male takeovers and to investigate migration strategies that depend on costs and benefits in a multi-male group, a model species should fulfil several different criteria. The most essential factor is that the reproductive success of males in a group should be highly variable. When this precondition is given, males with high reproductive benefits will be more willing to defend their reproductive benefits, which evoke costs for males trying to gain these benefits. In addition, migrating males would preferentially disperse under various physical conditions (e.g., fighting ability), thereby leading to different prospective benefits in the new group.

Crested macaques are in many ways an ideal primate species to investigate migration strategies, as well as their costs and benefits. The reproductive skew in this species is very high (around 85\% paternities for the alpha male (Engelhardt et al., in preparation)) as a consequence 
of a high monopolization potential for dominant males due to low female reproductive synchrony and clear female signals of fertility [Higham et al., 2012]. Thereby, male-male competition over access to females is extraordinarily high, leading to one of the most extreme canine dimorphisms in primates [Plavcan \& van Schaik, 1992]. Because of the large canines of males, severe injuries are often a consequence of escalated male fights. Reproductive benefits of high-ranking males are well above those of low ranking males, and dominance rank can normally only be increased by direct physical challenges [Engelhardt et al., in preparation]. Despite potential costs, males are known to migrate several times during their life.

The crested macaque is one of seven species of macaques endemic to the Indonesian island of Sulawesi [Riley, 2010]. As is true for most cercopithecine monkeys, crested macaques live in multi-male, multi-female groups, with females being the philopatric sex. Groups are comparably large, comprising up more than 100 individuals [unpublished data]. Males, as well as females, show a steep linear dominance hierarchy [Reed et al., 1997; Neumann et al., 2011; Duboscq et al., 2013]. While females are described as tolerant [Thierry, 2007; Duboscq et al., 2013], males show fierce competition over access to fertile females [Engelhardt et al., in preparation]. Male paternity is highly skewed, with alpha males siring around $85 \%$ of all infants [Engelhardt et al., in preparation]. Crested macaques are moderately seasonal according to the definition of van Schaik [1999] (33-67\% of births within a three-month period). Females show sexual swellings reliably indicating ovulation [Higham et al., 2012].

\subsection{Aims of this thesis}

The overall aim of this thesis is to better understand how social animals maximize their fitness in regard to dispersal and the achievement of top dominance rank. I was specifically interested in the decision-making, timing and the trade-off between the costs and benefits of male dispersal and alpha male takeovers.

In Chapter 2, I investigate inter-individual differences in costs and benefits of immigration into a new social group. Specifically, I am interested whether males of different physical conditions (fighting ability) use different immigration strategies that match their expected benefits in the new group. According to differences in reproductive success upon immigration due to a high reproductive skew, I assume that males of different fighting ability use different strategies to immigrate. Because of the low benefits to males of low fighting ability, we expect these males to use low-cost strategies, whereas males with high fighting ability are expected to be willing to bear higher costs and to use high-cost strategies. 
In Chapter 3, I investigate the physiological stress response of dispersing males during the transfer period, as well as during the immigration into a new social group. In more detail, I investigate the differences in the physiological stress response of males using different immigration strategies, as well as differences between natal emigrators and secondary migrating males. Additionally, to investigate potential physiological costs, I determine the duration of the physiological stress response and discuss potential costs.

In Chapter 4, I investigate the timing of alpha male takeovers in crested macaques and how the observed pattern fits into theoretical models of the achievement of the top dominant position. I discuss the observed pattern in a theoretical background in relation to expected infanticide risk and the social system of this species.

Finally, in Chapter 5, I will combine and discuss the results of the previous chapters. I will review the implications of my findings for crested macaques, for primates, and in a brother context for socially living mammals in general. 


\section{Chapter 2}

\section{Cost and benefit dependent migration strategies in male crested macaques}

(Macaca nigra)

Pascal R. Marty1,2,3 *, Keith Hodges² , Muhammad Agil ${ }^{4}$, Antje Engelhardt11,3

${ }^{1}$ Junior Research Group Primate Sexual Selection, German Primate Center, Göttingen, Germany

${ }^{2}$ Reproductive Biology Unit, German Primate Center, Göttingen, Germany

${ }^{3}$ Courant Research Center 'Evolution of Social Behaviour', Georg-August-University, Germany

${ }^{4}$ Faculty of Veterinary Medicine, Bogor Agriculture University, Indonesia 


\section{Summary}

Dispersal and immigration into a new social group is often accompanied by substantial costs for animals due to risks of predation, starvation and resistance from residents. Costs as well as benefits in terms of increased reproductive success may vary depending on factors such as the individual's fighting ability and the target group constellation. Whether or not dispersing individuals use different strategies according to the expected costs and/or benefits of immigration into a new group is unknown. We therefore aimed to investigate migration decisions in relation to costs and benefits in crested macaques, a primate species with a high reproductive skew in favor of high-ranking males and a high rate of male migrations. Data on three groups of wild crested macaques were collected from 2006 to 2012 in the Tangkoko Reserve, North Sulawesi, Indonesia. We found immigration events to be clumped with some males immigrating into new groups first (pioneers) followed by others (followers) that entered the group when the male hierarchy was destabilized by the immigration of the pioneer male. Pioneers experienced injuries but also generally achieved high rank more often, indicating high levels of fighting ability and an expectedly higher reproductive success in these individuals. Followers, in contrast, mostly reached low rank, and thus faced low costs with low expected reproductive benefits. We conclude that male crested macaques assess their fighting ability and either use a high-cost high-benefit strategy by immigrating as pioneers, or a low-risk low-cost strategy by immigrating as followers. Our study shows that individuals adjust their migration decisions in relation to the expected costs and benefits based on their individual fighting abilities. 


\section{Introduction}

In gregarious species, dispersal of individuals from their natal group is common. The main reasons for animals to disperse are generally selective pressures from within group competition and inbreeding avoidance (Clutton-Brock \& Lukas, 2012; Crnokrak \& Roff, 1999; Pusey, 1987]. Dispersal is a crucial event for the migrating individual with major implications for its future survival and lifetime reproductive success [e.g. Alberts \& Altmann 1995]. In addition to potential reproductive benefits of dispersal, there are, however, also potential costs [e.g. Bonte et al., 2012; Yoder, 2004], both during the transition period (i.e. between departure from the initial group and subsequent immigration into the new ones), as well as directly during the immigration process itself [Alberts \& Altmann, 1995; Bonte et al., 2012; Cheney \& Seyfarth, 1983; Eraud et al. 2011; Teichroeb et al. 2011; Wiens et al. 2006; Yoder, 2004; Zhao, 1996]. During the transition period, individuals transferring from one group or territory into another, face increased predation-risk and restricted access to known food resources [Alberts \& Altmann, 1995; Pärt, 1995]. For group living animals, resistance from resident individuals, often leading to fights resulting in severe injuries, is common and represents a significant cost to the immigrating individual [Cheney \& Seyfarth, 1983; Packer \& Pusey, 1983; Zhao, 1996].

Within mammals, primates are probably the best studied taxa regarding dispersal and migration behaviour. As in most other taxa, males are the dispersing sex, with emigration out of the natal group typically occurring around the time of puberty [Pusey \& Packer, 1987]. In contrast to most other mammals [Smale et al.1997] however, adult male primates can also migrate and join new groups several times during their lifespan [Jack, 2003; Pusey \& Packer, 1987]. In view of the high costs of migration, it is to be expected that males have evolved strategies to reduce these costs, and such strategies have now been described in a variety of primate species. These strategies have been explained by potentially reducing migration costs. For instance, by migrating to neighboring groups and thus reducing the time spent alone, the costs of the transition period can be reduced considerably. Alternatively, transition costs can potentially be eliminated by migrating during intergroup encounters [Cheney \& Seyfarth, 1983; Henzi \& Lucas, 1980; Melnick et al. 1984; Pope, 2000; van Noordwijk \& van Schaik, 1985, 2001; Zhao, 1994]. Males in some primate species have also been observed to potentially reduce migration costs posed by the resistance of resident males by immigrating with peers and kin, or into groups in which previously immigrated peers or kin are present [Cheney \& Seyfarth, 1983; Meikle \& Vessey, 1981; Schoof et al. 2009; van Noordwijk \& van Schaik, 1985]. In addition, by acquiring social knowledge of the target groups resident males prior to migration (e.g. during 
intergroup encounters or previous observations of neighboring groups during roaming), males may be able to assess the potential costs and benefits of immigration in a new group and base transfer decisions on the acquired knowledge [Cheney \& Seyfarth, 1990; van Noordwijk \& van Schaik, 2001; Teichroeb et al., 2011]. Further, an increased number of immigrations during male hierarchy instability caused by high-ranking immigrants [Bergman et al. 2005; Jack et al. 2011; Setchell et al. 2010] has been observed [van Noordwijk \& van Schaik, 2001]. In this situation, subsequently immigrating males may experience reduced costs, since male-male cooperation against intruders may be reduced and within group male-male aggression increased [Bergman et al., 2005] when resident males have to consolidate their position within the group. Evidence for such a scenario derives from vervet monkeys (Chlorocebus aethiops sabeus) [Schuster, Raleigh, McGuire, \& Torigoe, 1993]. In principle high ranking males are the ones potentially losing the most by the immigration of a new male. Consequently, the highest ranking males are the most likely ones to prevent new males from entering a group [Nunn, 2000]. However, upon their own immigration and a successful challenge of the resident alpha male, these new alpha males are unlikely to do so when having to consolidate their own rank first.

Given the number and nature of potential costs of dispersal, migrating males can be expected to be under high selective pressures to optimally time and locate immigration. For primates, it has been hypothesized that migration decisions are based to varying degrees on the male cohort and the number of adult females of the new group as a function of a species' degree of male-male competition and reproductive skew [Van Noordwijk \& Van Schaik, 2004]. In species in which male mating competition is mostly scrambled and male reproductive skew low male rank is of relatively little and the number of females available of relatively high importance for male reproductive success. Dispersing males of such species are therefore supposed to base their decision rather on a group's sex ratio than on the characteristics of group males [van Noordwijk $\&$ van Schaik, 2004]. For species in which male-male competition within the group is frequent and paternity is highly concentration to top ranking males, in contrast, it has been suggested that males mainly base migration decisions on the characteristics of resident males and the chances of achieving a high rank within a short period of time. In-between these extremes, the degree to which males should base their decision on either of the two parameters is supposed to depend on the degree of reproductive skew and thus on the potential reproductive benefit a male would achieve either through trying to gain a high rank or through living with an increased number of females.

The degree of male-male competition and reproductive skew can also be expected to play an important role for strategies to reduce migration costs. Whereas in species with low degree of male-male competition and reproductive skew, resistance of resident males against immigrating 
males can be expected to be low, the opposite should be the case in species where males fight fiercely over access to females and where reproductive skew is high. Accordingly, species with low reproductive skew show low male-male competition, escalated fights between males are rare, immigration costs comparably low and new immigrants often start at the bottom of the hierarchy [e.g. Japanese macaques, Macaca fuscata: Nakamichi et al. 1995]. In contrast, in species with a high reproductive skew, escalated fights are common and costs of immigration high [e.g. Hanuman langurs, Semnopithecus entellus: Borries, 2000]. Particularly in species with a high reproductive skew, one would expect males to migrate together or when the male hierarchy in the group is unstable.

In addition to inter-specific differences in migration decisions, there may also be interindividual differences within the same species since not all males may face the same costs and benefits when dispersing. Inter-individual differences in migration decisions can particularly be expected in species with a high male reproductive skew, i.e. in species in which variation in fighting ability leads to significant differences in reproductive benefits. Similar to the species specific predictions for migration decisions, males can be expected to base selection of a new group on the male and female cohort of the potential target group [van Noordwijk \& van Schaik, 2004]. Again, males with a high fighting ability are supposed to choose groups in which they can quickly achieve high rank, i.e. where resident males are comparatively weak. Males with low fighting ability, in contrast, are supposed to immigrate into groups with an absolute and/or relative higher number of females since this variable is more important for their reproductive success. In terms of cost reduction, particularly these latter males, i.e. those expecting a lower benefit after immigration, can be expected to migrate with others or to try to benefit from instable periods in a group to improve the cost-benefit ratio. Since mostly high rank immigrants cause group instabilities [Bergman et al. 2005; Jack et al. 2011; Setchell et al. 2010], low ranking males may immigrate with or shortly after such males (short alpha male tenure in the target group). Males with high fighting ability should, however, be more concerned with timing immigration to a period when success of reaching a high rank is most likely.

Although several studies on primates have investigated male migration decisions and strategies, to our knowledge only one so far has looked at intra-individual differences. Interestingly, data of this study, conducted on chacma baboons (Papio hamadryas ursinus), a species with high male reproductive skew, did not support the above mentioned relationship between reproductive skew and immigration decision [Clarke et al., 2008]. Opposite to what actually has been predicted [van Noordwijk \& van Schaik, 2004], male chacma baboons with high fighting ability chose new groups based on the number of females whereas for males of low quality, neither absolute nor relative number of females in the group seemed to play a role. All 
other studies on primate male migration decisions so far either concerned species specific strategies or compared differences between species [Jack et al., 2011; Teichroeb et al., 2011; van Noordwijk \& van Schaik, 1985, 2001, 2004; Yao et al., 2011; Q. Zhao, Borries, \& Pan, 2011]. There is thus clearly a lack of studies focusing on inter-individual differences in migration decisions. Crested macaques (Macaca nigra) are an ideal model to investigate inter-individual differences in migration strategies. They live in multi-male multi-female groups in which the alpha male monopolizes the vast majority of paternities (86\%)[Engelhardt et al. under revision]. Males fight fiercely for high-rank and alpha male tenures are expectedly short [Marty et al. submitted]. Migration from one group into another is very common and males are known to migrate several times in their life. In this species, inter-individual differences in migration decision should thus be substantial depending on an individual's fighting ability.

The aim of our study thus was to investigate inter-individual differences in migration decisions based on expected costs and benefits of migration. Since there are no felid predators in the species range [nocturnal pythons (Malayopython reticulatus) are the only predators ; Whitten, Mustafa, \& Hendersen, 1987] transition costs can be expected to be low. We thus focus on the process of immigration into a new group.

We predict i) males with high fighting ability (rank 1-3) to base migration decisions on characteristics of the target group's male cohort, i.e. to select groups with a low number of resident males and/or with an alpha male of long tenure rather than on the group's number of females or adult sex ratio. For males with low fighting ability, in contrast, we predict ii) to preferably immigrate into groups with high numbers of females. We further predict that iii) male crested macaques show joint dispersal, i.e. disperse together with other males that may serve as potential allies against resident males. We additionally expect males of low fighting ability to iv) align immigration to that of immigrants of high fighting ability in order to reduce immigration costs by exploiting circumstances of male hierarchy instability.

As a side aspect, we examined whether body mass is related to fighting ability in crested macaques and thus is a good indicator of body condition and ultimately fighting ability.

\section{Methods}

\section{Study site and subjects}

The study took place in the Tangkoko Reserve in North Sulawesi, Indonesia $\left(1^{\circ} 33^{\prime} \mathrm{N}\right.$, $125^{\circ} 10^{\prime} \mathrm{E}$ ) as part of an on-going long term project (Macaca nigra Project, www.macacanigra.org). The reserve ranges from sea level to $1350 \mathrm{~m}$ and comprises an area of 8867 ha lowland rainforest [Rosenbaum et al., 1998]. The habitat of the study groups was a mixture of 
undisturbed primary forest, secondary forest and regenerating former gardens. Wild crested macaques were studied from mid-2006 until the end of 2012 (R1\&R2)(Table 1). Two of the observed groups (R1 and R2) have been constantly studied since 2006, whereas one group (PB) has been studied by the project from 2008 onwards. A fourth group (R3) was sporadically followed since 2006, but regular data were only collected from July to December 2012. Group size varied between 60-90 individuals for the three groups R1,R2 and PB whereas the group size for R3 was around 25 individuals. All individuals were fully habituated to the presence of human observers.

Table 1: Number and composition of groups studied at the Tangkoko-Butuangas Nature Reserve.

\begin{tabular}{lllllll}
\hline Group & $\begin{array}{l}\text { Number of } \\
\text { adult females }\end{array}$ & $\begin{array}{l}\text { Number of } \\
\text { adult males }\end{array}$ & $\begin{array}{l}\text { Number of } \\
\text { immigrations }\end{array}$ & $\begin{array}{l}\text { Number of } \\
\text { emigrations }\end{array}$ & Study period & Follow days \\
\hline R1 & $18-28$ & $9-18$ & 29 & 29 & $3.2006-12.2012$ & 1854 \\
R2 & $13-21$ & $4-11$ & 8 & 6 & $3.2006-12.2012$ & 1452 \\
R3 & 7 & 4 & 3 & 0 & $7.2012-12.2012$ & 47 \\
PB & $15-25$ & $7-10$ & 18 & 18 & $8.2007-12.2012$ & 1100 \\
\hline
\end{tabular}

\section{Classification of males}

Census data on the group males were collected whenever the groups were followed. The three main study groups (R1, R2, PB) were followed on average 4-5 days per week. We therefore could determine the day of entry with an error of 2-3 days. Males were classified as immigrants when they joined a group (also called target group) and were observed to affiliatively interact with resident group members. A changepoint analyses (Change Point Analyzer 2.3; Taylor Enterprises, Inc.) was conducted to reveal significant changes in the mean squared error distribution of male immigrations [Taylor, 2000]. 10,000 boot- straps with replacements were run and the confidence interval was set at 99\%. Accordingly, immigrants were classified as pioneers and followers according to the previous migration history of the group they immigrated into. When two males or more immigrated within one day and no other immigrations occurred before, they were both considered pioneers. When a male immigrated alone without followers, he was also considered to be a pioneer. Males were considered to have emigrated when they left 
the group and did not return within two months. Two males who re-entered the group after being absent for more than two months were considered to be newly immigrated.

\section{Behaviour data collection}

All groups were regularly observed during all-day follows. Behavioural data on aggressive interactions were collected using focal animal sampling [Altmann, 1974] and ad libitum sampling. In order to quantify dominance hierarchies, we considered all displacements (approach/leave) and agonistic dyadic dominance interactions between males. All interactions were considered when a clear winner/loser could be determined, i.e. either fights with one animal fleeing, submitting or leaving, threats upon which the threatened individual left, or approach/leave interactions (supplants) . To measure the aggression received upon immigration, aggressive interactions of 16 immigrants (including 7 pioneers and 9 followers) in 2012 were analyzed. More than 2300 focal hours were included. Females were considered receptive when showing sexual swellings which reliably indicate the time of ovulation [Higham et al., 2012]. Groups were followed at least once a week but normally during several days a week. All data were entered in hand-held computers using spread-sheet software [PTab Spreadsheet v.3.0; Z4Soft].

\section{Determination of the dominance hierarchy}

In order to quantify dominance hierarchies, we considered all displacements (approach/leave interactions) and agonistic dyadic aggressive interactions between males with a clear winner/looser outcome. For all new immigrants we created winner-looser matrices for agonistic interactions and displacements with all adult males present after the immigration. Depending on the available data interactions within the first three to six months after the immigration were included in order to obtain an accurate rank. Dominance rank was assessed using corrected normalized David's score [de Vries et al., 2006], using the package "Steepness" [Leiva \& de Vries, 2011] in R [R Development Core Team 2009] based on a matrix of proportions of wins calculated for each dyad. Males whose recorded aggressive interactions were not sufficient to calculate a significant David's score but have been observed to successfully challenge or be challenged by a confirmed alpha male, were included into the analyses. To be able to compare the ranks within and between members of different groups, rank was normalized to range between zero and one with alpha males having the lowest score. Hierarchies were considered unstable for one month after the immigration of a high-rank immigrant [see Neumann et al., 2011]. 


\section{Body mass}

Body mass of 8 males were measured during a previous study carried out in 2007/2008 [Neumann et al., 2010]. In addition, the body mass of 12 adult males was measured in 2012 using a hanging scale (DLE, 3A scale manufacturer, weight step $0.01 \mathrm{~kg}$ ). The males were lured onto a small platform hanging underneath the scale using a small piece of coconut. Repeated measurements showed a high accuracy of the method (+/- 100g accuracy across males).

\section{Measurements of injuries}

Each study animal was checked for injuries (i.e. open wounds, cuts, as well as limping due to potentially broken bones) whenever the group was followed. All observed injuries were recorded.

\section{Statistical analyses}

To investigate the factors triggering male immigration in male crested macaques we carried out two generalized linear mixed models (GLMM): One for males with the highest fighting ability, i.e. males achieving alpha position in the new group (model 1), and one for lower ranking males (model 2). In order to investigate male migration preferences, we compared the condition in the target group to that of other available groups into which the male did not immigrate. These alternative groups were all in close reach to each other. According to our predictions, we expected high and low-ranking males to immigrate into the group with the most favorable condition, i.e. male with high fighting ability to migrate into the group with the lowest number of males and/or the longest alpha male tenure, and males with low fighting ability to migrate into the group with the highest number of females and/or the shortest alpha male tenure. For each immigration event, we entered two lines in our data set: one for the condition of the target group on the day of immigration, and one for the most favorable condition in other potential target groups on the same day. For example, in the model for males with low fighting ability, we compared the actual number of adult females in the target group with that of the alternative group that had the highest number of females. The response variable 0 was the most favorable condition in any of the alternative groups and the response variable 1 was the condition in the target group. In that sense, positive estimates indicate higher values of the predictor in the target group. The predictor variables for prospective alpha males were: 1 . the effect of the number of males in a group, 2. the tenure length of the alpha male. Predictors for lower ranking males were: 1. Number of females in a group, 2. the tenure length of the alpha male. The factors on the day of immigration in a specific group were compared to the most favorable group condition in nearby groups on the same day. Group ID and the immigrated males' ID entered the models as random 
factors. Since in both models two variables were compared with each other, binominal models were conducted using R (2.15.2)[R Development Core Team 2009]. All data were z-transformed. By using dfbeta, we checked for model stability. The derived estimates were all similar to the estimated values of the full models showing the absence of influential cases in our data. We checked for co-linearity using variance inflation factors [VIF, Field 2005] in the package car [Fox \& Weisberg, 2010] applied to a standard linear modal excluding the random factors. With all VIFs being smaller than 2.2 in our models, collinearity between the predictors was not a problem [Bowerman \& O'Connell, 1990; Myers, 1990].

We used a Mann Whitney $U$ test to determine whether the rank acquired in the new group differed between pioneers and followers as well as to investigate differences in aggression rate received upon immigration. To investigate the relationship between rank and body mass, we compared the body mass of each individual with its specific rank index during the period of body mass measures using a Spearman rank coefficient. Differences between pioneers and followers regarding their chance of getting injured were analyzed using a Fisher exact test. All significance levels were set at two-tailed p-values $<0.05$.

\section{Results}

\section{Impact of group constellation of the target group and potential other groups on the immigration decision}

During the study period, 57 immigrations by males were observed in our four study groups. For our GLMMs we used data from 31 immigration events were data was available from the group of immigration and at least one alternative group. Both full models of our GLMM were significantly different from the null models (Model 1: $\mathrm{P}=0.002, \chi 2=12.70, \mathrm{df}=5$, Model 2: $\mathrm{P}<0.001$, $\chi 2=18.21, \mathrm{df}=5$ ).

In model 1, investigating males with high fighting ability, the number of resident males was significantly higher in the immigration group than in the most favorable control group $(\mathrm{P}=0.040$, estimate $=1.26, \mathrm{SE}=0.61)$. Alpha male tenure did not significantly differ between potential groups (Table 2). In model 2, investigating lower ranking males, the number of females in the target group did not significantly differ from the most favorable group. The alpha male tenure was significantly lower in the target group compared to the lowest alpha male tenure in potential other groups $(\mathrm{P}=0.010$, estimate $=-7.12, \mathrm{SE}=2.78)$. 
Table 2: Results of the GLMM for males with high fighting ability in which the number of males as well as the tenure of the alpha male in the target groups was compared tothat in potential other target groups

\begin{tabular}{lclll}
\hline Model 1 & Estimate & SE & $\mathrm{Z}$ & $\mathrm{P}$ \\
\hline Intercept & 0.06 & 0.48 & 0.12 & 0.903 \\
Number of males & 1.49 & 0.62 & 2.38 & $0.017^{*}$ \\
Tenure of alpha male in the group & -0.38 & 0.50 & -0.75 & 0.450 \\
\hline
\end{tabular}

Table 3: Results of the GLMM for males with low fighting ability in which the number of females as well as the tenuere of the alpha male of the target groups was compared with that of potential other target groups

\begin{tabular}{lllll}
\hline Model 2 & Estimate & SE & Z & P \\
\hline Intercept & -0.87 & 0.78 & -1.77 & 0.265 \\
Number of females & -1.08 & 0.60 & -1.77 & 0.076 \\
Tenure of alpha male in the group & -4.63 & 2.05 & -2.55 & $0.024^{*}$ \\
\hline
\end{tabular}

\section{Inter-individual differences in immigration patterns and rank acquisition}

A change-point analysis revealed that the observed immigrations occurred in clusters (Figure 1) with 74\% of all males immigrating within 25 days (before or after) another male. 23 males immigrated as pioneers into the group whereas 17 males immigrated as followers. From nine males that immigrated as followers with known group of origin, six were known to be secondary transferring males and 3 were natal males. From eight immigration events with followers during which previously known males immigrated into one of our study groups, only two cases included followers immigrating from the same group of origin (within the same event, but not necessarily on the same day) and six others included followers immigrating from different groups. In only $21 \%$ cases $(\mathrm{N}=6)$ two males immigrated on the same day into the same group and in only one of these cases did the two males depart from the same group. In four of these cases, one of the two males left the group again within a couple of days.

From the observed 57 immigrations into one of the four study groups we could determine a linear David score for 40 males. $61 \%$ of males that immigrated as pioneers into a new group became the group's alpha male upon immigration, whereas only $12 \%$ of followers reached this position after immigrating into the group (Fig 2). Pioneers thus achieved significantly more often a higher rank than followers (Mann-Whitney U-test, $U=0.01, N=40$ ) (Fig 3). Pioneers who immigrated and did not obtain a high rank in the new group $(\mathrm{N}=7)$ never had any followers 
whereas 64\% $(\mathrm{N}=9)$ of pioneers achieving a high rank had followers. The subsequent tenure length of pioneers and followers did not significantly differ from each other (Mann-Whitney Utest, $\mathrm{U}=0.48, \mathrm{~N}=37$ ).

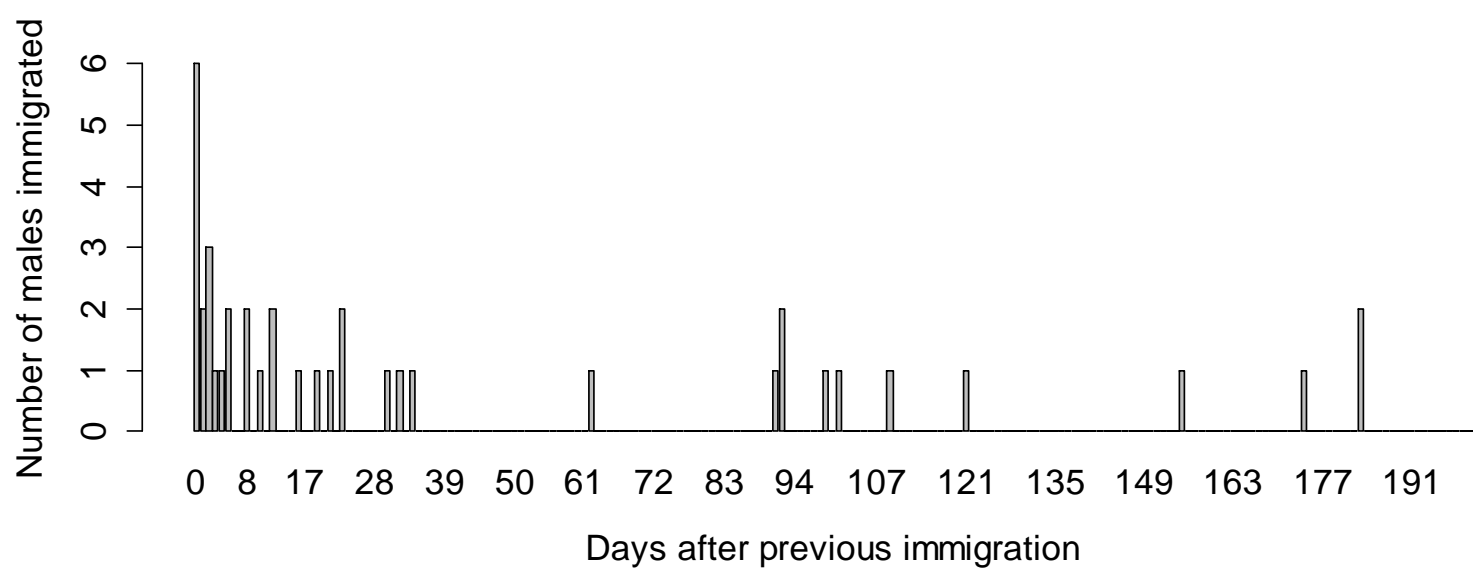

Figure 1: Time span (in days) between two immigration events and number of males immigrating into the same group. Bars represent single or multiple immigration events.

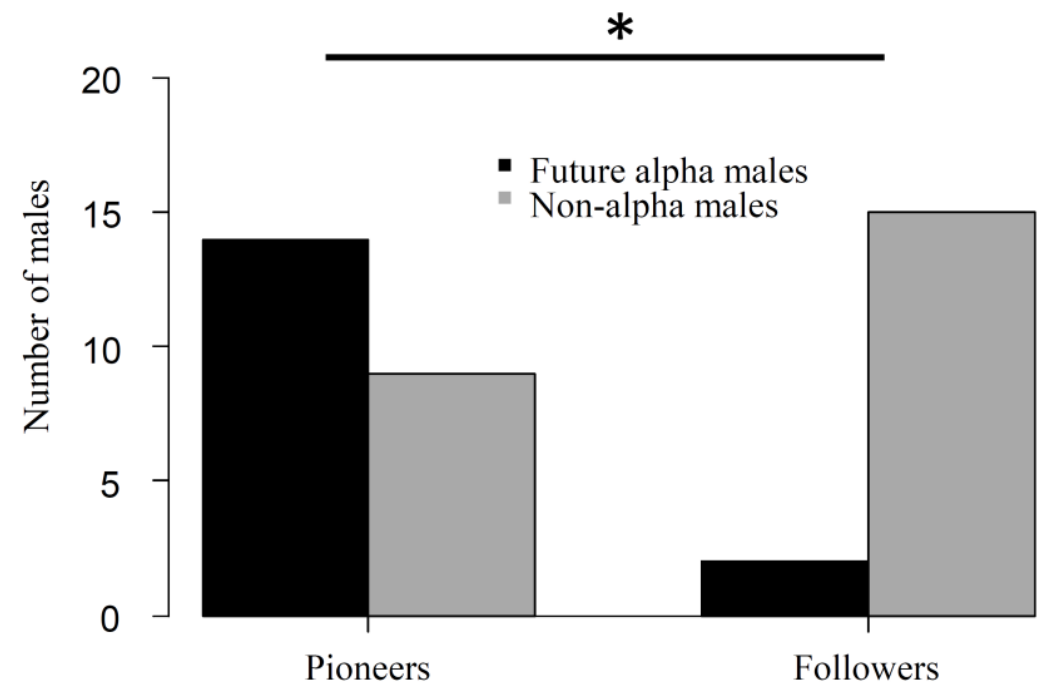

Figure 2: Achievment of top dominant position by pioneers and followers (two tailed Fisher exact test, $\mathrm{P}<0.01$ ). 


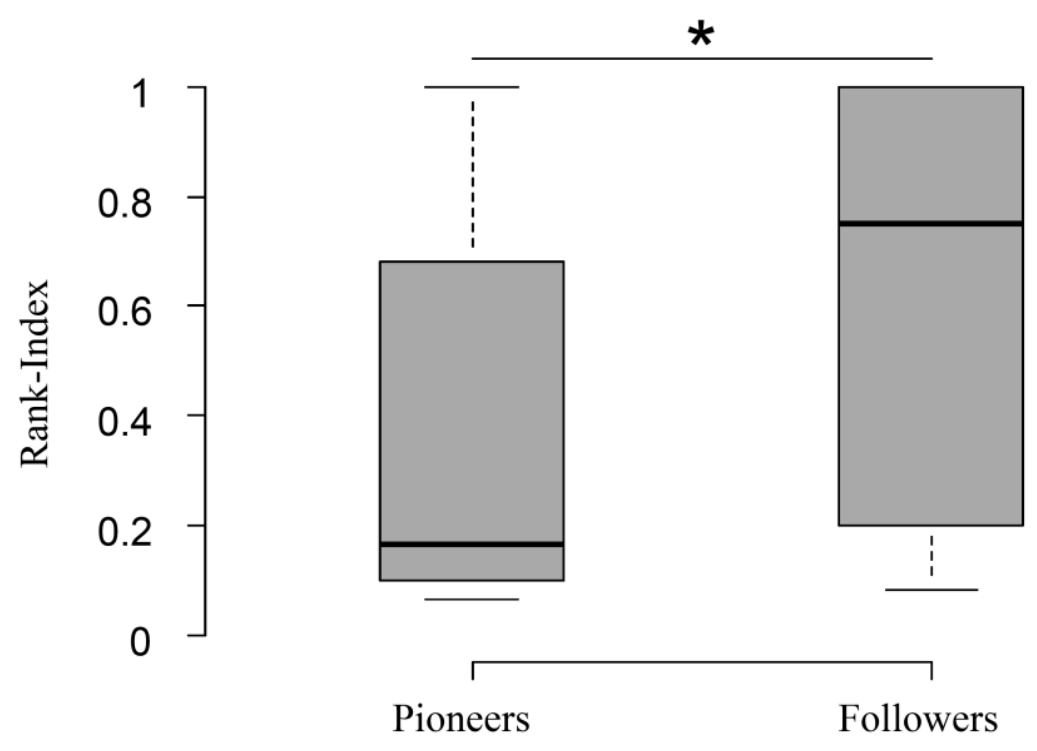

Figure 3: Difference in rank acquisition between pioneers and followers (Mann Whitney U test, $\mathrm{U}=270.5, \mathrm{P}=0.02, \mathrm{~N}=40$ ).

\section{Injuries and Aggression}

Observed direct male-male challenges were brief, and escalated fights between males were decided within minutes, often with one male becoming injured. We found pioneers to be significantly more likely to become injured in the first three weeks following the immigration than followers did (one tailed Fisher exact test, $\mathrm{P}=0.01) .30 \%(\mathrm{~N}=7)$ of pioneers got injured whereas only $6 \%(\mathrm{~N}=1)$ of followers did. Followers were found to receive more aggression from resident males than pioneers in the first two weeks upon immigration (Mann Whitney U test, $\mathrm{U}=9, \mathrm{P}=0.03, \mathrm{~N}=14$; Figure 4). However, aggression received by other males did not significantly change even after more than a month, when males were already fully integrated (Pioneers: Wilcoxon test, $\mathrm{T}^{+}=13 \mathrm{P}=0.98, \mathrm{~N}=5$, Followers: $\mathrm{T}^{+}=26, \mathrm{P}=0.22, \mathrm{~N}=6$ ).

Pioneers and followers, who did not immediately achieve alpha-position upon immigration, also did not do so later on [see also Marty et al. under review]. Unsuccessful challenges were occasionally observed but these males were always immediately expelled at the end of the fight and could not be further observed. Eight of twelve alpha males got injured at the time of replacement (whereby one injury was potentially a consequence of an intergroup conflict). Seven of the injured males left the group upon replacement and one stayed in the group. Another two males left the group immediately after replacement. In addition, we observed one 
case in which an alpha male got challenged, won the fight but both males got badly injured. This alpha male lost his position within a couple of hours and dropped severely in rank. Two days later, he left the group.

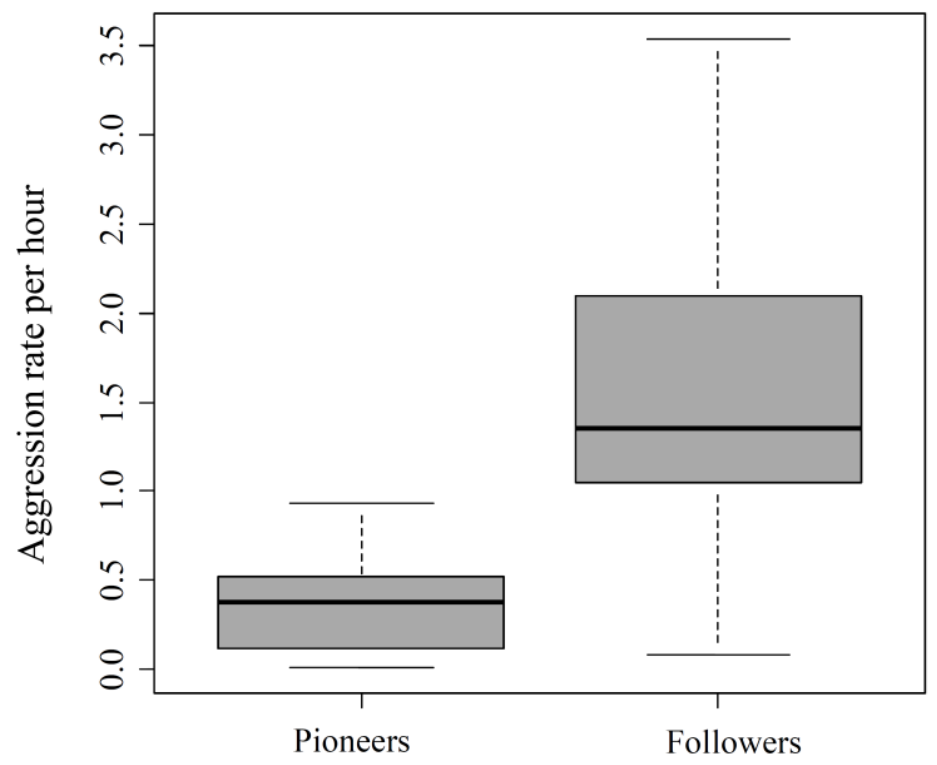

Figure 4: Aggression rate per hour received within the first two weeks upon immigration for pioneers and followers (Mann Whitney test, $\mathrm{U}=9, \mathrm{P}=0.03, \mathrm{~N}=14$ ).

\section{Body mass}

For group-living males, we found a significant positive correlation between male body mass and rank index (Pearson correlation, $\mathrm{R}=-0.8, \mathrm{~N}=20, \mathrm{P}<0.019$ ) (Figure 5). Three pioneers whose body mass could be determined had values above average $(13.8,12.9,12.7 \mathrm{~kg} /$ average of all males $=11.9 \mathrm{~kg}$ ). The body mass of two followers who gained a low rank was below average $(11.16,11.5 \mathrm{~kg})$. 


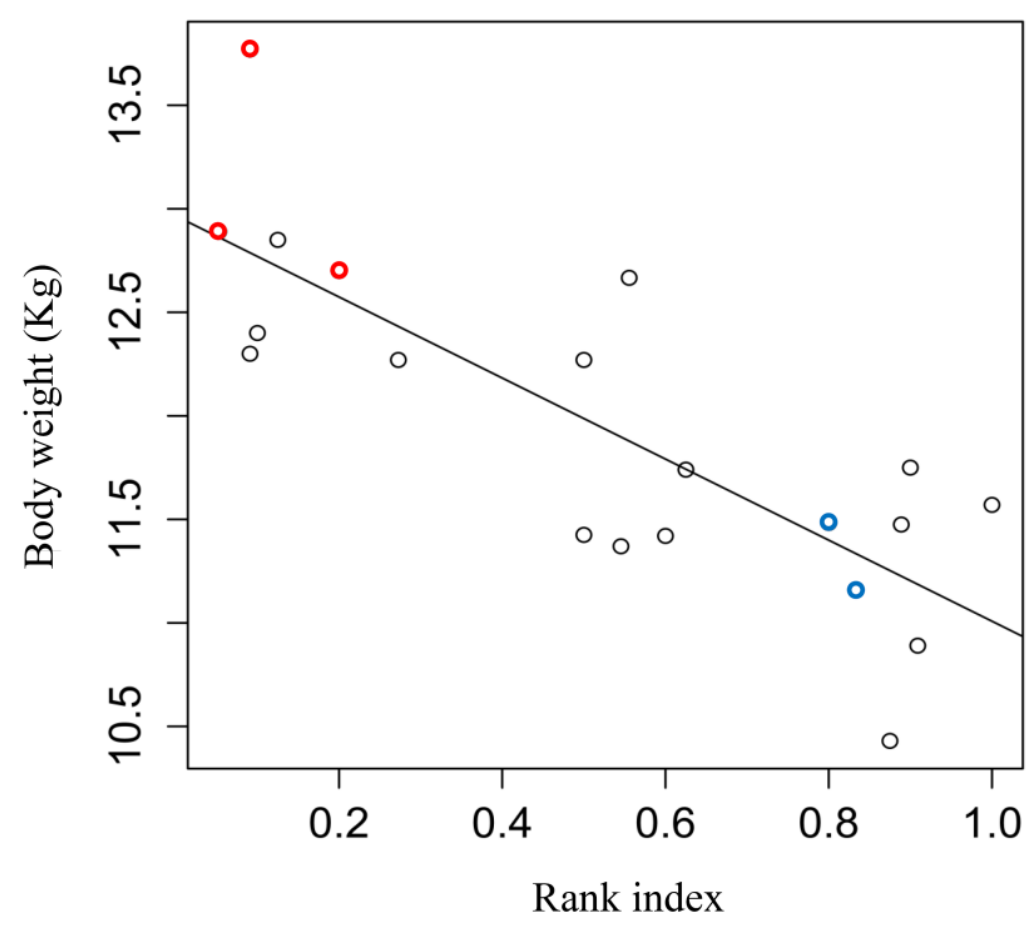

Figure 5: Correlation between rank and body mass in group living non-natal male crested macaques (Pearson correlation, $\mathrm{R}=-0.8, \mathrm{~N}=20, \mathrm{P}<0.019$ ). Marked in red are the body masses of three pioneers measured around the time of immigration. In blue are the body masses of two followers.

\section{Discussion}

Our results show that immigrations by male crested macaques typically occur during clustered immigration events whereby males follow two distinct strategies depending on potential costs and reproductive benefits of immigration. Males who entered the group independent of others (pioneers) were significantly more often males of high than of low fighting ability. These so called pioneers experienced significantly more injuries (i.e. costs), but also generally achieved high rank (i.e. potential future reproductive benefit). Males with a comparably lower fighting ability timed their immigration to the immigration of pioneers with high fighting ability. These so called followers were less often injured than pioneers, but also generally only reached a lower rank and thus low prospective reproductive output.

Our results do not support our prediction that male crested macaques with high fighting ability base their migration decision on characteristics of the target group males (i.e. number of males, alpha male tenure; see also van Noordwijk \& van Schaik 2004]. Males did not immigrate into the group with the lowest number of competitors. In most cases, there was at least one group with a lower number. The tenure of the alpha male also had no significant influence on 
migration decision of males with high fighting ability. The reason for this phenomenon may be that other characteristics of resident males, for example individual fighting ability, may be more important than the absolute number. Similarly, tenure length may not be a good measure of alpha male fighting ability in crested macaques since it can vary tremendously between individuals [see Marty et al. under review]. Future studies should try to include body mass into the analyses as a more precise measure of fighting ability since in contrast to one of our previous studies [Neumann et al. 2010], we found this parameter to be highly correlated with dominance rank.

We found pioneers to have higher body mass than average and in accordance with this, they also usually gained high-rank upon immigration, often even top-rank. It thus seems that reaching a high body mass is a key factor determining whether males migrate as pioneers and challenge high-ranking males for their position or not. A well timed immigration seems to be especially important in crested macaques where males are equipped with large canines capable of inflicting severe wounds. Escalated fights between pioneers and resident high-ranking males (often alpha males) are common and in contrast to other species [e.g. Macaca fascicularis: van Noordwijk \& van Schaik, 2001] are mostly decided within minutes with one opponent being badly injured. In crested macaques, injured males immediately drop in rank and often leave the group directly after. Many have been observed to not recover for several months and some not at all. Looking at the fate of these defeated males and assuming that many challenges of pioneers are not successful, we assume a high risk for pioneers in trying to enter a group. Even though successful, pioneers who achieved high rank in the new group were more likely to receive injuries than other immigrating males. Therefore, pioneers, who are often involved in escalated fights upon migration, face high immigration costs but profit, when successful, from priority of access to fertile females and high reproductive success.

Also contrary to our prediction, males with lower fighting ability did not show a preference for groups with a high number of females. They did, however, preferentially immigrate into groups with a recent changeover in the alpha position (short alpha tenure). Consequently, immigrations often occurred in clusters. This finding is in line with our prediction that males of species with high reproductive skew, particularly those with low fighting ability, should migrate together to exploit circumstances of group instability in this way reducing costs imposed by resident male resistance. Following a high rank immigration or take-over, hierarchal instability within the group has been observed in several primate species [e.g. Jack et al. 2011; Bergman et al. 2005; Setchell et al. 2010] including crested macaques [Neumann et al., 2011] and this can sometimes be associated with an increased immigration rate [van Noordwijk \& van Schaik, 2001]. Since followers appear to be less likely to receive injuries (although receiving 
more low intensity aggression), the use of group instabilities is likely to represent an adaptive strategy for males with a low fighting ability to reduce the costs of immigration. The observation that followers receive more aggression than pioneers is likely to be a consequence of their low rank in the new group rather than of their type of immigration. In crested macaques, highranking males are more aggressive per se than low-ranking males [Neumann, 2013], suggesting that aggression received is a consequence of rank and only indirectly of the immigration strategy. We therefore also did not find a difference in the aggression rate between the two weeks period after the immigration and in the following months when the males were fully integrated into the group. Although males of low fighting ability are unlikely to be subject to similar resistance as males with high fighting ability, we still expect some resistance, especially from the alpha male [Nunn, 2000]. We therefore assume that group instabilities, and specifically the immigration of a new alpha male, do lower resistance, and allow these males to enter a new group more easily. Other than predicted by van Noordwijk and van Schaik [2004], our results suggest that crested macaque males of low fighting ability do not base their migration decision on prospective reproductive benefits, but on potential costs during immigration.

In order to exploit circumstances of group instabilities in other groups, follower males appear to have information not only on the arrival of a new male in a group but also on group instability resulting from pioneer male immigrations. The only way for followers to gain this knowledge in advance is to regularly observe other groups and to wait for suitable immigration opportunities to arise and this behaviour has been regularly observed for various species [e.g. Hamilton \& Bulger, 1990; Henzi \& Lucas, 1980; Muroyama \& Imae, 2000; van Noordwijk \& van Schaik, 2001]. Since males often immigrate with previously unknown individuals, the identity of other immigrators does not seem to influence the migration decision. In contrast, the rank achieved by previously immigrated males seems to be very important since in our study the seven pioneers that immigrated alone and failed to achieve high rank did not have followers. In general, immigration as a follower is associated with lower costs but also lower reproductive benefits compared with pioneer males. The reason why males leave their group and migrate to another group with few prospective reproductive benefits is unclear. Intra-sexual mating competition and inbreeding avoidance have been postulated as main reasons for male transfers [Jack, 2003]. Since reproductive skew in crested macaques is very high, new low-ranking immigrants are not expected to sire many offspring in the new group at least not in the near future. Nevertheless, dispersal costs for future low-ranking males seem to be comparably low, which may facilitate migrations for males with a low fighting ability in this species. In addition, despite the general trend for followers to be low-ranking, several followers have been observed to achieve high rank upon immigration (although only 11\% the alpha position). These males may 
have profited from reduced costs of immigration as a follower and still gain access to females, something that may motivate even males with low fighting ability to try out their chances in new groups.

Even though migrating in cluster, we could not find evidence that male crested macaques preferentially immigrate in cohorts. Only $21 \%$ of the males were found to immigrate on the same day, whereas all other males immigrated alone. Immigration in cohorts thus does not seem to be a typical male strategy in crested macaques. This conclusion is supported by our observation that in those cases where males immigrated together, one of the new immigrants usually left the group again within a couple of days indicating no direct benefit for these males. Assuming the cases where parallel immigrations occur are not by chance, some advantages must be conferred for one or both males. What these advantages are is presently unclear. One possibility is that the lower ranking partner derives some indirect fitness benefit (e.g. support) by migrating with a related male. Since in crested macaques, males of the same age are likely to be half-brothers due to the high reproductive skew in a group, supporting a half-brother in gaining access to females will increase a male's indirect reproductive benefit. However, since only a few males immigrate in cohorts, and only one pair is confirmed as coming from the same group (and therefore potential half-brothers), it is unlikely to be a strategy widely adopted by males.

To our knowledge, this is the first study systematically investigating cost and benefit dependent migrating strategies in mammals living in multi-male, multi-female societies. In comparison to other studies focusing mainly on benefits, we could show that at least for males of low fighting ability, migrations are more driven by avoiding costs than by potential benefits. Based on our findings of alternative immigration strategies in crested macaques, we would also expect alternative migration strategies to occur in other taxa, especially in species with a high reproductive skew, where costs and benefits of migration are likely to be closely related to fighting ability. Further studies should therefore incorporate alternative migration strategies when looking at male careers and life history and ultimately investigating the lifetime reproductive success of males. 


\section{Chapter 3}

\section{Experience rather than external factors predict the physiological stress response upon immigration in male crested macaques}

(Macaca nigra)

Pascal R. Marty1,2,3* ${ }^{*}$ Keith Hodges ${ }^{2}$, Michael Heistermann ${ }^{5}$, Muhammad Agil ${ }^{4}$, Antje Engelhardt1,3

${ }^{1}$ Junior Research Group Primate Sexual Selection, German Primate Center, Göttingen, Germany

${ }^{2}$ Reproductive Biology Unit, German Primate Center, Göttingen, Germany

${ }^{3}$ Courant Research Center 'Evolution of Social Behaviour', Georg-August-University, Germany

${ }^{4}$ Faculty of Veterinary Medicine, Bogor Agriculture University, Indonesia 


\section{Summary}

In gregarious species, dispersal events probably represent the most dramatic shift in social life and environment an animal will experience during life. Increased predation risk, aggression and challenges from unfamiliar conspecifics as well as the lack of social support are expected to be major stressors for the dispersing individual. However, very little is known about how individuals respond physiologically to these stressors, what the timely pattern of such response is, how individuals differ in the extent of their response and whether such response may potentially impair their health. We therefore studied the physiological stress response during dispersal in a primate species, the crested macaque. Over a period of 14 months and 15 migration events in 4 groups, we, determined stress hormone levels during the period of transition between two groups as well as during the process of immigration into a new group. Our study males did not show any physiological stress response during the transition period, which may be due to the low risk of predation crested macaques face in their natural environment. Male stress hormone levels increased, however, substantially during the immigration process. Males differed significantly in the extent to which stress hormone levels increased. Males freshly dispersing from their natal group showed a significantly stronger physiological stress response than secondary migrating males. Furthermore, males who followed a male with high fighting ability into a group showed comparably higher stress hormone levels than the male they were following. Interestingly, males that were in close proximity to resident males showed lower stress hormone levels than those that were further away. Overall, stress hormone levels dropped to baseline already in the second week after immigration. We conclude that male experience as well as self-confidence and the ability to socially integrate into a new group influence the physiological stress response in male crested macaques. Furthermore, given that stress hormone levels stayed increased only for a short period of time, we do not expected males to experience any physiological costs during dispersal. This may be one of the reasons why crested macaque males migrate relatively often between groups even when reproductive benefits do not seem to increase much. Given our limited knowledge on stress hormones and dispersal, this study contributes to the better understanding of dispersal in general and potential physiological cost in particular. 


\section{Introduction}

In gregarious living animals, certain individuals are often forced to leave their natal group as a consequence of selective pressures from within group competition and inbreeding avoidance (Clutton-Brock \& Lukas, 2012; Crnokrak \& Roff, 1999; Pusey, 1987). The migration of an individual from one social unit to another is likely to represent the most fundamental shift in social life and environment in an animal's life [Smale et al., 1997]. In comparison to philopatric individuals, individuals transferring from one group or territory to another often face an unknown environment, increased predation risk, and restricted access to known food resources (e.g. Alberts and Altmann, 1995; Pärt, 1995; Ridley et al., 2008). Dispersal from a social group is therefore a potentially highly stressful situation for the dispersing individual as it not only represents the most dramatic shift in environmental conditions during an animal's lifetime, but also an abrupt and profound change in its social life [Smale et al., 1997]. Furthermore, upon arrival in a new social group, dispersing individuals are often faced with increased aggression [Ydenberg et al., 1988; Teichroeb et al., 2011], need to establish a permanent residency in a new social order, are exposed to unfamiliar competitors and consequently have to alter their behaviour according to this potentially stressful situation [Smale et al., 1997].

As an adaptation to cope with the new environment, increased predation risk, and social challenges during the transition period and upon immigration, dispersing individuals can be expected to show a physiological stress response (activation of the hypothalamic-pituitary-adrenal axis, resulting in elevated glucocorticoid adrenal hormone (GC) secretion) [e.g. Sapolsky, 2002]. This stress response enables the mobilization of energy for immediate use (e.g. 'flight or fight')[Sapolsky, 2002]. Enhanced cognition, analgesia, and sensory function, as well as decreased pain perception are adaptive consequences of the physiological stress response increasing the chances to overcome stressful situations [Sapolsky, 1992; Nelson, 2005]. Whereas a short term increase in stress hormones is adaptive and beneficial for an individual, when activated too long or too frequently, an extended high stress hormone titre (chronic stress) can compromise fitness, due to its diverse negative effects on health (e.g. immunosuppression, decreased growth, impaired reproduction) potentially even leading to early death [Sapolsky, 1992; Balm, 1999; Nelson, 2005]. Hence, a short term physiological stress response allows an individual to better cope with a stressful situation, whereas a long term stress response is maladaptive and leads to physiological costs.

Elevated stress hormones, as a consequence of increased predation risk and food scarcity, has been shown in diverse taxa (e.g. Amphibians: Narayan et al., 2013; Mammals: Sheriff et al., 2009). Studies on the direct link between increased stress levels and time spent outside a social group are scarce. The only one known by us has been carried out on carnivores [Young \& Monfort, 2009]. In meerkats (Suricata suricatta), subordinate males show increased stress hormone levels 
when conducting extra-territorial forays. Elevated GC levels upon immigration into a new social group, however, has been shown in a number of primate species [long-tailed macaques (Macaca fasicularis): van Schaik et al., 1991; yellow baboons (Papio cynocephalus): Alberts et al., 1992; Chacma baboons (Papio ursinus): Bergman et al., 2005; gray-cheeked mangabeys (Lophocebus albigena): Arlet et al., 2009; but see black howler monkeys (Alouatta pigra): van Belle et al., 2009] and thus seems to be a more common pattern at least in this taxon.

In primates, males are in the majority of cases the dispersing sex and newly arriving individuals often challenge resident males to achieve a high rank in the new group, often at the expenses of high risks such as severe injuries [e.g. Packer, 1979]. Other immigrants, those with comparably lower fighting ability, only achieve a lower rank in the new group and develop strategies with which to circumvent contest, in this way reducing costs of immigration (e.g. Marty et. al in revision). Given these differences in immigration costs, males of different fighting ability can be expected to also differ in stress hormone levels. Whether this is the case and to which extent males differ inter-individually in their physiological stress response upon immigration, remains, however, to date unknown.

The aim of this study, thus, is to investigate the pattern of and inter-individual differences in the physiological stress response in migrating males of a gregarious mammal, the crested macaque (Macaca nigra), and to examine whether it brings physiological costs to these animals. Crested macaques are endemic to the island of Sulawesi (Indonesia) and show a social system typical for cercopithecines with groups consisting of several males and females. Females are philopatric whereas males disperse after reaching their physical prime (Marty et al. under review). Regarding predation during the transition, crested macaques are not expected to incur a high risk (Marty et al. 2015). Migration from one group to another is very common and males are known to migrate several times in their life (Marty et al. 2015). Male-male competition and reproductive skew is high and males show a steep linear hierarchy [Reed et al., 1997; Neumann et al., 2011](Engelhardt et al. under review). Male crested macaques show two distinct strategies when immigrating into a new group (Marty et al. 2015). Males with high fighting ability, mainly young males migrating from their natal group for the first time, immigrate into a group independent of other immigrations (pioneers) and often achieve the alpha male position. Males with lower fighting ability, usually use the instability caused in a group's male dominance hierarchy when a pioneer has recently entered a group and achieved the alpha position. These males usually are of lower fighting ability and enter the group at the lower end of the hierarchy (followers).

For males in the transition between two social groups (transient males), we predict that (1) they will show higher levels in stress hormones than group living individuals (group males) due to the absence of familiar conspecifics and social support, an unknown environment, and the potential of 
challenges from conspecifics. Upon the immigration, we predict (2) to see overall elevated GC levels in the immigrants given the social and environmental changeover during migration. We particularly predict (3) individuals that spend more time in the vicinity of group males to show increased stress hormone levels due to the increased risk of contest when being close to these males. However, due to differences in a male's social status reached upon immigration, his fighting ability and migration experience, we expect to see inter-individual differences in the physiological stress response. Specifically, we predict (4) pioneers to initially show higher stress hormone levels than followers since they are more likely to get involved in escalated fights due to their challenging approach. Since primate males in particular are known to often migrate several times during their lives [Pusey \& Packer, 1987], we predict (5) secondary migrating males to show comparably lower GC levels (due to experience) than natal emigrants during the immigration process.

\section{Methods}

\section{Study subjects and study site}

Four groups of wild crested macaques were studied from November 2011 until January 2013 in the Tangkoko Reserve in North Sulawesi, Indonesia (1 $\left.{ }^{\circ} 33^{\prime} \mathrm{N}, 125^{\circ} 10^{\prime} \mathrm{E}\right)$ as part of an ongoing long term project (Macaca Nigra Project, www.macaca-nigra.org). The reserve ranges from sea level to 1350m and comprises 8867 ha of lowland rainforest (Collins et al.1991; Rosenbaum et al.1998). The groups live in a mixture of regenerating former gardens, secondary forest, and undisturbed primary forest. Two of the observed groups (R1 and R2) have been periodically studied during the last ten years [O'Brien \& Kinnaird, 1997; Reed et al., 1997] and systematically since 2006 (e.g. Neumann et al., 2010), whereas the two other groups (PB and R3) were habituated by the project in 2008 and 2010, respectively. All individuals were fully habituated to the presence of human observers. All adult individuals of the groups were individually known by the observers. For the present study, data were collected in 2012.

\section{Behaviour data collection}

Upon the arrival of a new male in a group, newly immigrated males were followed all day, from one sleeping tree to the next sleeping tree. Whenever possible, these males were followed on a daily basis for the first 14 days. Focal data were collected using all occurrence event sampling of all agonistic and affiliative behaviours with group members, as well as scan sampling every 5 minutes recording position, nearest neighbours, and activity [Altmann, 1974]. All interactions between the focal animal and other group members were entered into handheld computers (Psion Workabout Pro 
G2) using spread-sheet software (PTab Spreadsheet v.3.0; Z4Soft). In Addition, data on six solitarily roaming males was collected while following them for a total of 111 focal hours. Overall, more than 2300 focal hours of data were collected.

\section{Determination of the dominance hierarchy}

All displacements (approach/leave interactions) and agonistic dyadic aggressive interactions between males with a clear winner/loser outcome were considered in order to quantify dominance hierarchies. Depending on the available data, interactions within the first three to six months after the immigration were included into analysis in order to obtain an accurate rank for the newly immigrated male. Dominance rank was assessed using corrected normalized David's score (de Vries et al., 2006), using the package "Steepness" [Leiva \& de Vries, 2011] in R (R Development Core Team 2009) based on a matrix of proportions of wins calculated for each dyad.

\section{Sample collection}

Faecal samples were non-invasively collected from newly immigrated males continuously for the first 14 days upon immigration into the new group. If possible, one sample was collected each in the morning, noon, and late afternoon. The freshly defecated faeces was homogenized before an aliquot of $2-3 \mathrm{~g}$ was placed in a polypropylene tube. Samples were directly stored in a cool box filled with ice. After return to camp, samples were stored in a freezer $\left(-18^{\circ} \mathrm{C}\right)$. Overall, 346 faecal samples were collected from immigrating males within the first 14 days upon immigration. An additional 187 faecal samples were collected from the immigrating males after the initial 14 days.

\section{Hormone analyses}

For analysis, all faecal samples were freeze-dried and pulverized, then an aliquot of $0.05-$ $0.08 \mathrm{~g}$ was extracted with $3 \mathrm{ml}$ of $80 \%$ methanol in water as described in detail by Heistermann et al. (1995). For assessing glucocorticoid output, faecal extracts were assayed for concentrations of cortisol metabolites using an enzymeimmunoassay (EIA) for the measurement of immunoreactive

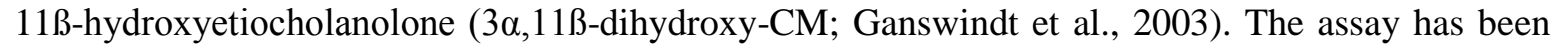
applied successfully to monitor adrenocortical activity in various primates species (e.g. Heistermann et al., 2006; Fichtel et al., 2007; Ostner et al., 2008, Marty et al. 2014) and was recently also validated for the use in crested macaques (Gholib 2010). Sensitivity of the assays at $90 \%$ binding was $1 \mathrm{pg}$ and intra- and inter-assay coefficients of variation of high- and low value quality controls were $10.9 \%(n=48)$ and $5.2 \%(n=24)($ high $)$ and $14.7 \%(n=48)$ and $8.06 \%(n=24)$ (low), respectively. 


\section{Statistical analyses}

In order to determine differences in GC levels between transient and group males, a MannWhitney-U Test was conducted in R (2.15.2)(R Development Core Team 2009). To investigate factors determining the stress response upon immigration, a generalized linear mixed model (GLMM) with Gaussian error distribution was carried out. For this, GC levels were all natural logarithmic transformed. The mean natural logarithm transformed level of GC of a day for each individual entered the analysis as the response variable $(\mathrm{N}=125)$. The predictor variables were: 1 . day after immigration, 2 . proximity to other males measured in meters, 3. rank achieved upon immigration, 4. immigration strategy (pioneer/follower) according to the timing of immigration in relation to other immigrating males (for definition, see Marty et al. 2015). Aggression received from other males entered the model as a control variable. Two males changed group twice within the study period and were accordingly given a number for the immigration event ( 1 for the first immigration, 2 for the second respectively). This immigration number, as well as male and group identity entered the model as random factors.

With a reduced subset of the dataset including only males for which it was known whether they were natal emigrators or secondary migrating males, a second model was run including this information as predictor variables well as those predictor variables that in the previous model, turned out to have a significant influence on stress hormone levels. All categorical variables were transformed to numeric values and subsequently z-transformed, allowing interpretation of the results according to the estimates [Schielzeth, 2010]. Both models were conducted using the package "lmer" in R.

We checked various diagnostics of model validity and stability (Cook's distance, DFBetas, DFFits, and Variance Inflation Factors; distribution of residuals, residuals plotted against fitted values), and none of these indicated obvious influential cases, nor obvious deviations from the assumptions of normality and homogeneity of residuals [Quinn \& Keough, 2002; Field, 2005]. To get reliable p-values, a likelihood ratio test was used to compare the full model with respective reduced models using the function 'drop1' in the package 'car' [Chambers, 1992].

To compare GC levels of immigrating males with their respective levels in the following months, a Wilcoxon paired rank test was used. To test whether transient males had higher GC levels than group living males, a Mann-Whitney-Test was conducted in R. All tests were conducted two-tailed and alpha-levels set to 0.05 . 


\section{Results}

During the study period, 13 males immigrated into one of the four study groups. Two of these males immigrated twice into different groups (Table 1). Therefore, a total of 15 immigrations could be observed.

Table 1: Study male ID, number of observed immigrations, ID of the group the males immigrated into, rank achieved upon immigration, immigration strategy and type.

\begin{tabular}{ccccc}
\hline ID & Group & Rank & Strategy & Migration \\
& & & & \\
\hline BN & R1 & H & Follower & na \\
OL & PB & L & Follower & Secondary \\
QL & PB & L & Follower & na \\
UL & PB & L & Follower & Primary \\
AN & R1 & H & Pioneer & na \\
JL & PB & H & Follower & Primary \\
EL & PB & H & Pioneer & Secondary \\
JM & PB & na & Pioneer & Primary \\
LL & R1 & M & Pioneer & Secondary \\
PL & R3 & H & Pioneer & na \\
CN & R3 & H & Pioneer & na \\
NL * & PB & L & Follower & na \\
NL** & R3 & L & Follower & Secondary \\
FL * & PB & H & Follower & Primary \\
FL** & R1 & H & Pioneer & Secondary \\
\hline na= unknown, * = first observed migration, ** = second observed migration \\
\end{tabular}

During the transition period, the four migrating males sampled $(\mathrm{N}=4)$ did not show significantly elevated GC levels in comparison to resident males $(\mathrm{N}=14)$ (Mann-Whitney-Test, $\mathrm{p}=0.32, \mathrm{n}=18$ ) (Fig $1)$. 


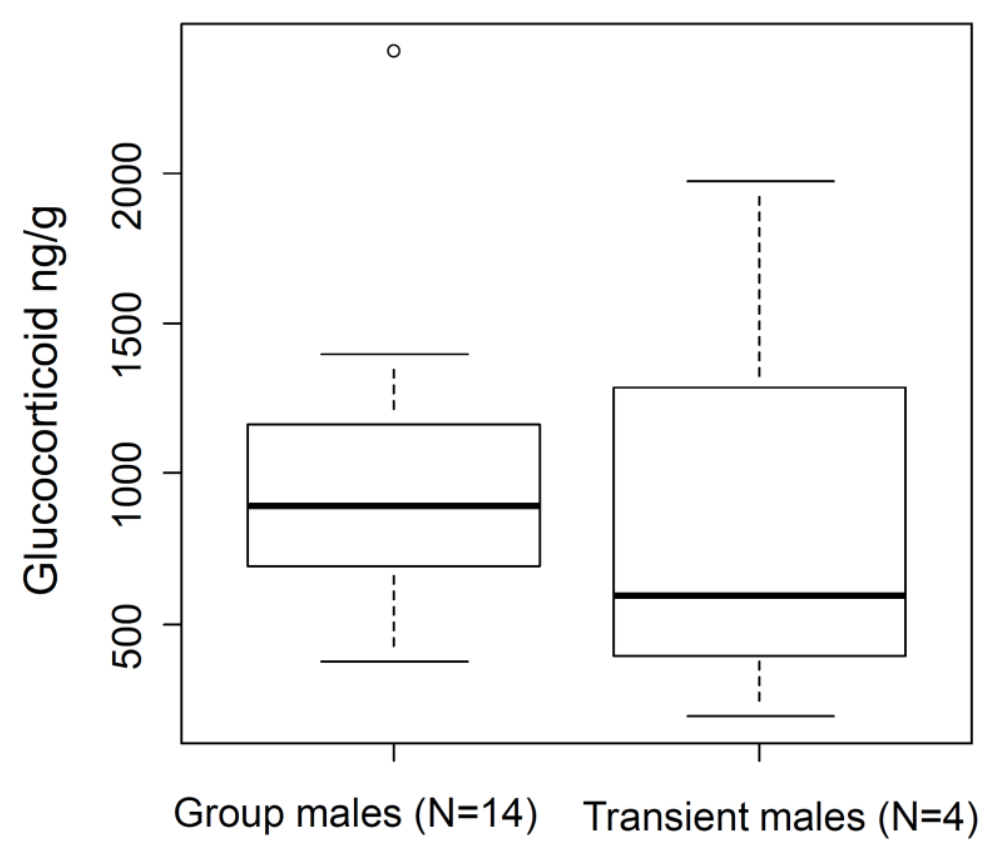

Fig 1: Difference in GC levels of males living in a group and transient males (median, 1st and 3rd quartile, $95 \%$ variance and outliers); Mann-Whitney-Test, $p=0.32, n=18$ ).

The daily mean GC levels of immigrating males showed a high variation within the first seven days, but did not differ from baseline anymore in the second week after immigration (Wilcoxon rank sum test, $\mathrm{P}=0.24, \mathrm{~N}=24$ )(Figure 2).

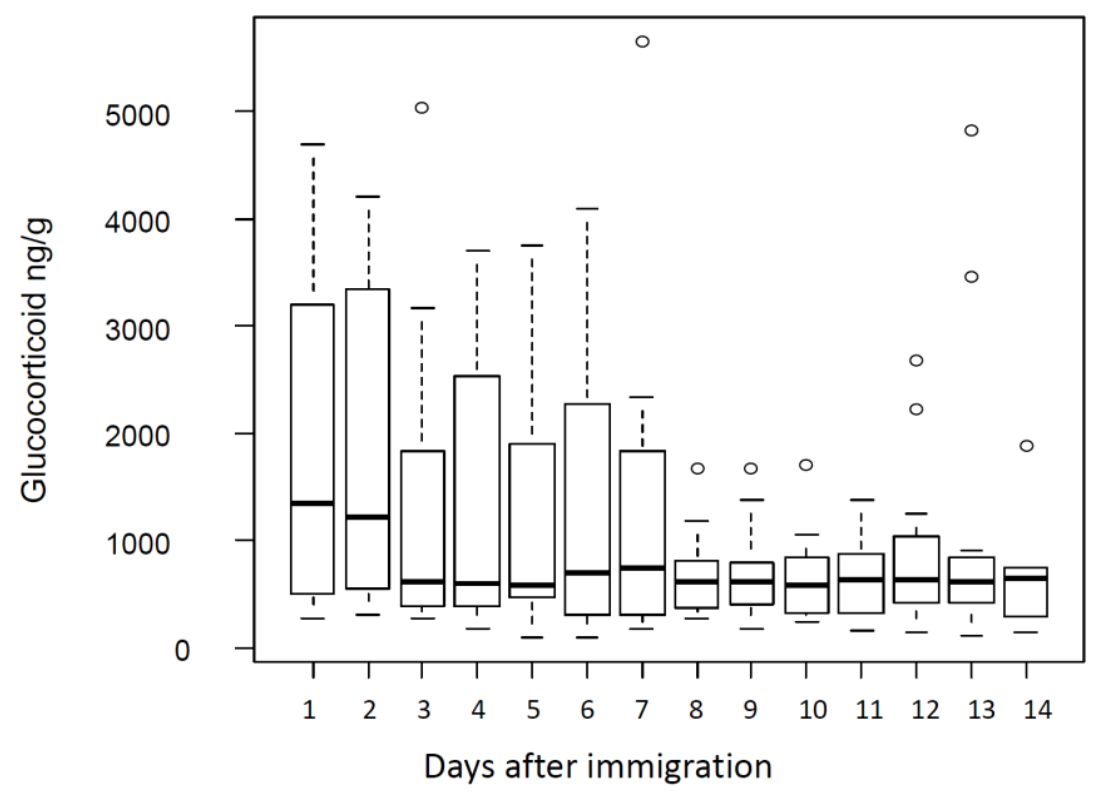

Fig 2: Changes in stress response levels over the first 14 days after immigration (median, 1st and 3rd quartile, $95 \%$ variance and outliers). 
In the GLMM investigating the stress response of all study males, the null model was significantly different from the full model $\left(\mathrm{chi}^{2}=43.56, \mathrm{df}=7, \mathrm{P}<0.001\right)$. GC levels were highest upon immigration and declined over time (estimate $\pm \mathrm{SE}=-0.21 \pm 0.05, \mathrm{P}=0.016$ ). In addition, proximity to other males had a significant influence on the stress hormone levels (estimate $\pm \mathrm{SE}=-0.26 \pm 0.06$, $\mathrm{P}=0.014$ ). Immigrating males who were closer to other males showed lower GC levels than males with fewer male neighbours. In addition, whether males immigrated into the group as pioneers or followers significantly influenced the stress response (estimate $\pm \mathrm{SE}=-0.98 \pm 0.37, \mathrm{P}=0.020$ ). Followers showed higher GC levels than pioneers. The rank achieved upon immigration did not significantly influence the stress response.

Table 2: Results of the GLMM testing the influence of the day after immigration, the agression received from males, the rank achived, immigration strategy (pioneer or follower) and proximity to other males on the stress response of immigrating males.

\section{Model 1}

\begin{tabular}{lllll}
\hline Model & Estimate & SE & $\mathrm{t}$ & $\mathrm{P}$ \\
\hline Intercept & 7.27 & 0.25 & 28.8 & $<0.001$ \\
Day after immigration & -0.21 & 0.05 & -4.52 & $\mathbf{0 . 0 1 6}$ \\
Aggression received & -0.03 & 0.07 & -0.05 & 0.615 \\
Rank achieved & -0.03 & 0.18 & -0.16 & 0.875 \\
Immigration strategy & -0.98 & 0.37 & -2.16 & $\mathbf{0 . 0 2 0}$ \\
Proximity & -0.26 & 0.06 & -4.53 & $\mathbf{0 . 0 1 4}$ \\
\hline
\end{tabular}

The second model including only known natal or secondary migrating males was also significantly different from the null model $\left(\mathrm{chi}^{2}=46.74, \mathrm{df}=6, \mathrm{P}<0.001\right)$ whereby the predictors which were significant in the previous model remained significant (Table 2). In addition, the second model revealed a significant difference in GC levels between natal and secondary migrating males (estimate $\pm \mathrm{SE}=-0.63 \pm 0.12, \mathrm{P}<0.001)$. Natal migrating males showed a significantly higher stress response than secondary migrating males. A comparison between estimates revealed that the effect of natal vs. secondary dispersal had the strongest effect on the measured GC levels. 
Table 3: Results of the GLMM testing the influence of the immmigration day, proximity to other males, immigration strategy and the timing of a migration (primary or secondary migrating males) on the stress hormone levels upon immigration

\section{Model 2}

\begin{tabular}{lllll}
\hline Model & Estimate & SE & t & P \\
\hline Intercept & 10.33 & 0.50 & 20.67 & $<0.001$ \\
Day after immigration & -0.22 & 0.06 & -3.77 & $<\mathbf{0 . 0 0 1}$ \\
Proximity & -0.42 & 0.08 & -5.34 & $<\mathbf{0 . 0 0 1}$ \\
Immigration strategy & -0.71 & 0.23 & -3.11 & $\mathbf{0 . 0 1 7}$ \\
Primary / secondary dispersal & -1.52 & 0.12 & -5.36 & $<\mathbf{0 . 0 0 1}$ \\
\hline
\end{tabular}

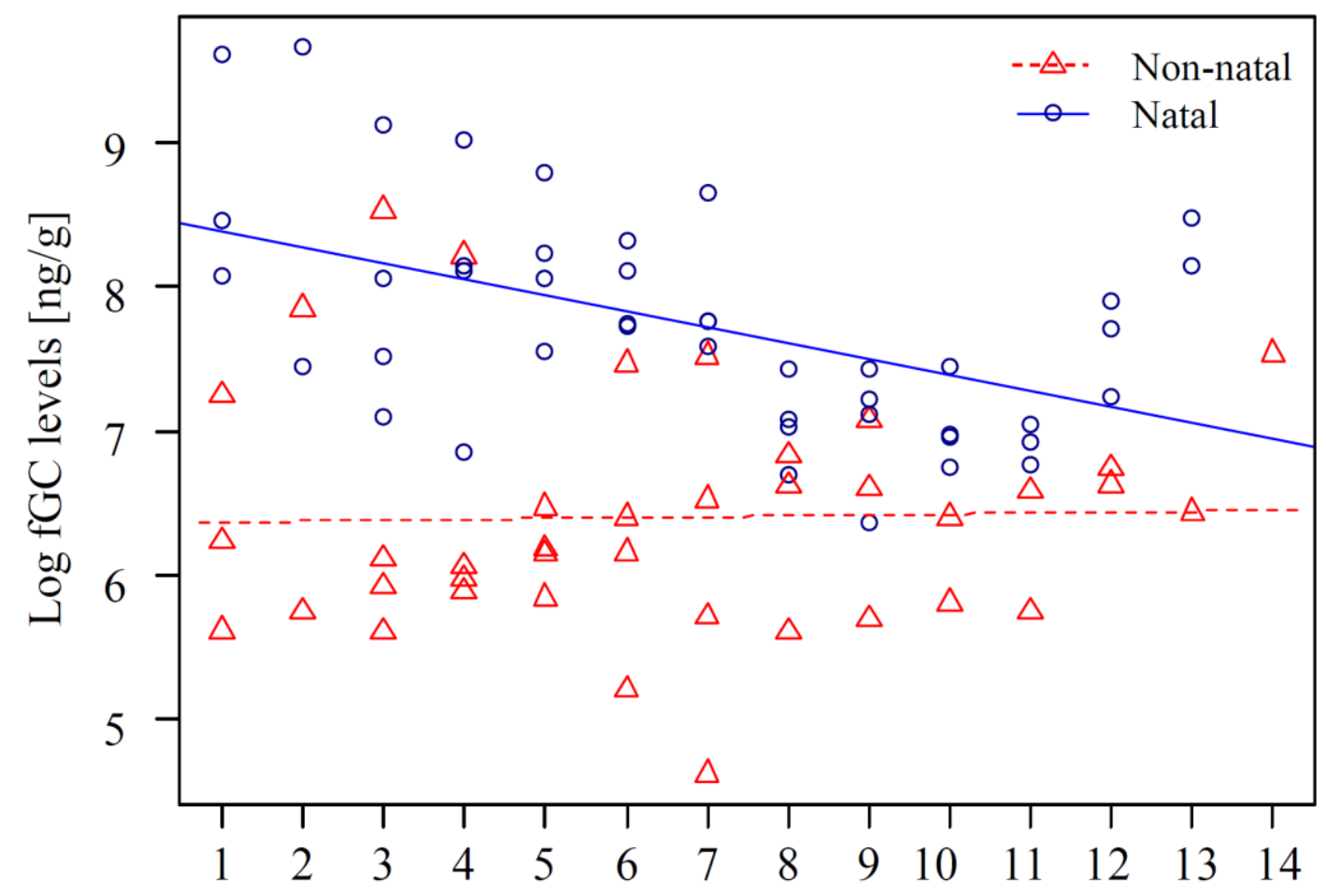

Days after immigration

Figure 3: Changes in stress hormone excretion between natal emigrators (red) and secondary immigrating males (blue) over the first 14 days after immigration into a new group. The plot represents orginal values. 


\section{Discussion}

Opposite to what we expected, the studied male crested macaques did not show elevated stress hormone levels during the transition between two social groups. A physiological stress response was, however, observed when males immigrated into a new group. The stress response itself was relatively short and male hormone levels dropped to baseline already in the second week upon immigration. We found a significant influence on individual stress hormone levels by the strategy with which males immigrated into the group. Pioneers, who entered a group first, showed lower stress hormone levels than followers did. Furthermore, male migration experience significantly influenced the physiological stress response upon immigration with natal males showing higher stress hormone levels than experienced migrators. Finally, proximity to other males upon immigration also influenced the physiological stress response. However, in the opposite direction than predicted: males that were closer to resident males had lower GC levels than those being further away from these males. The rank achieved upon immigration had no significant influence on stress hormone levels.

During the transition period, the absence of former social partners an increased risk of being attacked by conspecifics, and an unknown environment constitute a potentially very stressful situation for a dispersing individual [Smale et al., 1997; Young \& Monfort, 2009]. In contrast to our prediction, however, dispersing male crested macaques did not show significantly increased GC levels during the transition between two groups. In Sulawesi, where felids are absent and only large reticulated pythons (Malayopython reticulatus) threaten the life of adult male crested macaques, risk of predation may be similarly high during dispersal as when living in a group. This may explain our observation [Marty et al. under review]. Aggressions from conspecifics towards strangers, on the other hand, are common in migrating individuals and severe injuries inflicted by attacks on solitary males have been observed (personal observation). Nonetheless, our results suggest that solitary males are able to mainly avoid stressors and incidences of open aggressions from conspecifics. In the few cases, in which we observed attacks towards solitary males, these occurred only when transient males approached a group. They may therefore mainly occur when a male attempts to enter a group. As our sample size is relatively low, we cannot conclusively rule out a general stress response in male crested macaques during the transition period, but at least the studied individuals did not show GC levels significantly elevated over those of resident group males. If the absence of a stress response during the transition period in crested macaques is based on the absence of predation risk, in other species with a higher predation risk this factor may have a substantial influence on the occurrence of a stress response during the transition period. Studies on other primate species are absent and a stress response could only been shown so far in roaming meercats (Suricata suricata), a species underling a very high predation risk [Young \& Monfort, 2009]. Consequently, more studies are urgently needed to investigate whether or not 
individuals of other species show a stress response during the transition period and whether or not predation risk is the driving factor. Nonetheless, due to the difficulties to follow solitary individuals and the requirement of these animals to be habituated to avoid observer induced stress, data collection is very difficult.

As expected and observed in other primate species [Alberts et al., 1992; Bergman et al., 2005; Arlet et al., 2009], male crested macaques showed a stress response upon immigration. In comparison to other studies that were not able to look at inter-individual differences due to a low sample size, we found strong inter-individual differences in the magnitude of the stress response. In a previous study, we found that males show two different immigration strategies. Pioneers achieved high rank, but were also more likely to get injured than males following them (followers). Accordingly, we expected pioneers to be more stressed than followers according to the likelihood of getting injured. Yet, the opposite effect could be observed. Followers generally showed a stronger stress response than pioneers did. Since this finding was independent of rank attained and aggression received upon immigration it is unclear why males experienced higher GC when following a pioneer male. Pioneer males, may potentially be males who are more self-confident with their decision to migrate and may therefore be less stressed upon immigration. Further studies are however needed investigating this phenomenon more thoroughly to draw final conclusion.

Interestingly, the most profound difference in GC levels was found between natal and secondary migrating males. Natal emigrating males, who experience dispersal for the first time, showed higher levels of stress hormones than secondary migrating males, and this independent of whether they were followers or pioneers. Experience in migrating therefore seems to be an important factor in the prevention of stress upon immigration into a new group. Although it is well known that a stress response decreases after repeated exposure to the same stimulus as a result of habituation [Grissom \& Bhatnagar, 2009], dispersal events in crested macaques however, are unlikely to qualify as a repeated stimulus for a stress response as they do not occur at such high frequencies.

In addition to experience in dispersing, we found a second factor to substantially influence the physiological stress response of immigrating males: proximity to resident males. Interestingly, however, the response was opposite to what we had expected. Males had lower GC levels when being in closer proximity to males of the new group. This seems counterintuitive given that resident males can be expected to be perceived as competitors by the immigrating male and potentially preventing him from successfully joining the group. In general, aggression is more likely to be received when being in proximity to conspecifics. A potential reason for our observation may be that males who spend a lot of time in the vicinity of their new group mates are those better integrated into the new social structure. Males who manage to get socially accepted by resident group members within a short time are more 
likely to be in close proximity to resident males than males who stay at the periphery. This fact may then lead to a reduction in stress hormone levels in these males. Socially more experienced males might therefore also be better able to socially integrate themselves and in this way may not need a physiological stress response. Additional evidence for experience facilitating stress reduction comes from olive baboons. In this species, secondary migrating males seem to have fewer difficulties in transferring than natal emigrators. This has been attributed to the ability of secondary migrating males to use experience in forming consortships with fertile females and therefore "buffering" themselves against aggression [Packer, 1979]. Natal males on the other hand do not have this experience since they do not consort females until they have left their natal group.

In regard to physiological costs, dispersal does not seem to have any negative consequences for the dispersing individual in crested macaques. The observed stress response is clearly adaptive and does not last for an extended period of time. It can, therefore, be expected to not pose any threat to the individuals' health. In other species, however, an elongated stress response might be detrimental for a male's health. There is to date one study that provides some evidence for the assumption that males might show an elongated physiological stress response at least in some species. In gray-cheeked mangabeys (Lophocebus albigena) individuals show an elongated physiological stress response upon immigration whereby the reason is not clear [Arlet et al., 2009]. All other studies investigating stress hormone levels upon immigration have measured stress hormone levels using averages over relatively long periods making it impossible to analyse fine scale differences in stress hormones and determining the end of a physiological stress response [Alberts et al., 1992; Bergman et al., 2005].

This study provides essential new insights into the physiological consequences of dispersal and inter-individual differences between males of a socially living mammal. Dispersal is assumed to be highly stressful and a physiological stress response is expected in males of most mammal species. Whether or not males of other species are as easily able to adapt to stressful events during immigration as crested macaques or whether in some species, individuals show an elongated stress response remains still unknown and needs further investigations. 


\section{Chapter 4}

\section{Alpha male replacements and delayed dispersal in crested macaques}

(Macaca nigra)

Pascal R. Marty ${ }^{1,2,3}{ }^{*}$, Keith Hodges ${ }^{2}$, Muhammad Agil ${ }^{4}$, Antje Engelhardt ${ }^{1,3}$

${ }^{1}$ Junior Research Group Primate Sexual Selection, German Primate Center, Göttingen, Germany

${ }^{2}$ Reproductive Biology Unit, German Primate Center, Göttingen, Germany

${ }^{3}$ Courant Research Center 'Evolution of Social Behaviour', Georg-August-University, Germany

${ }^{4}$ Faculty of Veterinary Medicine, Bogor Agriculture University, Indonesia 


\section{Summary}

In species with a high male reproductive skew, competition between males for the top dominant position is high and escalated fights are common between competitors. As a consequence, challenges incur potentially high costs. Selection should favor males who time an alpha male challenge to maximize chances of a successful outcome minimizing costs. Despite the importance of alpha male replacements for individual males, we know little about the timing of challenges and the condition of the challenger. We investigated the timing and process of alpha male replacements in a species living in multi-male groups with high male reproductive skew, the crested macaque. We studied four wild groups over six years in the Tangkoko reserve, North Sulawesi, Indonesia, during which 16 alpha male replacements occurred. Although unusual for cercopithecines, male crested macaques delayed their natal dispersal until they attained maximum body mass and therefore fighting ability whereupon they emigrated and challenged the alpha male in another group. Accordingly, all observed alpha male replacements were from outside males. Ours is the first report of such a pattern in a primate species living in multi-male groups. Although the majority of alpha male replacements occurred through direct male-male challenges, many also took place opportunistically (i.e. after the alpha male had already been injured or had left the group). Furthermore, alpha male tenure was much shorter than expected. We hypothesize that this unusual pattern of alpha male replacements in crested macaques is related to the speciesspecific combination of high male reproductive skew with a large number of males per group. 


\section{Introduction}

In primates, as well as in other mammals living in multi-male groups, high- and especially top ranking males normally have higher reproductive success than other males in the group [Alberts et al., 2003; Ostner et al., 2008; Schülke \& Ostner, 2008]. However, the difference in reproductive success between top ranking (alpha) and lower ranking males varies among species [Kutsukake \& Nunn, 2006]. When the reproductive benefits of being alpha are high, males compete fiercely for this position [van Noordwijk \& van Schaik, 1985; Hamilton \& Bulger, 1990; Perry, 1998; Borries, 2000]. Escalated fights and severe injuries are often consequences of these challenges and bear high risks and potential costs for the males involved. Selective pressures should therefore lead to males timing their alpha male challenges according to the likelihood of winning, in order to minimize costs. Clearly the ability of a male to attain and maintain the alpha rank position is critical to his overall reproductive success, but our understanding of how alpha male replacements take place in primates remains limited.

The potential for males to monopolize females, and therefore reproduction, directly influences the benefits a male obtains from being in the alpha position [Kutsukake \& Nunn, 2006]. The higher the monopolization potential, the higher the reproductive skew, thereby leading to the evolution of high risk strategies in rank acquisition, such as individual challenges and escalated fights [van Noordwijk \& van Schaik, 2004]. As a consequence of the cost and benefit trade-off, males of species in which the monopolization potential of single males is low often achieve the alpha male position through low-risk tactics, such as queuing or succession by the death or departure of the former alpha male, rather than by fighting [e.g. Huffman, 1991]. In contrast, species with a high reproductive skew show intense malemale competition over access to females, and males most often achieve alpha rank through high risk challenges leading to common escalated fights between males [Port \& Cant, 2013]. Alpha rank in primate species with a high reproductive skew can also be attained opportunistically (e.g. due to the absence of the resident alpha male), however, or through succession [e.g. Jack \& Fedigan, 2004].

Alpha male replacements can occur from either resident group males, i.e. from within the group, or newly immigrated males, i.e. from outside. For multi-male groups, predation risk may play a role in this regard [Pradhan \& van Schaik, 2008]. According to this hypothesis younger, low-ranking males grow to full strength within a non-natal group only if they stay at the periphery: in the group's center they would face frequent harassment by the alpha-male. In species facing high predation risk, young-, non-natal males thus face the trade-off between achieving safety from predators vs. avoiding alpha-male aggression. For this reason, males of such species, should grow into their physical prime within their natal group and only subsequently emigrate to challenge alpha-males in other groups. By contrast, if predation risk is low, even on the group's periphery, males can afford to grow into their prime and challenge the alpha-male from within a non-natal group. Evidence that supports this hypothesis so far comes from chacma baboons, a species facing high predation risk [Alberts \& 
Altmann, 1995], where males grow to full strength within their natal group and then emigrate to challenge alpha males in other groups [Hamilton \& Bulger, 1990; Beehner et al., 2005].

Regardless of whether a male challenges from within the group or from outside, he generally acts on his own [van Noordwijk \& van Schaik, 1985; Hamilton \& Bulger, 1990; Suzuki et al., 1998; Borries, 2000]. There are some known exceptions, however, in which coalitions of several males take over a group [Pope, 1990] or where male bonds within a group are useful for a challenger to achieve a high rank [Schülke et al., 2010]. These exceptions aside, individual fighting ability characterizes the general pattern of acquiring alpha status in males, and therefore physical condition and fighting ability are the principal determinants of male rank in the majority of primate species [e.g. Henzi \& Lucas, 1980; Perry, 1998; Borries, 2000; van Noordwijk \& van Schaik, 2001; Marty et al., in revision]. Accordingly, challengers are generally described as in their prime [van Noordwijk \& van Schaik, 2004].

The decision by a male to challenge a resident alpha male is a trade-off between the derived benefits of a successful challenge and the potential costs of an escalated fight. A well-timed challenge will increase the chances of success, whereas an ill-timed challenge may lead to defeat, severe injuries, and a reduced chance of success in the near future. The potential to win a challenge depends on both the physical condition of the challenger and that of the challenged male. As such, males should time their challenges according to their own physical condition in relation to the potential strength of the alpha male. In long-tailed macaques (Macaca fascicularis), for example, the chances of winning a challenge increase with tenure length of the alpha male [van Noordwijk \& van Schaik, 2004].

In the case of extra-group challenges, males seeking to take over top rank should also assess group composition, since a comparable lower number of males could lead to greater future reproductive success. Since information on a group's operational sex ratio and the alpha male's condition is easier to obtain from within, pre-prime males of many species immigrate into non-natal groups where they may soon achieve a high rank [Pusey \& Packer, 1987]. In some species challenges from outside are common, however, and males of these species may also acquire knowledge on the group structure and potential benefits of a migration by surreptitiously observing a group prior to an immigration [Cheney \& Seyfarth, 1990; van Noordwijk \& van Schaik, 2001; Teichroeb et al., 2011]. Once established in the top dominant position, a male will strive for long tenure to increase his reproductive benefits [van Noordwijk \& van Schaik, 2004].

The overall aim of this study was to investigate alpha male replacements in a primate species with a high reproductive skew and intense male-male competition, the crested macaque (Macaca nigra). We were particularly interested in the correlation between male condition and variables of the target group. In crested macaques, the fitness benefits of being alpha are extensive because both groups contain many females and male reproductive skew is high [Marty et al., in revision, Engelhardt et al. in 
revision]. We assume predation pressure is relatively low because of the absence of diurnal predators [e.g. van Schaik, 1989], though we know that large reticulated pythons prey on crested macaques (pers. obs.). Attacks from birds of prey have never been observed nor do crested macaques give and alarm calls after spotting any birds.

Here, we investigated the timing of alpha male replacements, and determined both internal and external factors leading to alpha male challenges. Based on the knowledge obtained on comparable species, we predicted that (1) alpha males would be replaced by challengers from within the group, (2) the longer the tenure of the alpha male, the more likely he would be challenged, and (3) challengers would be in their physical prime when challenging.

A secondary aim of our study was to investigate the alpha male tenure in male crested macaques. In a recent study, the number of females in a group, sex ratio, and inter-birth interval were all identified as predictors of alpha male tenure and the frequency of alpha male replacements in mammals living in multi-male multi-female groups [Lukas \& Clutton-Brock, 2014]. We tested whether this pattern held true for our study species. Since the number of females in groups of crested macaques is high, [Marty et al., in revision] but the inter-birth interval is long [Engelhardt. unpublished], we predicted (5) an intermediate (ca. 50 months [Lukas \& Clutton-Brock, 2014, supplementary material]) alpha male tenure compared to other primates.

\section{Methods}

\section{Study species}

Crested macaques (Macaca nigra) live in large multi-male multi-female groups with up to 100 individuals [Reed et al., 1997; Duboscq et al., 2013]. The sex ratio is around three adult females per male [O’Brien \& Kinnaird, 1997]. Females are philopatric whereas all males leave their natal group [Neumann et al., 2010]. Males often migrate several times during their lives and males with low fighting ability immigrate into a new group along with males who have high fighting ability [Marty et al. in revision]. Migrations are not restricted to certain times but occur year-round. Crested macaques are frugivorous and spend the majority of their time on the ground [O'Brien \& Kinnaird, 1997]. Males and females both show linear dominance hierarchies [Reed et al., 1997; Neumann et al., 2011; Duboscq et al., 2013]. While females are described as socially tolerant [Duboscq et al., 2013] according to the four grade scale designed for macaques [Thierry, 2007], males show intense malemale competition and high reproductive skew, because high-ranking males have priority of access to fertile females [Engelhardt et al. in prep.]. Male body mass is highly correlated with rank and therefore a reliable predictor of fighting ability in this species (Marty et al. in revision). Females show large sex 
skin swellings of the anogenital region, which relatively reliably indicate the fertile phase of the ovarian cycle [Higham et al., 2012]. Crested macaques are moderately seasonal breeders as per the definition of van Schaik [1999] (Engelhardt et al. in prep). Because of a high monopolization potential of females during the fertile phase, especially during the conceptive cycle, infanticide is likely to occur in this species. Although we have not yet directly observed infanticide, the mortality rate of infants increases after new alpha males immigrate into a group, which hints that sexually selected infanticide may occur [Kerhoas et al., 2014].

\section{Study site and subjects}

We collected our data in the Tangkoko Reserve in North Sulawesi, Indonesia $\left(1^{\circ} 33^{\prime} \mathrm{N}\right.$, $125^{\circ} 10^{\prime} \mathrm{E}$ ) as part of an ongoing long-term project (Macaca nigra Project, www.macacanigra.org). The reserve ranges from sea level to $1350 \mathrm{~m}$ and spans an area of 8867 ha of lowland rainforest [Rosenbaum et al., 1998]. The habitat of the study groups was a mixture of undisturbed primary forest, secondary forest, and regenerating former gardens.

We studied groups of wild crested macaques from mid-2006 until the end of 2012. Two of the observed groups (R1 and R2) were constantly studied during this period, whereas one group (PB) was studied by the project only from 2008 onwards. We followed a fourth group (R3) sporadically beginning in 2006, but we collected regular data from July to December 2012. Group size varied between 60-90 individuals for three of the groups R1, R2 and PB, whereas R3 consisted of around 25 individuals. All adult animals were individually recognized and fully habituated to the presence of human observers.

\section{Data collection}

We observed all groups regularly during all-day follows to collect behavioral data on aggressive interactions using focal animal sampling [Altmann, 1974] and ad libitum sampling. We recorded the number of females with a sexual swelling every day in the field. We followed groups at least once a week, but normally several times per week. All data were entered into hand-held computers using spreadsheet software (PTab Spreadsheet v.3.0; Z4Soft). We classified males as immigrants when they joined a group and were observed to affiliatively interact with resident group members.

\section{Determination of the dominance hierarchy}

We calculated dominance ranks, as David's scores [de Vries et al., 2006] with the package "Steepness" [Leiva \& de Vries, 2011] in R [R Team, 2009]. As input data, we included all male-male displacements (approach/leave interactions) and dyadic agonistic interactions with a clear winner/loser 
outcome (e.g. displacements) in order to quantify dominance hierarchies. For some males, we did not have enough aggressive interactions to calculate a David's score, but if these males successfully challenged and expelled a confirmed alpha male, we included them as alphas in our analyses.

\section{Body mass}

As body mass is a reliable indicator of dominance and thus of fighting ability in male crested macaques [Marty et al., in revision], we measured body mass of five natal emigrants, either shortly before or after their first dispersal, and of eight non-natal resident males. For our non-invasive measurements we used a hanging scale [Scalematic enterprise, 3A-DLE scale, weight step $0.01 \mathrm{~kg}$ : Marty et al. in revision]. We supplemented our data set with body mass data from two natal and six non-natal group males measured during a previous study [Neumann et al., 2010].

\section{Statistical analyses}

We used multiple Wilcoxon signed rank tests to investigate based on which parameters a male decides to challenge a group's alpha male position. Specifically, we compered selected parameters of a group during two periods: 1 . on the day of the takeover and 2. on the day 90 days before the takeover. The selected parameters were: (1) the number of males and (2) the tenure length of the alpha male at this time. To correct for multiple testing, we used the Benjamini-Hochberg correction [Benjamini \& Hochberg, 1995]. We used a Mann-Whitney U test (in R) to determine whether the body mass of dispersing natal males (prospective alpha males) differed from the body mass of resident non-natal males. All tests were carried out with two-tailed probabilities and the alpha level set to 0.05 .

This research adheres to the legal requirements of the German and Indonesian governments, and adheres to the American Society of Primatologists Principles for the Ethical Treatment of NonHuman Primates.

\section{Results}

We observed 21 alpha male takeovers and could verify the alpha male position for 16 of these (Table 1). For 10 males, we could determine a significant steep and linear David score upon immigration. For an additional six males, we observed a fight or a direct replacement of a confirmed alpha male. All takeovers involved outside males whose alpha status was detectable within a few hours after immigration. About half ( 5 of 9) of the observed alpha male takeovers involved a direct challenge from a newly immigrated male, while the rest were opportunistic takeovers after the resident alpha male left the group or was injured during a previous challenge. The average tenure of an alpha male was 361 days (range: $21-1258, \mathrm{~N}=14$ ). 
Most (6 of 8) of the new alpha males with known group of origin were males dispersing from their natal group. After correcting for multiple testing, neither the number of males (Wilcoxon signed rank test, $\mathrm{P}=0.62, \mathrm{~N}=16$ ), nor the alpha male tenure (Wilcoxon signed rank test, $\mathrm{P}=0.03, \mathrm{~N}=16$ ) were significantly different on the day of immigration compared to the control day three months before. Separate post-hoc analyses for natal group emigrants revealed that $75 \%$ of these males achieved alpha male status upon their initial migration. The remaining males gained alpha male status within a half a year in another group (and one male after a group fission).

The body mass of natal group emigrants was significantly higher than the average body mass of non-natal males in the group (Mann-Whitney $\mathrm{U}, \mathrm{U}(\mathrm{df})=81.5, \mathrm{P}=0.01$; Figure 1). We found alpha male tenure in crested macaques to be very short (12 months) and the inter-birth interval of crested macaques to be about 23 months (unpublished data).

Table 1: Characteristics of 16 male takeovers, including identity of the male identity of the group in which the take-over occurred, takeover date, tenure length after takeover, whether the takeover was opportunistic (i.e. followed prior injury to/absence of former alpha male) or not, and whether the male taking over the alpha-position had transferred directly from his natal group or not. Hyphens indicate lack of data.

\begin{tabular}{lrrrll}
\hline ID & Group & $\begin{array}{l}\text { Date of entry } \\
\text { “DD/MM/YR” }\end{array}$ & $\begin{array}{l}\text { Tenure } \\
\text { length (d) }\end{array}$ & $\begin{array}{l}\text { Opportunistic } \\
\text { takeover }\end{array}$ & $\begin{array}{l}\text { Natal } \\
\text { dispersal }\end{array}$ \\
\hline LL & PB & $20 / 07 / 09$ & 908 & - & - \\
EL & PB & $14 / 01 / 12$ & 115 & yes & no \\
JL & PB & $19 / 05 / 12$ & - & yes & yes \\
AJ & R1 & $26 / 09 / 07$ & 159 & - & - \\
PM & R1 & $03 / 03 / 08$ & 21 & no & - \\
IM & R1 & $24 / 03 / 08$ & 100 & no & - \\
TJ & R1 & $13 / 01 / 09$ & 371 & yes & yes \\
MM & R1 & $19 / 01 / 10$ & 36 & yes & yes \\
DL & R1 & $21 / 02 / 10$ & 99 & - & - \\
VL & R1 & $31 / 05 / 10$ & 470 & - & yes \\
EL & R1 & $03 / 09 / 11$ & 80 & - & - \\
AN & R1 & $14 / 03 / 12$ & 418 & no & - \\
ZJ & R2 & $08 / 03 / 07$ & 1258 & - & yes \\
TL & R2 & $17 / 05 / 11$ & 582 & - & yes \\
FL & R2 & $19 / 12 / 12$ & 435 & no & no \\
CN & R3 & $26 / 07 / 12$ & - & no & - \\
\hline
\end{tabular}




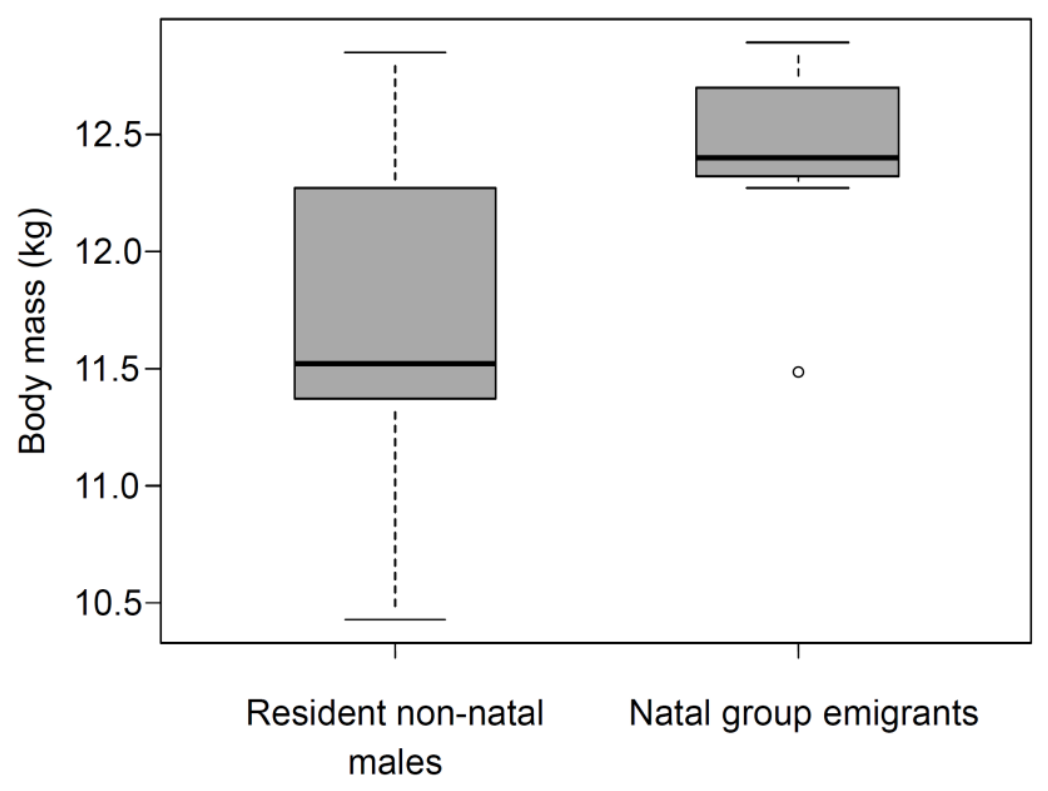

Fig. 1: Body mass (median, $1^{\text {st }}$ and $3^{\text {rd }}$ quartile, $95 \%$ variance and outliers) of males leaving their natal group compared to non-natal males. Natal group emigrants were significantly heavier than resident group members (Mann-Whitney $\mathrm{U}$ test, $\mathrm{U}(\mathrm{df})=81.5, \mathrm{P}=0.01$ ).

\section{Discussion}

Our results do not fit Pradhan and van Schaik's [2008] hypothesis, which assumes that males in species with low predation pressure should challenge alpha males from within the group rather than from outside. In our study population, alpha male replacements were exclusively conducted by newly immigrated males. While extra-group replacements are obligatory in species with one-male groups, takeovers of the alpha-rank position in multi-male groups may be executed by both resident and newly immigrated males [e.g. long tailed macaques: van Noordwijk \& van Schaik, 1985; tufted capuchins: Robinson, 1988; chacma baboons: Beehner et al., 2005]. Our observations suggest that predation pressure may not be the only reason that males of this species strongly prefer to challenge alpha males from outside the group.

An alternative explanation for this phenomenon may be the combination of having many males present in a group and the fitness value of high-ranking positions, related to high skew in male reproductive success [Engelhardt et al. in revision]. As a consequence, pre-prime males immigrating into a new group may not have a chance to sire offspring there before reaching physical prime, and also may face costs that are too high when they fight to move themselves up the hierarchy later on. Strong weaponry (e.g. canine size dimorphism) reflecting high male-male competition may reinforce outside 
takeovers by adding additional cost to each challenge. Indeed, crested macaques exhibit one of the most pronounced canine dimorphisms of all primates [Plavcan \& van Schaik, 1992]. As a consequence, males involved in escalated fights often get injured and immediately drop precipitously in rank, often leaving the group (personal observation). It took months for many of our study males to recover following injuries from intrasexual competition, and others never fully recovered. A severe injury from a fight might therefore be the end of a male's reproductive career. Thus, young males may be better off gaining strength in their natal group, where they do not compete over access to females, and timing challenges to coincide with reaching their peak physical strength. Additionally, with a very high reproductive skew in this species, young males who are not in their prime are less likely to gain reproductive advantages in a new group. We therefore hypothesize that, in our study species at least, delayed dispersal is an adaptive strategy to avoid the costs of immigrating as a pre-prime male, thus maximizing fighting ability and chance of successfully challenging an established alpha male immediately upon first immigration. A similar example can be seen in chacma baboons, which are also characterized by high reproductive skew [Alberts et al., 2006], high canine dimorphism [Plavcan \& van Schaik, 1992], and a large number of adult males per group [Engh et al., 2006]. Should our hypothesis be true, we would expect to find outside takeovers in other primates with high reproductive skew, and many males per group as well. However, such species are probably rare in primates, because the number of males and reproductive skew are usually negatively correlated with each other [Gogarten \& Koenig, 2012]. The reason why some species do not follow this pattern is still unclear and merits further study.

Although we observed that newly immigrated males often attained top rank by physical challenges, this was not always the case. A substantial number of alpha male replacements were opportunistic, in that already injured alpha males were replaced by a newly immigrating male without a fight and within a few days. These injured alpha males sometimes won a fight with an outside challenger, but their ranks dropped immediately if they were seriously injured. Even though these replacements were opportunistic, all of the newly arriving prospective alpha males were in their physical prime. Crested macaques appear to learn before joining them, and thus can respond quickly to changes [Marty et al., in revision]. Opportunities for learning occur during frequent intergroup encounters or when males temporarily leave their group and potentially observe other groups. Group residency may thus be less important to learn about the condition of alpha males than previously thought [van Noordwijk \& van Schaik, 2004].

In addition to the challenger's physical condition, we predicted that the characteristics of the target group and the condition of the alpha male, especially the length of his tenure to date, would influence the timing of a challenge by a young prime male as seen in other species [van Noordwijk \& van Schaik, 2004]. However, our data did not confirm this prediction. In our study animals, the length 
of alpha male tenure did not differ between the day of challenge and a control day. Furthermore, the constellation of the target group in general does not seem to have an influence on the challengers' decision to immigrate or not.

In addition to determining the process behind alpha male replacements, we were also interested in how long male crested macaques are able to defend their top position once it was won. According to a recent meta-analysis carried out across various mammalian species [Lukas \& Clutton-Brock, 2014], group characteristics such as the number of females in the group, sex ratio, and inter-birth interval all influence length of alpha male tenure in multi-male groups. Following the detected pattern, we expected alpha male tenure in crested macaques to be intermediate for primates (ca. 50 months, see [Lukas \& Clutton-Brock, 2014]), since the high number of females in the group and the high sex ratio predict a short tenure, whereas the relatively long inter-birth interval suggests a rather long tenure. Instead, with an average of ca. 12 months, our crested macaques showed one of the shortest tenures known for any primate species (average 50 months in multi-male, multi-female primate groups [Lukas \& Clutton-Brock, 2014]), with only chacma baboons holding shorter tenures [Hamilton \& Bulger, 1990; Palombit, 2003]. Here again, crested macaques do not seem to follow the general pattern possibly because the inter-birth interval has far less influence on tenure length than the other two variables. A high operational sex ratio in combination with a high number of females in the group is expected to place high pressure on outside males to reach the top dominant position. Because of this pressure, in combination with the high value of the top dominant position, males might not be able to defend the alpha male position for an extended period, regardless of inter-birth interval.

Altogether, crested macaques seem not only to show extreme patterns in alpha male replacements and tenure lengths, but also to be a species more generally at one extreme of the primate spectrum with respect to male-male competition. We think this is a consequence of different factors reinforcing each other, leading to a feedback loop. With high reproductive skew and alpha male replacements taking place only from outside males, short alpha male tenure and long inter-birth intervals, infanticide risk in this species is high and cannot be reduced by paternity confusion in group males, since all new alpha males had no chance to sire offspring before they arrived (no extra group paternities have been found in 67 tested infants, unpublished data). As a consequence, females should provide clear signals of fertility to concentrate paternity on the highest ranking male, who is more likely to protect offspring with increasing degree of paternity certainty [Hrdy, 1979; Soltis et al., 2000; Heistermann et al., 2001]. In this way, females reinforce the existing reproductive skew and heighten male-male contest competition, thus leading to an exaggerated sexual dimorphism in weaponry. Intense male-male competition over the alpha male position should, in turn, lead to shorter tenure for top dominant males and to delayed natal dispersal. Indeed, there is particular risk of infanticide after alpha male replacements in crested macaques [Kerhoas et al., 2014], and females seem to have the clearest 
signals of fertility observed in anthropoid primates so far [Higham et al., 2012]. Because of these characteristics, crested macaques are excellent models for testing current predictions on the evolution of sexual selection and male-male competition. These macaques seem not to match the dispersal and alpha male replacement patterns observed in most other primate species, which yields opportunities to question current theories and to develop new ideas on the evolution of these patterns. 


\section{Chapter 5}

General discussion 
$\mathrm{T}$ he overall aim of this study was to investigate male adaptive strategies to maximise reproductive success via migrations between social groups, and to achieve the alpha male position in a gregarious mammal with female philopatry and high male reproductive skew, the crested macaque. I investigated condition-dependent dispersal strategies, the physiological consequences of dispersal and immigration in terms of physiological stress, as well as strategies male crested macaques use to achieve the top dominance position in a group.

In the general discussion, I first briefly discuss our finding that males in the transition period between two social groups do not show a physiological stress response. Next, I discuss the observed strategies males use to join a new social group (section 5.1). Since these strategies differed greatly between individuals depending on their fighting ability, I explore them separately in the two sub-chapters. In chapter 5.1.1, I discuss the cost-benefit trade-off of dispersal for males with high fighting ability, how it leads to a delayed dispersal and outside alpha male takeovers, the implications for the social system of this species and their significance for other species. In chapter 5.1.2, I discuss the observed strategies males of low fighting ability use to immigrate into a new group despite the low benefits expected. I highlight the potential for these males to reduce costs, as well as potential alternative strategies to gain access to females and therefore increase reproductive benefits in a new group. The results of this study and their applicability to other mammals will be reviewed in section 5.2, before I finish the discussion with a conclusion and an outlook for future directions (section 5.3).

\subsection{Migrating strategies}

Migration from one group to another is primarily driven by a male's pursuit of increasing his reproductive success [Pusey \& Packer, 1987]. Therefore migrations are expected to lead to fitness benefits for migrating males [Jack, 2003; van Noordwijk \& van Schaik, 2004]. Similar to dispersing males of other species, male crested macaques are assumed to face a trade-off between potential costs of a migration and the expected reproductive benefits in a new group. There are two major phases during the migration: the transition period between two social groups, and the immigration into a new group; both are associated with specific costs. Interestingly, migration in general does not seem to produce any physiological costs in terms of increased stress hormone levels in crested macaques. In contrast to what could have been expected due to social isolation and the elevated risk of attacks by conspecifics, males in the transition period between two groups did not show elevated glucocorticoid levels (chapter 3). 
The absence of a stress response during the transition period might, however, be directly related to the absence of felid predators in Sulawesi. In species with a higher predation risk, dispersing males potentially show a stress response. In contrast, GC levels were elevated during immigration. However, this rise in GC levels can be interpreted as adaptive rather than devastating, since GC levels dropped to baseline again within a couple of days. Physiological stress becomes chronic and detrimental for the dispersing male's health only if the stress response is elongated.

In terms of individual strategies to immigrate into a new social group, two major strategies were detected: either males immigrated into a group first, as "pioneers", i.e. with no previous immigrations within the previous 25 days, or as "followers", i.e. immigrating into groups with a recent changeover in the alpha position, leading to clumped immigrations (chapter 2). Pioneers were often natal emigrating males of high fighting ability mostly attaining the alpha male position in a group and therefore gaining the highest possible benefit in terms of future reproductive success (chapter 4). Followers were mostly males of low fighting ability attaining a low rank upon immigration (chapter 2) and presumably also low reproductive success (chapter 4).

\subsubsection{Cost and benefit trade-off of dispersal for males of high fighting ability (pioneers)}

As previously mentioned, pioneers were males who entered a group which did not experience an immigration in the last 25 days. These males were found to be often natal emigrating males of high fighting ability attaining the alpha male position in a group and therefore gaining the highest possible benefit in terms of future reproductive success (chapter 4). Pioneers, however, also bore high costs and were more likely to get injured than other males upon immigration (chapter 2). Thus, we expected males of high fighting ability to preferentially immigrate into groups where they have a chance to achieve a high rank. In contrast to our prediction, males of high fighting ability did not preferentially immigrate into groups where they are most likely to outcompete the resident males, but timed their emigration according to their fighting ability (chapter 4).

A rather unexpected finding of my study was that natal males delayed their dispersal until reaching a body mass and fighting ability well above the group average. So far, delayed dispersal is mostly discussed in the context of "helping" in cooperative breeders [e.g. Kokko \& 
Ekman, 2002; Sparkman et al., 2011]. Little is therefore known about delayed dispersal in noncooperatively breeding primates [van Noordwijk \& van Schaik, 2004]. As most primate males disperse from their natal group before reaching adult size, it is assumed that these early emigrators gain direct or indirect reproductive benefits either directly upon immigration or in the future [Pusey \& Packer, 1987]. The extent of the reproductive success a sub-adult male can gain in a new group, however, is likely related to the male reproductive skew in a species. In species with a high reproductive skew, immigration as a sub-adult male at the bottom of the hierarchy may result in low reproductive benefits and immigration costs may outweigh these benefits. In contrast, in species with a low reproductive skew, where competition over access to females is scrambled resulting in low male-male competition, sub-adult males may already obtain some reproductive benefits as pre-prime males, since more dominant males are not able to monopolise reproduction. Additionally, in such species, rank often increases with time through succession, thus leading to males with the longest group tenure often occupying the highest ranks [e.g. rhesus macaques: Berard, 1999]. An early migration may therefore ultimately lead to a high reproductive success in the future [Pusey \& Packer, 1987]. Since many species with a low reproductive skew are seasonal breeders, males may use additional strategies to reduce the costs of immigration. Here we may get some insights from other taxa: in seasonally breeding rodents, males have been observed to migrate as sub-adults. They time their dispersal to emigrate shortly after breeding season, when male-male competition is lowest and sub-adult males face the least resistance when settling [belding's ground squirrels (Urocitellus beldingi): Nunes, 2007]. Accordingly, primates with a short reproductive season might be more likely to reduce immigration cost when migrating as sub-adults outside the breeding season. Hence, many primate species known to disperse as sub-adults are also seasonal (e.g. rhesus monkeys, Japanese macaques, Barbary macaques, toque macaque), while species dispersing at adult size are non-seasonal (e.g. yellow baboons, olive baboons, chacma baboons, gorillas) [Pusey \& Packer, 1987; Janson \& Verdolin, 2005]. Following this hypothesis, sub-adult males of seasonally breeding species should immigrate before or after the breeding season to avoid high resistance from resident males. Non-seasonally breeding species on the other hand would face high resistance year-round. Some species, however, show a dispersal at adult size despite a highly seasonal reproduction (e.g. vervet monkeys) [Pusey \& Packer, 1987; Janson \& Verdolin, 2005], highlighting the need for further investigations.

In addition to the influence of the breeding season, I propose that the delayed dispersal in crested macaques is a consequence of a trade-off between costs and benefits in the specific social system of this species. As a result of the high reproductive skew [Engelhardt et al., in preparation], sub-adult males, which are expected to be only able to obtain a low rank in the new 
group, are not expected to gain noteworthy reproductive success in the new group. They are also not able to gain any future reproductive advantages as a result of long group tenure since the alpha male position is attained through challenge rather than succession (chapter 4). An additional factor might lower a sub-adult's chance to successfully reproduce in a new group even more: crested macaque groups contain a relatively high number of adult males in comparison to other primate species [Neumann et al., 2010, 2011; Lukas \& Clutton-Brock, 2014 (suplementary material)]. These males are all expected to be able to physically outcompete a sub-adult male and have priority of access to fertile females. Although a high number of adult males in a species was associated with a decreased reproductive skew [Ostner et al., 2008; Gogarten \& Koenig, 2012], a deviant result has been found for highly dimorphic primate species such as crested macaques [Cowlishaw \& Dunbar, 1991; Thorén et al., 2006]. In summary, benefits for male crested macaques migrating as sub-adults are supposed to be negligible. Consequently, sub-adult males would disperse only if the expected costs during dispersal are even lower than the benefits. As solitary male crested macaques have been observed to be chased and sometimes badly and potentially fatally injured by resident group males, dispersal as a sub-adult male with very low fighting ability (and therefore low potential to defend), may be associated with high costs. Strong weaponry (e.g. canine size) due to high male-male competition may reinforce delayed dispersal by adding additional cost to an immigration attempt. Male crested macaques thus seem to be better off staying in their natal group until they reach a body mass that would enable them to physically compete with high ranking males in another group. The cost-benefit ratio of resident males to attack a newcomer also shifts with the immigrants' potential to defend. As resident males are more likely to get injured themselves, they may be less willing to get involved in an escalated fight with a male in his physical prime. In this situation, the alpha male has the most to lose and is therefore the individual most likely to repel the intruder [Nunn, 2000].

An alternative explanation for the evolution of delayed dispersal was postulated by Pradhan and van Schaik [2008]. Observations from captivity indicate that it is difficult to keep multi-male primate groups in an enclosure due to high aggressions from the dominant male towards subordinates [e.g. Clarke et al., 1995]. In the most extreme outcome, subordinate males are not capable of reproducing anymore due to the social pressure from dominant males [Eberhart et al., 1985]. Pradhan and van Schaik [2008] concluded that in the wild, subordinate males can only mature within a non-natal group when they are able to escape the aggression of the dominant male by being on the periphery. This strategy is only feasible when predation risk is low and peripheral animals therefore do not face higher predation risk. Consequently, in species with low predation risk, sub-adult non-natal males can grow and gain fighting ability at 
the periphery of the group and subsequently challenge the alpha male from within the group [e.g. long-tailed macaques: van Noordwijk \& van Schaik, 2001]. In contrast, where predation risk is high, male takeovers are more common from outside males [e.g. tufted capucines (Cebus apella): Jack \& Fedigan, 2004]. An additional example supporting Pradhan and van Schaik's hypothesis comes from baboons, where males have been observed to mature in their natal group before they transfer and challenge an alpha male [Hamilton \& Bulger, 1990; Beehner et al., 2005]. This pattern has been attributed to a high predation risk for solitary individuals [Alberts \& Altmann, 1995].

Since crested macaques are not expected to experience high predation risk (chapter 2), the observed migration pattern in this species cannot be explained by Pradhan and van Schaik's hypothesis. In contrast, our prediction that male reproductive skew, the number of males per group, and the resulting potential reproductive benefit for sub-adult non-natal males are the main factors for delayed dispersal also holds for chacma baboons, where there is a high mating skew and a high number of adult males per group [Weingrill et al., 2000; Beehner et al., 2005]. Specifically in chacma baboons and crested macaques, male-male competition is intense, resulting in significant costs when being attacked as a sub-adult. Since species with a high reproductive skew and a large number of males are rare due to a negative correlation between these two factors [Gogarten \& Koenig, 2012], it might be difficult to test this assumption.

Since the timing of emigration for natal males is predictable by their body mass, the resulting fighting ability is assumed to be the main factor leading to dispersal and the following challenge of an alpha male. Demographic factors in the target group potentially increasing the chances of a successful challenge, such as a low number of male competitors or a long tenure of the resident alpha male, do not seem to influence a prime natal emigrator's decision to challenge a specific alpha male. Other factors not included in this study, however, potentially influence a male's decision to challenge. Although I was able to determine the timing of an alpha male challenge, I was not able to determine particular attributes of challenged alpha males that would lead a natal dispersing male to challenge him (e.g. fighting ability). Yet, previously proposed factors could be excluded (e.g. length of alpha male tenure [van Noordwijk \& van Schaik, 2004]). Although natal emigrators seem to be willing to take a high risk by challenging an alpha male, a high percentage of alpha male replacements were observed to be opportunistic. Similarly, many prime male capuchins have been found to opportunistically take over a group without having to challenge a resident male [Jack \& Fedigan, 2004]. Prospective alpha males seem to be aware of the costs a challenge may entail, and therefore preferentially use a strategy by which they can achieve the alpha male position with the lowest possible costs involved. 
The delayed dispersal and alpha male takeovers upon natal emigration in crested macaques have a striking impact on the social dynamics of the species. In theory, females should prefer groups with multiple males and within-group takeovers where counterstrategies to infanticide, such as paternity confusion, are most effective [Pradhan \& van Schaik, 2008; Heistermann et al., 2001]. In contrast, males should favour single-male groups where paternity is most certain or multi-male groups with outside takeovers, as within-group takeovers would favour the evolution of female strategies for paternity confusion. In support of this hypothesis, Clarke [2009] found the degree of male reproductive skew in primate species characterised by within-group takeovers to be significantly reduced, in comparison to species with outside takeovers. Since all observed takeovers took place from extra-group males, the social structure in crested macaques is shifted in favour of males.

When all takeovers occur from extra-group males, females are expected to shift their strategy to concentrate paternity into the most dominant male, who is the one most likely to defend their offspring against new outside challengers [Pradhan \& van Schaik, 2008]. Accordingly, in female crested macaques, sexual signals of ovulation are reliable [Higham et al., 2012] and are likely to promote paternity concentration, as predicted. By doing so, females reinforce male-male competition over access to females, thus leading to an exaggerated sexual dimorphism in weaponry. Not surprisingly, crested macaques exhibit one of the most pronounced canine dimorphisms in primates [Plavcan \& van Schaik, 1992]. The pronounced weaponry of males will add additional costs for potential challengers, reinforcing the occurrence of delayed dispersal to assure a male challenges an alpha male only when he is in his absolute physical prime (chapter 3). Consequently, several factors will reinforce each other in a positive feedback loop leading to the observed pattern in crested macaques (Figure 1). 


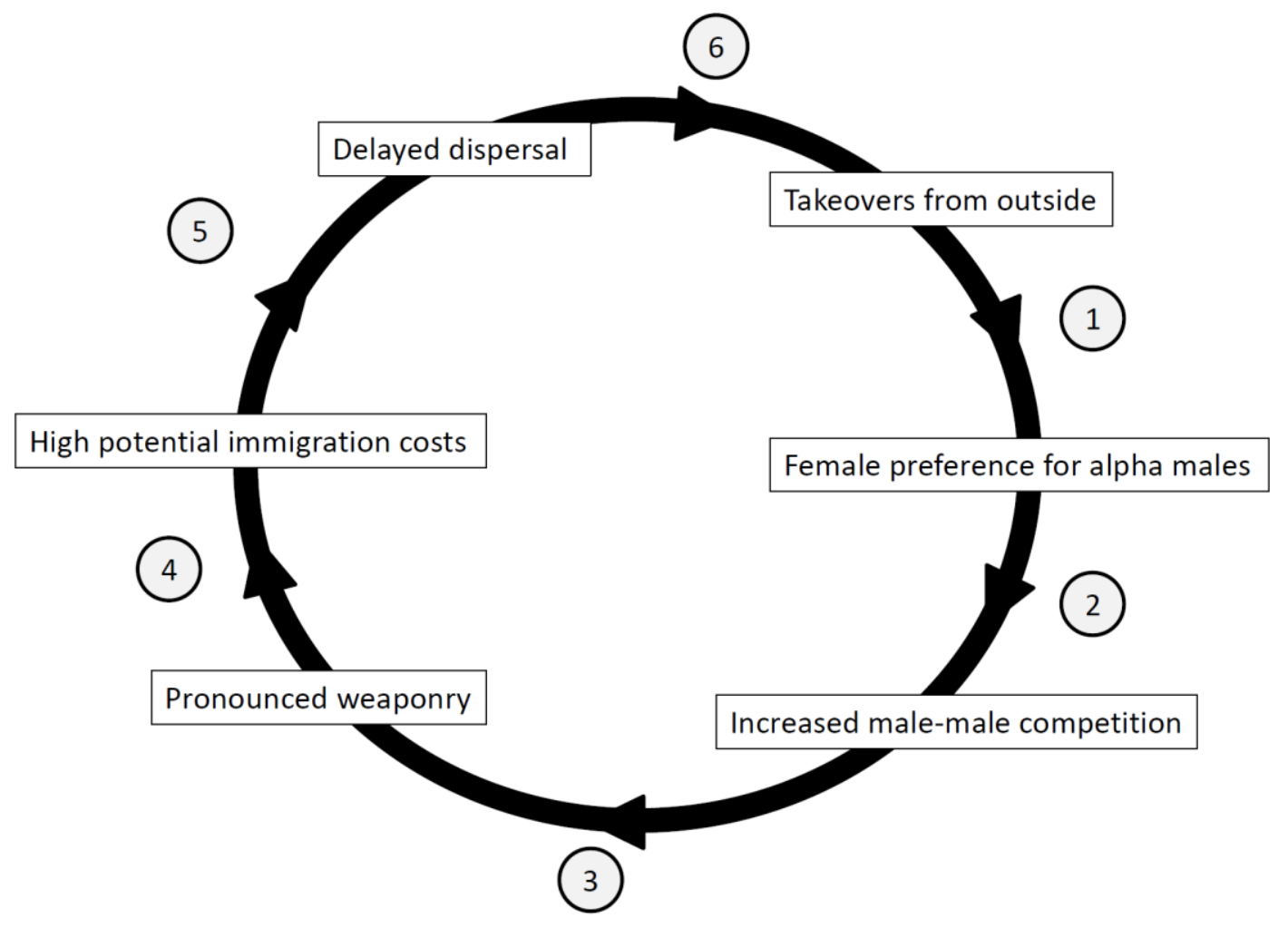

Figure 1: 1) Takeovers from outside lead to a preference of females for alpha males and reliable signals of fertility [Pradhan \& van Schaik, 2008; Clarke et al., 2009a; Higham et al., 2012]. 2) This leads to a higher reproductive skew, and therefore increased male-male competition. 3) Pronounced weaponry is a consequence of male-male competition [e.g. Plavcan \& van Schaik, 1992], and 4) high weaponry increases the risk for males to get injured during immigration. 5) This risk can be assumed to be too high when male-male competition reaches a certain level ending only in adult males migrating.

Interestingly, data on other primate species with a high sexual dimorphism (e.g. chacma baboons, yellow baboons, mandrills, gorillas, and pig-tailed macaques (Macaca nemestrina) [Plavcan \& van Schaik, 1992]) support my observation: all these species, with the exception of pig-tailed macaques, are characterised by outside takeovers [Clarke et al., 2009] and natal dispersal occurring when full body size is attained (e.g. chacma baboons, yellow baboons, gorillas) [Pusey \& Packer, 1987]. As a next step, systematic analyses of these species would be necessary to confirm the postulated positive feedback loop. Whether or not these males emigrate 
at their maximal physical fighting ability is unknown so far and would have to be measured by physical attributes such as body mass.

\subsubsection{Cost and benefit trade-off of dispersal for males of low fighting ability (followers)}

A second strategy, mainly used by males of low fighting ability, is to immigrate into groups with a recent changeover in the alpha position. In my study, this often led to clumped immigrations. As a result of a low rank attained in the new group, direct benefits can be assumed to be low for these males. Due to the group instabilities upon the arrival of a high ranking pioneer, followers are assumed to be able to drastically reduce the immigration cost implied by the resistance of resident males. Accordingly, followers were less likely to get injured following an immigration than pioneers did, leading to lower costs (chapter 2). Since all natal emigrators achieved a high rank directly upon immigration or within a very short time period, followers achieving only a low rank were most likely post-prime males during secondary migration. While natal emigrating males benefit from dispersing by getting access to unrelated female mating partners, little is known about secondary migrating primate males in general [Jack, 2003]. In crested macaques, where most dispersing males of low fighting ability were secondary migrating males, an increase in mating opportunities would be expected as for all dispersing males [Packer, 1979; Moore \& Ali, 1984]. Intra-sexual competition over mating partners has been proposed as a main reason for secondary dispersal [e.g. Pusey, 1987]. Although data is very limited due to difficulties following the fates of dispersing males, some evidence of males increasing their rank (and therefore presumably their access to females) by dispersing into another group could be shown [reviewed in Jack, 2003]. In crested macaques, however, secondary migrating males of low fighting ability achieved a low rank with very little direct reproductive benefits in the new group. Thus, it is unclear why these males migrate in the first place.

Similar to natal dispersal, secondary dispersal has been proposed to be partly based on inbreeding avoidance [e.g. Cheney \& Seyfarth, 1983; Pusey, 1987]. Thus, males are expected to leave their breeding group before their potential daughters reach sexual maturity to avoid inbreeding [Cheney \& Seyfarth, 1983]. Accordingly, in some species, males have been found to leave a group after a tenure which is close to the time of reproductive maturity of their potential daughters [e.g. yellow baboons: Alberts \& Altmann, 1995], with males of other species leaving well before that time [reviewed in Jack, 2003]. However, in some species, male tenure exceeds female age of first reproduction, in contrast to the inbreeding avoidance hypothesis [e.g. ring- 
tailed lemurs (Lemur catta): Sauther et al., 1996; long-tailed macaques: van Noordwijk \& van Schaik, 2001]. Species characterised by male philopatry and female dispersal further provide evidence against the inbreeding avoidance hypothesis, since females often do not exhibit secondary dispersal [e.g. chimpanzees: Boesch, 1997; muriqui monkeys (Brachyeteles arachnoides): Strier, 1997; red howler monkeys: Pope, 2000]. Additionally, at least in some primate species, individuals are able to recognise paternal kin, and therefore can potentially avoid inbreeding without leaving the group using mechanisms such as female choice [Alberts, 1999; Pfefferle et al., 2014].

Eviction from a previous group, as an alternative explanation for secondary dispersal is often seen in one-male groups [Pusey \& Packer, 1987], but is rare in multi-male groups [but see Henzi \& Lucas, 1980]. As migrations are voluntary, benefits are expected to exceed the cost of a transfer. Although direct reproductive benefits seem to be low, dispersal costs for males of low fighting ability appear to be reduced drastically by immigrating during instabilities of the male dominance hierarchy. Additionally, my results indicate a complete absence of physiological costs during migration. These factors may directly lead to males migrating despite the low reproductive benefits upon migration. Male crested macaques of low fighting ability may just make the best out of a bad job by migrating between groups to find opportunities to mate. As a consequence of the low migration costs incurred by males of low fighting ability through their use of condition-dependent strategies, male dispersal is very common in crested macaques.

The results of this thesis indicate that males of low fighting ability use conditiondependent strategies to reduce immigration costs. However, whether or not they gain reproductive benefits upon immigration is so far unclear. Males may benefit from factors which are independent of their rank achieved in the group. In some primate species, females show a great interest in extra-group or newly immigrated males [e.g. rhesus monkeys: Manson, 1995; Thomas's langurs (Presbytis thomasi): Steenbeek et al., 1999], which would make newly immigrated males more attractive to females. While still not being able to physically outcompete other males, males of low fighting ability may gain some reproductive success by alternative mating strategies such as "sneak copulations" (mating conspicuously out of sight of other group members) [e.g. Overduin-de Vries et al., 2013]. Several studies show that males in different primate species are able to temporarily [yellow baboons: Alberts et al., 2003] or regularly circumvent the dominance hierarchy by using alternative mating strategies [e.g. sneak copulations: Japanese macaques: Soltis et al., 2001; coalitions: Barbary macaques: Young et al., 2013]. In this way, low ranking males and potentially sub-adult males might have a higher chance to reproduce than expected according to the PoA model [Altmann, 1962b]. In crested macaques, 
where females are assumed to concentrate paternity into the alpha male as a consequence of outside takeovers [Pradhan \& van Schaik, 2008], they are not expected to reinforce alternative mating strategies by female choice. Notably, female choice for top ranking males may even suppress the occurrence of alternative mating strategies [Alonzo \& Warner, 2000]; whether or not this theoretical model is applicable to crested macaques remains to be investigated.

Alternatively, males of low fighting ability may gain some other, more indirect, benefits in the group. A recent study could show that primates are able to recognise unfamiliar paternal kin using facial cues [Pfefferle et al., 2014]. Assuming crested macaques are equally able to do so, males may preferentially immigrate into groups with close male kin present. By supporting a son or brother, a male could increase his indirect reproductive benefit well beyond the time he is physically capable to obtain a dominant position in a group. As this would be highly interesting and would potentially have major implications on our understanding of male-male relationships, further studies should incorporate genetic analyses to determine kinship between males.

\subsection{Implication for other mammal species}

As primates are probably the best studied taxa regarding dispersal, much of our current knowledge was gained investigating this order of mammals [e.g. Pusey \& Packer, 1987; van Noordwijk \& van Schaik, 2004]. Costs during migration, however, are well known in many other taxa [e.g. ungulates: Holzenbein \& Marchinton, 1992; rodents: van Vuren \& Armitage, 1994b; birds: Ridley et al., 2008; carnivores: Young \& Monfort, 2009]. In carnivores, for instance, an increased mortality during dispersal could be observed in mongooses (Helogale parvula), wolves (Canis lupus), badgers (Taxidea taxus) and lions (Panthera leo) [Waser, 1996]. The high mortality was directly attributed to escalated fights between resident males and males trying to immigrate into a social group [e.g. wolves: Fritts \& Mech, 1981; lions: Packer \& Pusey, 1982; dwarf mongoose: Creel et al., 1993]. A well-timed dispersal and take-over attempt (e.g. in lions), seems therefore essential for males to gain access to receptive females. Similar to male primates, males of other mammal species are likely to face a trade-off between cost and benefit of dispersal. In diverse species such as lions and impalas, males will have to assess the risk of challenging a male of a pride or a territorial male within a female herd, respectively, to get access to females [Sinclair, 1992]. Individuals of many species face similar decisions and are confronted with a trade-off between costs and benefits. Evolution would favour individuals timing their dispersal and challenge according to the best chance to be successful. Accordingly, my findings are directly applicable to many other socially living species. Nevertheless, dispersal behaviour remains 
mostly understudied, and factors promoting dispersal are often of a theoretical rather than an empirical nature.

As observed in primates, dispersing individuals in other species are expected to use strategies to reduce the costs of migration whenever possible. Nonetheless, evidence of such strategies is scarce. In lions, for example, coalitionary takeovers are common, directly enhancing the chances of winning a challenge and reducing immigration costs [Packer \& Pusey, 1982]. Similar to males in some primate species [vervet monkeys: Cheney \& Seyfarth, 1983; western Gorillas: Bradley et al., 2007], female horses have been observed to preferentially immigrate into groups with familiar mares which are less likely to aggress the newcomer [Monard \& Duncan, 1996]. Although we do find some evidence of individuals using specific strategies to reduce costs or increase benefits, whether or not inter-individual plasticity in migrating decisions as found for crested macaques also exist in other mammal species remains unknown.

A main result of this thesis is the observation of behavioural plasticity of males using condition-dependent dispersal strategies. The evolution of condition-dependent plasticity is likely when payoffs of specific behaviours hinge on internal states [Gross, 1996; Brockmann, 2001]. Condition dependant strategies are well known to be used by individuals in a variety of species to get access to mating partners [Gross, 1996; Shuster, 2010]. This thesis provides evidence that in socially living animals, condition dependant strategies can be used not only to get access to mating partners, but also to join a social group, a necessary precondition to get access to mating partners. Consequently, condition-dependent strategies to disperse and immigrate into a new social group are expected to have evolved in species where costs and benefits of a migration (and ultimately fitness consequences) are unequally distributed among dispersers. Since dispersal and intrasexual competition are assumed to be the major factors leading to a comparably higher mortality in males than in females [e.g. Greenwood, 1980; Dunbar, 1987; Alberts \& Altmann, 1995; Kraus et al., 2008], selection would favour males using condition-dependent strategies to reduce the probability of mortality or severe injury during dispersal. Due to the implications of condition-dependent dispersal strategies on an individual's fitness, further studies are needed to better understand the selection pressure on dispersing animals. 


\subsection{Conclusion and outlook}

By using demographic, behavioural, and physiological data from male crested macaques, this thesis provides further evidence of the costs that males of gregariously living mammals face during the transition between two groups and the following immigration. Furthermore, I could show that benefits between immigrating males are likely to be unequally shared, with males immigrating at the top of the hierarchy attaining the highest benefits. However, immigrating males of high fighting ability also bore higher costs than males of low fighting ability. As a consequence of a trade-off between costs and benefits, crested macaque males use condition dependant dispersal strategies to increase reproductive benefits and to decrease costs of dispersal. By systematically investigating a male's career from natal dispersal to the achievement of top dominance position and consecutive secondary migrations into other social groups, I described and investigated the trade-off between reproductive benefits and costs males face during these crucial stages in their life. Males of various physical conditions use differing strategies to reduce costs by timing alpha male challenges according to their fighting ability, by opportunistically taking over groups, or by using hierarchical instabilities to immigrate. The condition-dependent migrating strategies found in crested macaques were mostly expressed by males taking advantage of specific events allowing them to reduce costs of immigration (e.g. injured alpha male, previous immigration). This however requires males to regularly observe other groups to time their dispersal accordingly. Although males of many species have been found to do so [e.g. Cheney \& Seyfarth, 1990; van Noordwijk \& van Schaik, 2001; Teichroeb et al., 2011], this behaviour may itself entail costs and males of some species may not be able to do so due to a high predation risk [Altmann, 2000]. Additionally, I could exclude a potential cost rarely investigated: an elongated stress response. Although I could measure a stress response upon immigration, it was limited to a short time and therefore is most likely adaptive.

I showed that the trade-off between costs and benefits of dispersal promotes conditiondependent strategies and can have a high impact on a male's ability to get access to a social group and ultimately to fertile females. I highlighted that dispersal patterns of crested macaques, which are shaped by individual cost-benefit trade-offs, not only impact the potential fitness of an individual male, but also are strongly connected to other social attributes in this species. A positive feedback loop increases male-male competition, male weaponry, and increased dispersal costs, leading to delayed natal dispersal, outside group takeovers and finally a strong female preference for top dominant males. As this set of features is likely to be limited to highly 
dimorphic species [Cowlishaw \& Dunbar, 1991], additional studies are needed to investigate this further.

Crested macaques are likely to represent an extreme, in which intersexual competition is strongly shifted towards the male optimum [Pradhan \& van Schaik, 2008]. In other species, however, we see the opposite, with female infanticide avoidance strategies and male alternative reproductive strategies effectively lowering male-male competition [e.g. rhesus monkeys: Dubuc \& Muniz, 2011; barbary macaques: Young et al., 2013] resulting in a lower sexual dimorphism [Plavcan \& van Schaik, 1992; Thorén et al., 2006] and alpha male replacements from inside the group [Clarke et al., 2009]. Clearly, most primate species fall between these extremes and some species may not fit at all. This thesis, however, provides interesting insights from a species on one extreme end of male-male competition, providing evidence for the importance of male dispersal strategies on the social dynamics of a species. In addition, this thesis provides data to help bridge the gap between empirical data and theory of the causes and consequences of dispersal.

Since studies on dispersal are limited by the ability to follow the fate of dispersing individuals, data collection is difficult by nature. Although data from a long-term study was available, I was bound by the extent and quality of data collected on immigrating males. Newly immigrated males are often not habituated and therefore likely to avoid data collection tasks by observers, such as measuring body weight. Consequently, several different habituated study groups are needed to provide sufficient data. Due to these restrictions, research on dispersal patterns is still in its infancy. New remote sensing techniques may, however, provide a tool to follow dispersing individuals in the future. By following young natal males' dispersal patterns, distances and exploring strategies may be revealed. In order to increase our knowledge on dispersal strategies in general, long-term research projects need to start collecting detailed data on immigrating males to quantify the costs these males have to bear during immigration and by using paternity analyses to quantify the reproductive success males' gain upon immigration.

As alternative migrating strategies are expected to be widespread, alternative model species may provide more data in a shorter time frame. Many rodent species, for example, live in stable social groups, show male natal and secondary dispersal, and alternations of generations are fast [e.g. Sinclair, 1992; Stenseth \& Lidicker, 1992; Wolff \& Sherman, 1992]. Studying primates, on the other hand, not only allows us to investigate inter-individual dispersing strategies, but also their impact on the evolution of sexual selection traits, inter- and intra-sexual competition and ultimately the evolution of different social systems in primates and hominids. 


\section{References}

Alberts SC, Altmann J. 1995. Balancing Costs and Opportunities: Dispersal in Male Baboons. The American Naturalist 145:279.

Alberts SC, Buchan JC, Altmann J. 2006. Sexual selection in wild baboons: from mating opportunities to paternity success. Animal Behaviour 72:1177-1196.

Alberts SC, Sapolsky RM, Altmann J. 1992. Behavioral, endocrine, and immunological correlates of immigration by an aggressive male into a natural primate group. Hormones and Behavior 26:167-78.

Alberts SC, Watts HE, Altmann J. 2003. Queuing and queue-jumping: long-term patterns of reproductive skew in male savannah baboons, Papio cynocephalus. Animal Behaviour 65:821-840.

Alberts SC. 1999. Paternal kin discrimination in wild baboons. Proceedings of the Royal Society B: Biological Sciences 266:1501-1506.

Alberts SC. 2012. Magnitude and sources of variance in male reproductive performance. In: Mitani JC, Call J, Kappeler PM, Palombit RA, Silk JB, editors. The evolution of primate societies. Chicago: University of Chicago Press. p 412-431.

Alonzo SH, Warner RR. 2000. Female choice, conflict between the sexes and the evolution of male alternative reproductive behaviours. Evolutionary Ecology Research 2:149-170.

Altmann J. 1974. Observational Study of Behavior: Sampling Methods. Behaviour 49:227-267.

Altmann J. 2000. Models of outcome and process: predicitng the number of males in primate groups. In: Kappele PM, editor. Primate Males: Causes and Consequences of Variation in Group Composition. Cambridge: Cambridge University Press. p 236-247.

Altmann SA. 1962. A field study of the sociobiology of rhesus monkeys, Macaca mulatta. Annals of the New York Academy of Sciences 102:338-435.

Anthony T, Gill DE, Small DM, Parks J, Sears HF. 2013. Post-Fledging Dispersal of Grasshopper Sparrows (Ammodramus savannarum) On A Restored Grassland In Maryland. The Wilson Journal of Ornithology 125:307-313.

Arlet M, Grote M, Molleman F. 2009. Reproductive tactics influence cortisol levels in individual male gray-cheeked mangabeys (Lophocebus albigena). Hormones and Behavior.

Balm PH. 1999. Stress Physiology in Animals. Sheffield: Sheffield Academic Press.

Bateman A. 1948. Intra sexual selection in Drosophila. Heredity 2:349-368. 
Beehner JC, Bergman TJ, Cheney DL, Seyfarth RM, Whitten PL. 2005. The effect of new alpha males on female stress in free-ranging baboons. Animal Behaviour 69:1211-1221.

Berard J. 1999. A four-year study of the association between male dominance rank, residency status, and reproductive activity in rhesus macaques (Macaca mulatta). Primates 40:159-175.

Berger J. 1986. Wild horses of the great basin. Chicago: University of Chicago Press.

Bergman T, Beehner J, Cheney D, Seyfarth R, Whitten P. 2005. Correlates of stress in freeranging male chacma baboons, Papio hamadryas ursinus. Animal Behaviour 70:703-713.

Boesch C, Kohou G, Néné H, Vigilant L. 2006. Male competition and paternity in wild chimpanzees of the Taï forest. American Journal of Physical Anthropology 130:103-115.

Boesch C. 1997. Evidence for dominant wild female chimpanzees investing more in sons. Animal Behaviour 54:811-5.

Bonte D, Van Dyck H, Bullock JM, et al. 2012. Costs of dispersal. Biological reviews of the Cambridge Philosophical Society 87:290-312.

Borries C. 2000. Male dispersal and mating season influxes in Hanuman langurs living in multi-male groups. In: Kappeler PM, editor. Primate Males: Causes and Consequences of Variation in Group Composition. Cambridge: Cambridge university press. p 146-158.

Bowerman B., O'Connell R. 1990. Linear statistical models: An applied approach. Second edi. Duxbury, Belmont, CA: Duxbury.

Boyd R, Silk JB. 2009. How Humans Evolved. 5th Editio. New York: W.W. Norton \& Company.

Bradley BJ, Doran-Sheehy DM, Vigilant L. 2007. Potential for female kin associations in wild western gorillas despite female dispersal. Proceedings of the Royal Society London B: Biological Sciences 274:2179-85.

Bradley BJ, Robbins MM, Williamson EA, et al. 2005. Mountain gorilla tug-of-war: silverbacks have limited control over reproduction in multimale groups. Proceedings of the National Academy of Sciences of the United States of America 102:9418-23.

Brock M, White B. 1992. Application of DNA fingerprinting to the recovery program of the endangered Puerto Rican parrot. Proceedings of the National Academy of Sciences of the United States of America 89:11121-11125.

Brockmann HJ. 2001. The evolution of alternative strategies and tactics. Advances in the Study of Behavior 30:1-51.

Chambers JM. 1992. Linear models. In: Chambers JM, Hastie TJ, editors. Statistical Models in S. Wadsworth \& Brooks. 
Chancellor RL, Satkoski J, George D, et al. 2011. Do Dispersing Monkeys Follow Kin? Evidence from Gray-cheeked Mangabeys (Lophocebus albigena). International Journal of Primatology 32:474-490.

Cheney DL, Seyfarth RM. 1982. Recognition of Individuals Within and Between Groups of Free-Ranging Vervet Monkeys 1. Integrative and Comparative Biology 22:519-529.

Cheney DL, Seyfarth RM. 1983. Nonrandom Dispersal in Free-Ranging Vervet Monkeys: Social and Genetic Consequences. The American Naturalist 122:392.

Cheney DL, Seyfarth RM. 1990. How Monkeys See the World. Chicago: Chicago University Press.

Cheptou P-O, Donohue K. 2011. Environment-dependent inbreeding depression: its ecological and evolutionary significance. The New Phytologist 189:395-407.

Clarke a. S, Czekala NM, Lindburg DG. 1995. Behavioral and adrenocortical responses of male cynomolgus and lion-tailed macaques to social stimulation and group formation. Primates 36:41-56.

Clarke P, Pradhan GR, van Schaik CP. 2009. Intrasexual conflicts in primates: infanticiede, paternity allocation, and the role of coersion. In: Muller MN, Wrangram RW, editors. Sexual Coercion in Primates and Humans. Cambridge, Messacchusetts: Harvard University Press. p 42-80.

Clarke PMR, Henzi SP, Barrett L, Rendall D. 2008. On the road again: competitive effects and condition-dependent dispersal in male baboons. Animal Behaviour 76:55-63.

Clutton-Brock T, Lukas D. 2012. The evolution of social philopatry and dispersal in female mammals. Molecular ecology:472-492.

Clutton-Brock TH. 1988. Reproductive success: Studies of individual variation in contrasting breeding systems. Chicago: Chicago University Press.

Clutton-Brock TH. 2004. What is sexual selection? In: Kappeler PM, van Schaik CP, editors. Sexual Selection in Primates. Cambridge: Cambridge University Press. p 24-36.

Collet JM, Dean RF, Worley K, Richardson DS, Pizzari T. 2014. The measure and significance of Bateman's principles. Proceedings of the Royal Society London B: Biological Sciences 281:20132973.

Cowlishaw G, Dunbar R. 1991. Dominance rank and mating success in male primates. Animal Behaviour 41:1045-1056.

Creel S, Wildt DE, Monfort SL. 1993. Aggression, reproduction, and androgens in wild dwarf mongooses: a test of the challenge hypothesis. The American Naturalist 141:816-825.

Cressman R, Křivan V. 2006. Migration dynamics for the ideal free distribution. The American Naturalist 168:384-397. 
Crnokrak P, Roff DA. 1999. Inbreeding depression in the wild. Heredity 83:260-270.

Darwin C. 1859. On the Origin of Species by Means of Natural Selection, or the Preservation of Favoured Races in the Struggle for Life. New York : D. Appleton and Co.

Darwin C. 1871. The descent of man, and selection in relation to sex. London: John Murray.

De Vries H, Stevens JMG, Vervaecke H. 2006. Measuring and testing the steepness of dominance hierarchies. Animal Behaviour 71:585-592.

Dobson FS. 1982. Competition for mates and predominant juvenile male dispersal in mammals. Animal Behaviour:1183-1192.

Duboscq J, Micheletta J, Agil M, et al. 2013. Social Tolerance in Wild Female Crested Macaques (Macaca nigra) in Tangkoko-Batuangus Nature Reserve, Sulawesi, Indonesia. American Journal of Primatology 15:361-375.

Dubuc C, Muniz L. 2011. Testing the priority-of-access model in a seasonally breeding primate species. Behavioral Ecology and Sociobiology:1615-1627.

Dunbar R. 1987. Demography and Reproduction. In: Smuts BB, Cheney DL, Seyfarth R, Wrangham R, Struhsaker TT, editors. Primate Sociesties. Chicago: Chicago University Press. p 240-249.

Eberhart JA, Yodyingyuad U, Keverne EB. 1985. Subordination in male talapoin monkeys lowers sexual behaviour in the absence of dominants. Physiology \& Behavior 35:673677.

Emery Thompson M, Wrangham RW. 2008. Male Mating Interest Varies with Female Fecundity in Pan troglodytes schweinfurthii of Kanyawara, Kibale National Park. International Journal of Primatology 29:885-905.

Eraud C, Jacquet A, Legagneux P. 2011. Post-Fledging Movements, Home Range, and Survival of Juvenile Eurasian Collared-Doves in Western France. The Condor 113:150-158.

Fedigan L. 1993. Sex differences and intersexual relations in adult white-faced capuchins (Cebus capucinus). International Journal of Primatology 14:853-877.

Field A. 2005. Discovering statistics using SPSS. London: Sage Publications.

Fox J, Weisberg HS. 2010. An R companion to applied regression. Second edi. Thousend Oaks, CA: Saga Publications.

Fritts SH, Mech LD. 1981. Dynamics, Movements, and Feeding Ecology of a Newly Protected Wolf Population in Northwestern Minnesota. Wildlife Monographs 80:3-79.

Gandon S, Michalakis Y. 1999. Evolutionarily stable dispersal rate in a metapopulation with extinctions and kin competition. Journal of Theoretical Biology:275-290. 
Gandon S. 1999. Kin competition, the cost of inbreeding and the evolution of dispersal. Journal of Theoretical Biology:345-364.

Garrett MG, Franklin WL. 1988. Behavioral Ecology of Dispersal in the Black-Tailed Prairie Dog. Journal of Mammalogy 69:236.

Gillis E, Krebs C. 2000. Survival of dispersing versus philopatric juvenile snowshoe hares: do dispersers die? Oikos 2:343-346.

Glander KE. 1992. Dispersal patterns in Costa Rican mantled howling monkeys. International Journal of Primatology 13:415-436.

Gogarten JF, Koenig A. 2012. Reproductive seasonality is a poor predictor of receptive synchrony and male reproductive skew among nonhuman primates. Behavioral Ecology and Sociobiology 67:123-134.

Greenwood P. 1980. Mating systems, philopatry and dispersal in birds and mammals. Animal Behaviour 28:1140-1162.

Grissom N, Bhatnagar S. 2009. Habituation to repeated stress: Get used to it. Neurobiology of Learning and Memory 92:215-224.

Gross MR. 1996. Alternative reproductive strategies and tactics: diversity within sexes. Trends in Ecology \& Evolution 11:92-98.

Hager R, Jones CB. 2009. Reproductive skew in vertebrates: proximate and ultimate causes. Cambridge: Cambridge University Press.

Hamilton W, Bulger J. 1990. Natal male baboon rank rises and successful challenges to resident alpha males. Behavioral Ecology and Sociobiology 26:357-362.

Heistermann M, Ziegler T, van Schaik CP, et al. 2001. Loss of oestrus, concealed ovulation and paternity confusion in free-ranging Hanuman langurs. Proceedings of the Royal Society London B: Biological Sciences 268:2445-51.

Henzi SP, Lucas JW. 1980. Observations on the Inter-troop movement of adult vervet monkeys (Cercopithecus aethiops). Folia Primatologica 33:220-35.

Higham JP, Heistermann M, Saggau C, et al. 2012. Sexual signalling in female crested macaques and the evolution of primate fertility signals. BMC Evolutionary Biology 12:89.

Holzenbein S, Marchinton RL. 1992. Emigration and Mortality in Orphaned Male White-Tailed Deer. The Journal of Wildlife Management 56:147.

Hrdy SB. 1979. Infanticide among animals: A review, classification, and examination of the implications for the reproductive strategies of females. Ethology and Sociobiology 1:1340. 
Huffman MA. 1991. History of the Arashiyama Japanese macaques in Kyoto, Japan. In: Fedigan LM, Asquith PJ, editors. The Monkeys of Arashiyama. Albany, New York: State University of New York press. p 21-53.

Inman AJ, Krebs J. 1987. Predation and group living. Trends in Ecology \& Evolution 2:31-32.

Isbell LA, Cheney DL, Seyfarth RM. 1993. Are immigrant vervet monkeys, Cercopithecus aethiops, at greater risk of mortality than residents? Animal Behaviour 45:729-734.

Isbell LA, Van Vuren D. 1996. Differential Costs of Locational and Social Dispersal and Their Consequences for Female Group-Living Primates. Behaviour 133:1-36.

Isbell LA. 1990. Sudden short-term increase in mortality of vervet monkeys (Cercopithecus aethiops) due to leopard predation in Amboseli National Park, Kenya. American Journal of Primatology 21:41-52.

Jack K. 2003. Secondary Dispersal by Male Primates. Primate report 67:61-83.

Jack KM, Fedigan LM. 2004. Male dispersal patterns in white-faced capuchins, Cebus capucinus. Animal Behaviour 67:771-782.

Jack KM, Sheller C, Fedigan LM. 2011. Social factors influencing natal dispersal in male whitefaced capuchins (Cebus capucinus). American Journal of Primatology 7:1-7.

Janson CH, Verdolin JL. 2005. Seasonality of primate births in relation to climate. In: Brockman DK, van Schaik CP, editors. Seasonality in primates. New York: Cambridge University Press. p 307-350.

Johnson M. 1990. Evolution of Dispersal: Theoretical Models and Empirical Tests using Birds and Mammals. Annual Review of Ecology and Systematics 21:449-480.

Keller L, Reeve HK. 1994. Partitioning of reproduction in animal societies. Trends in Ecology \& Evolution 9:98-102.

Kerhoas D, Perwitasari-Farajallah D, Agil M, Widdig a., Engelhardt a. 2014. Social and ecological factors influencing offspring survival in wild macaques. Behavioral Ecology 25:1164-1172.

Kokko H, Ekman J. 2002. Delayed dispersal as a route to breeding: territorial inheritance, safe havens, and ecological constraints. The American Naturalist 160:468-484.

Kraus C, Eberle M, Kappeler PM. 2008. The costs of risky male behaviour: sex differences in seasonal survival in a small sexually monomorphic primate. Proceedings of the Royal Society London B: Biological Sciences 275:1635-44.

Krebs C j., Lambin X, Wolff JO. 2007. Social Behavior and Self-Regulation in Murid Rodents. In: Wolff JO, Sherman PW, editors. Rodent Societies: An Ecological and Evolutionary Perspective. London: Chicago University Press. p 173-181. 
Kutsukake N, Nunn CL. 2006. Comparative tests of reproductive skew in male primates: the roles of demographic factors and incomplete control. Behavioral Ecology and Sociobiology 60:695-706.

Leiva D, de Vries H. 2011. Testing Steepness of Dominance Hierarchies. :(R Package).

Le Boeuf BJ, Reiter J. 1988. Lifetime Reproductive Success in Northern Elephant Seals. In: Clutton-Brock TH, editor. Reproductive success: studies of individual variation in contrasting breeding systems. Chicago: Chicago University Press. p 344-384.

Leturque H, Rousset F. 2002. Dispersal, Kin Competition, and the Ideal Free Distribution in a Spatially Heterogeneous Population. Theoretical Population Biology 62:169-180.

Liu XH, Yue LF, Wang DW, Li N, Cong L. 2013. Inbreeding avoidance drives consistent variation of fine-scale genetic structure caused by dispersal in the seasonal mating system of Brandt's voles. PloS one 8:e58101.

Lukas D, Clutton-Brock T. 2014. Costs of mating competition limit male lifetime breeding success in polygynous mammals. Proceedings of the Royal Society London B: Biological Sciences 281.

Lynch M, Conery J, Burger R. 1995. Mutation accumulation and the extinction of small populations. American Naturalist 146:489-518.

Magnhagen C. 1991. Predation risk as a cost of reproduction. Trends in Ecology \& Evolution 6:183-6.

Manson JH. 1995. Do female rhesus macaques choose novel males? American Journal of Primatology 37:285-296.

Meikle DB, Vessey SH. 1981. Nepotism among rhesus monkey brothers. Nature 294:160-161.

Melnick DJ, Pearl MC, Richard AF. 1984. Male migration and inbreeding avoidance in wild rhesus monkeys. American Journal of Primatology 7:229-243.

Monard A, Duncan P. 1996. Consequences of natal dispersal in female horses. Animal Behaviour 52:565-579.

Moore J, Ali R. 1984. Are dispersal and inbreeding avoidance related? Animal Behaviour 32:94-112.

Muroyama Y, Imae H, Okuda K. 2000. Radio tracking of a male Japanese macaque emigrated from its group. Primates 41:351-356.

Myers RH. 1990. Classical and modern regression with applications. Boston: Duxbury.

Nakamichi M, Kojima Y, Itoigawa N, Imakawa S, Machida S. 1995. Interactions among adult males and females before and after the death of the alpha male in a free-ranging troop of Japanese macaques. Primates 36:385-396. 
Narayan EJ, Cockrem JF, Hero J-M. 2013. Sight of a predator induces a corticosterone stress response and generates fear in an amphibian. PloS one 8:e73564.

Nelson R. 2005. An introduction to behavioiural endocrinology. Sunderland, MA: Sinauer Associates, Inc.

Neumann C, Assahad G, Hammerschmidt K, Perwitasari-Farajallah D, Engelhardt A. 2010. Loud calls in male crested macaques, Macaca nigra: a signal of dominance in a tolerant species. Animal Behaviour 79:187-193.

Neumann C, Duboscq J, Dubuc C, et al. 2011. Assessing dominance hierarchies: validation and advantages of progressive evaluation with Elo-rating. Animal Behaviour 82:911-921.

Neumann C. 2013. Achievement and maintenance of dominance in male crested macaques (Macaca nigra).

Nunes S. 2007. Dispersal and phylopatry. In: Wolff JO, Sherman PW, editors. Rodent Societies: An Ecological and Evolutionary Perspective. Chicago: Chicago University Press. p 150162.

Nunn C. 2000. Collective benefits, free-riders, and male extra-group conflicts. In: Kappeler PM, editor. Primate Males: Causes and Consequences of Variation in Group Composition. Cambridge: Cambridge university press. p 192-204.

O'Brien TGT, Kinnaird MMF. 1997. Behavior, diet, and movements of the Sulawesi crested black macaque (Macaca nigra). International Journal of Primatology 18:321-351.

Ostner J, Nunn CL, Schülke 0. 2008. Female reproductive synchrony predicts skewed paternity across primates. Behavioral ecology 19:1150-1158.

Overduin-de Vries a. M, Olesen CU, de Vries H, Spruijt BM, Sterck EHM. 2013. Sneak copulations in long-tailed macaques (Macaca fascicularis): No evidence for tactical deception. Behavioral Ecology and Sociobiology 67:101-111.

Packer C, Pusey AE. 1982. Cooperation and competition within coalitions of male lions: kin selection or game theory? Nature 296:740-742.

Packer C, Pusey AE. 1983. Male takeovers and female reproductive parameters: A simulation of oestrous synchrony in lions (Panthera leo). Animal Behaviour 31:334-340.

Packer C. 1979. Inter-troop transfer and inbreeding avoidance in Papio anubis. Animal Behaviour 27:1-36.

Palmqvist E, Lundberg P, Jonzén N. 2000. Linking resource matching and dispersal. Evolutionary Ecology:1-12.

Palombit R. 2003. Male infanticide in wild savanna baboons: adaptive significance and intraspecific variation. In: Jones C, editor. Sexual Selection and Reproductive Competition in in Primates: New Perspectives and Directions. New York: American Society of Primatologists. p 364-411. 
Pärt T. 1995. The importance of local familiarity and search costs for age- and sex-biased philopatry in the collared flycatcher. Animal Behaviour 49:1029-1038.

Perry S. 1998. A case report of a male rank reversal in a group of wild white-faced capuchins (Cebus capucinus). Primates 39:51-70.

Petersburg ML, Alldredge AW, de Vergie WJ. 2000. Emigration and survival of 2-year-old male elk in northwestern Colorado. Wildlife Society Bulleti 28:708-716.

Pfefferle D, Kazem AJN, Brockhausen RR, Ruiz-Lambides A V, Widdig A. 2014. Monkeys spontaneously discriminate their unfamiliar paternal kin under natural conditions using facial cues. Current Biology 24:1806-10.

Plavcan J, van Schaik CP. 1992. Intrasexual Competition and Canine Dimorphism in Anthropoid Primates. American Journal of Physical Anthropology:461-471.

Pope TR. 1989. The influence of mating system and dispersal patterns on the genetic structure of red howler monkey populations.

Pope TR. 1990. The reproductive consequences of male cooperation in the red howler monkey: paternity exclusion in multi-male and single-male troops using genetic markers. Behavioral Ecology and Sociobiology 27:439-446.

Pope TR. 2000. The evolution of male philopatry in neotropical monkeys. In: Kappeler PM, editor. Primate Males: Causes and Consequences of Variation in Group Composition. Cambridge university press. p 219-235.

Port M, Cant MA. 2013. Reproductive Competition Among Males in Multimale Groups of Primates: Modeling the Costs and Effectiveness of Conflict. International Journal of Primatology 35:746-763.

Pradhan G, van Schaik CP. 2008. Infanticide-driven intersexual conflict over matings in primates and its effects on social organization. Behaviour:251-275.

Pray LA, Schwartz JM, Goodnight CJ, Stevens L. 1994. Environmental Dependency of Inbreeding Depression: Implications for Conservation Biology. Conservation Biology 8:562-568.

Pusey A, Packer C. 1987. Dispersal and Philopatry. In: Smuts BB, Cheney DL, Seyfarth RM, Wrangram RW, Struhsaker TT, editors. Primate Sociesties. Chicago University Press. p 250-266.

Pusey AE. 1987. Sex-biased dispersal and inbreeding avoidance in birds and mammals. Trends in Ecology \& Evolution 2:295-9.

Quinn GP, Keough MJ. 2002. Experimental Designs and Data Analysis for Biologists. Cambridge: Cambridge university press. 
Reed C, O’Brien TG, Kinnaird MF. 1997. Male social behavior and dominance hierarchy in the Sulawesi crested black macaque (Macaca nigra). International Journal of Primatology 18:247-260.

Ridley AR, Raihani NJ, Nelson-Flower MJ. 2008. The cost of being alone: the fate of floaters in a population of cooperatively breeding pied babblers Turdoides bicolor. Journal of Avian Biology 39:389-392.

Riley EP. 2010. The endemic seven: Four decades of research on the Sulawesi macaques. Evolutionary Anthropology: Issues, News, and Reviews 19:22-36.

Robinson JG. 1988. Group size in wedge-capped capuchin monkeys Cebus olivaceus and the reproductive success of males and females. Behavioral Ecology and Sociobiology 23:187197.

Rödel HG, Bora a., Kaetzke P, et al. 2004. Over-winter survival in subadult European rabbits: Weather effects, density dependence, and the impact of individual characteristics. Oecologia 140:566-576.

Saltzman W, Schultz-darken NJ, Abbott DH. 1997. Familial Influences on Ovulatory Function in Common Marmosets (Callithrix jacchus). American Journal of Primatology 177:159-177.

Sapolsky RM. 1992. Stress, the Aging Brain, and the Mechanisms of Neuron Death. Cambridge: MIT Press.

Sapolsky RM. 2002. Endocrinology of the stress-respone. In: Becker J, Breedlove S, Crews D, McCarthy M, editors. Behavior Endocrinology. Cambridge: The MIT Press. p 409-450.

Sauther ML, Sussman RW, Gould L. 1996. The Socioecology of the Ringtailed Lemur: ThirtyFive Years of Research. Evolutionary Anthropology 8:120-132.

Schielzeth H. 2010. Simple means to improve the interpretability of regression coefficients. Methods in Ecology and Evolution 1:103-113.

Schoof V, Isbell L, Jack K. 2009. What traits promote male parallel dispersal in primates? Behaviour 146:701-726.

Schülke O, Bhagavatula J, Vigilant L, Ostner J. 2010. Social bonds enhance reproductive success in male macaques. Current bBology 20:2207-10.

Schülke 0, Ostner J. 2008. Male reproductive skew, paternal relatedness, and female social relationships. American Journal of Primatology 70:695-8.

Setchell JM, Charpentier M, Wickings EJ. 2005. Mate guarding and paternity in mandrills: factors influencing alpha male monopoly. Animal Behaviour 70:1105-1120.

Setchell JM, Smith T, Wickings EJ, Knapp LA. 2010. Stress, social behaviour, and secondary sexual traits in a male primate. Hormones and Behavior 58:720-8. 
Setchell JM. 2002. Female mate choice in mandrills (Mandrillus sphinx). Caring for Primates. Abstracts of the Xixth Congress. the International Primatological Society:202.

Sheriff MJ, Krebs CJ, Boonstra R. 2009. The sensitive hare: sublethal effects of predator stress on reproduction in snowshoe hares. The Journal of Animal Ecology 78:1249-58.

Shuster AM. 2010. Alternative Mating Strategies. In: Westneat DF, Fox CW, editors. Evolutionary Behavioral Ecology. New York: Oxford university press. p 434-450.

Sinclair ARE. 1992. Do large mammals disperse like smal mammals? In: Stenseth NC, Lidicker WZ, editors. Animal dispersal: Small mammals as a model. Cornwall: Chapman \& Hall. p 229-241.

Slos S, Stoks R. 2008. Predation risk induces stress proteins and reduces antioxidant defense. Functional Ecology 22:637-642.

Smale L, Nunes S, Holekamp K. 1997. Sexually dimorphic dispersal in mammals: patterns, causes, and consequences. Advances in the Study of Behavior 26:181-250.

Soltis J, Thomsen R, Matsubayashi K, Takenaka 0. 2000. Infanticide by resident males and female counter-strategies in wild Japanese macaques (Macaca fuscata). Behavioral Ecology and Sociobiology 48:195-202.

Soltis J, Thomsen R, Takenaka 0. 2001. The interaction of male and female reproductive strategies and paternity in wild Japanese macaques, Macaca fuscata. Animal Behaviour 62:485-494.

Sparkman AM, Adams JR, Steury TD, Waits LP, Murray DL. 2011. Direct fitness benefits of delayed dispersal in the cooperatively breeding red wolf (Canis rufus). Behavioral Ecology 22:199-205.

Sprague DS. 1992. Life history and male intertroop mobility among Japanese macaques (Macaca fuscata). International Journal of Primatology 13:437-454.

Steenbeek R, Wich S, Assink P. 1999. Tenure related changes in wild thomas's langures: looud calls. Behaviour 136:627-650.

Stenseth NC, Lidicker WZ. 1992. Animal dispersal: Small mammals as a model. Cornwall: Chapman \& Hall.

Strier KB. 1997. Mate Preferences of Wild Muriqui Monkeys (Brachyteles arachnoides):Reproductive and Social Correlates. Folia Primatologica 68:120-133.

Suzuki S, Hill DA, Sprague D. 1998. Intertroop transfer and dominance rank structure of nonnatal male Japanese macaques in Yakushima, Japan. International Journal of Primatology 19:703-744.

Taylor W. 2000. Change-point analysis: A powerful new tool for detecting changes.

Team RDC. 2009. R: A language and environment for statistical computing. 
Teichroeb J a., Wikberg EC, Sicotte P. 2011. Dispersal in male ursine colobus monkeys (Colobus vellerosus): influence of age, rank and contact with other groups on dispersal decisions. Behaviour 148:765-793.

Thierry B. 2007. Unity in diversity: Lessons from macaque societies. Evolutionary Anthropology: Issues, News, and Reviews 16:224-238.

Thorén S, Lindenfors P, Kappeler PM. 2006. Phylogenetic analyses of dimorphism in primates: evidence for stronger selection on canine size than on body size. American Journal of Physical Anthropology 130:50-9.

Trivers RL. 1972. Parental investment and sexual selection. Sexual selection and the descent of man 1871-1971 12:136-179.

van Belle S, Estrada A, Ziegler TE, Strier KB. 2009. Social and hormonal mechanisms underlying male reproductive strategies in black howler monkeys (Alouatta pigra). Hormones and Behavior 56:355-63.

van Noordwijk MA, van Schaik CP. 1985. Male migration and rank acquisition in wild longtailed macaques (Macaca fascicularis). Animal Behaviour 33:849-861.

van Noordwijk MA, van Schaik CP. 2001. Career moves: transfer and rank challenge decisions by male long-tailed macaques. Behaviour 138:359-395.

van Noordwijk MA, van Schaik CP. 2004. Sexual selection and the careers of primate males: paternity concentrations, dominance-acquisition tactics and transfer decitions. In: Kappeler PM, van Schaik CP, editors. Sexual Selection in Primates. Cambridge university press. p 208-229.

van Schaik CP, van Noordwijk M, Nunn C. 1999. Sex and social evolution in primates. In: Lee P, editor. Comparative primate socioecology. Cambridge: Cambridge university press. $\mathrm{p}$ 204-231.

van Schaik CP, Van Noordwijk MA, Vanbragt T, Blankenstein MA. 1991. A Pilot-Study of the Social Correlates of Levels of Urinary Cortisol, Prolactin, and Testosterone in Wild LongTailed Macaques (Macaca fascicularis). Primates 32:345-356.

van Schaik CP. 1983. Why are diurnal primates living in groups? Behaviour 137:120-144.

van Schaik CP. 1989. The ecology of social relationships amongst female primates. In: Standen V, RA F, editors. The ecology of social relationships amongst female primates. Boston: Blackwell Sceintific Publications. p 195-218.

van Vuren D, Armitage KB. 1994. Survival of Dispersing and Philopatric Yellow-Bellied Marmots: What Is the Cost of Dispersal? Oikos 69:179-181.

Waser PM. 1996. Patterns and consequences of dispersal in gregarious carnivores. In: Gittleman JL, editor. Carnivore behaviour, ecology, and evolution. New York: Cornell University Press. p 267-295. 
Watanabe K. 2001. A review of 50 years of research on the Japenese monkeys of Koshima: status and dominance. In: Matsuzawa T, editor. Primate Orgins of Human Cognition and Behaviour. Tokyo: Springer. p 405-417.

Weingrill T, Lycett J, Barrett L, Hill R, Henzi SP. 2003. Male consortship behaviour in chacma baboons: the role of demographic factors and female conceptive probabilities. Behaviour 140:405-427.

Weingrill T, Lycett JE, Henzi SP. 2000. Consortship and Mating Success in Chacma Baboons (Papio cynocephalus ursinus). Ethology 106:1033-1044.

Whitten A, Mustafa M, Hendersen G. 1987. The Ecology of Sulawesi. Yogyakarta: Gadjah Mada University Press.

Widdig A, Bercovitch FB, Streich WJ, et al. 2004. A longitudinal analysis of reproductive skew in male rhesus macaques. Proceedings of the Royal Society London B: Biological Sciences 271:819-26.

Wiens JD, Noon BR, Reynolds RT. 2006. Post-Fledging Survival Of Northern Goshawks: The Importance Of Prey Abundance, Weather, And Dispersal. Ecological Applications 16:406418.

Wolff JO, Sherman PW. 2007. Rodent societies. Chicago: University of Chicago Press.

Yao H, Liu X, Stanford C, et al. 2011. Male dispersal in a provisioned multilevel group of Rhinopithecus roxellana in Shennongjia Nature Reserve, China. American journal of primatology 73:1280-8.

Ydenberg R, Giraldeau L, Falls J. 1988. Neighbours, strangers, and the asymmetric war of attrition. Animal Behaviour 36:343-347.

Yoder JM. 2004. The cost of dispersal: predation as a function of movement and site familiarity in ruffed grouse. Behavioral Ecology 15:469-476.

Young AJ, Monfort SL. 2009. Stress and the costs of extra-territorial movement in a social carnivore. Biology Letters 5:439-441.

Young C, Hähndel S, Majolo B, Schülke O, Ostner J. 2013. Male coalitions and female behaviour affect male mating success independent of dominance rank and female receptive synchrony in wild Barbary macaques. Behavioral Ecology and Sociobiology 67:16651677.

Zhao Q, Borries C, Pan W. 2011. Male takeover, infanticide, and female countertactics in whiteheaded leaf monkeys (Trachypithecus leucocephalus). Behavioral Ecology and Sociobiology.

Zhao Q-K. 1994. Mating competition and intergroup transfer of males in Tibetan macaques (Macaca thibetana) at Mt. Emei, China. Primates 35:57-68. 
Zhao Q-K. 1996. Etho-ecology of Tibetan macaques at Mount Emei, China. In: Fa JE, Lindburg DG, editors. Evolution and Ecology of Macaques Societies. Cambridge: Cambridge University Press. p 263-89. 


\section{Acknowledgements}

Many people provided me with help, support and advice during my PhD. Foremost, I would like to thank Antje Engelhardt and Keith Hodges for their support and advice while writing proposals, publications and finally this thesis. Thank you very much for your thoughtful supervision, logistic, moral and intellectual support in the last years!

I am grateful to Julia Fischer for accepting to be my official supervisor, and Julia Ostner, Michael Mühlenberg and Bernhard Fink to be in my evaluation committee.

Within the former Reproductive Biology unit, I would like to thank Ellen Wiese for her support in handling the sometimes overwhelming bureaucracy. Thanks to Andrea Heistermann and Kerstin Fuhrmann for their support in the hormone lab and a special thanks to Michael Heistermann for his support and inspiring discussions.

I am grateful to the Indonesian State Ministry for Research and Technology (RISTEK), the Director General Department Kehutanan (PHKA), the Department Dalam Negri, the local Government in North Sulawesi and BKSDA Manado for giving me the permission to conduct research in Indonesia. I thank Muhammad Agil, Edith Sabara, Maria Panggur and Aminah for their administrative support in Bogor and Jakarta.

For their help in the field, collecting data for this thesis, I am immensely grateful to my assistance Ismael Agung, Arief Imansyah, Caitlin Hannah and Maura Tyrrell. I had a wonderful time in Indonesia thanks to my team! Terima kasih! I also would like to thank Ugi and Stephan for their help in the camp. A special thanks also to our field assistance Iwan and Meldy who always supported me and my project!

I would like to thank my friends and colleagues in Göttingen, Chris, Cedric, Rebecca, Christof, Julie, Philip, Marlies, Sally, Gisela, Christine, Steffi, Tabby, Josi, Anni, Matthis, Fede, Eva, Adeelia, Celine, Lisa, Philipp, Peter, Tanja and Claudi, and many more for a great time in this lovely town! Additionally, I wish to thank all the people who commented on this thesis: Chris and Chris, Celine, Lisa, Eva, Heather, Josi and Niki, thanks you so much for your help!

Last but not least I would like to thank my family who always supported me and respected what I am doing. I am glad and privileged to have such a nice family supporting me whatever comes. 


\section{Curriculum Vitae}

\section{Pascal Roger Marty}

Born in Zürich, Switzerland, 02.06.1982

\section{Academic Education}

$2011-2015 \quad$ PhD candidate

Institution: German Primate Center, Göttingen.

PhD Project: $\quad$ Male migration in crested macaques (Macaca nigra)

Supervisor: Dr. Antje Engelhadt, Prof. Dr. Keith Hodges and

Prof. Dr. Julia Fischer

2007 - 2009 Master of Science in Biology, Specialization in Anthropology

Institution: Anthropological Institute and Museum, University of Zurich

Masters project: $\quad$ Behavioural Endocrinology of Male Bornean Orangutans (Pongo pygmaeus wurmbii)

Supervisor: Dr. Tony Weingrill, Dr. Maria van Noordwijk and

Prof. Carel P. van Schaik

10/2007-12/2009 Master studies in Anthropology

2007 Diploma in animal handling and experiments on animals

2006-2007 Bachelor of Science in Biology

University of Zurich, Switzerland

$2004-2006 \quad$ Basic studies in Biology

University of Zurich, Switzerland 


\section{Research Experience}

Macaca Nigra Project. North Sulawesi, Indonesia. October 2011- December 2012. Field work including behavioural data collection, Hormone sampling, DNA sampling and Experiments. Data collection for PhD thesis, German Primate Center, Göttingen, Germany.

Study species: Crested macaques (Macaca nigra)

Useless loop Dolphin Project. Shark Bay, Australia. April 2010 - July 2010. Behavioural data collection.

Study species: Bottlenose dolphins (Tursiops sp.)

Faculty of Veterinary Medicine. Bogor Agricultural University, Indonesia. January 2009 February 2009. Laboratory Work (extracting and preparing hormone samples).

Tuanan Research Station. Mawas Reserve, Central Kalimantan, Indonesia. June 2008December 2008. 6 months field work including observational data collection, Hormone sampling, DNA sampling and camp managing. MSc research, University of Zurich.

Study species: Bornean orangutans (Pongo pygmaeus wurmbii)

Kalahari Meerkat Project. Kuruman River Reserve, South Africa. August 2007, Experimental Field course in Behaviour, Ecology and Evolution.

\section{Laboratory skills}

Preparing, conducting and analysing enzyme immunoassays for glucocorticoids and androgens (trained in the hormone laboratory of Dr. Michael Heistermann, German Primate Center)

\section{Linguistic skills}

German (native)

English (fluent)

French (communication skills)

Indonesian (communication skills)

\section{Computer skills}

Geographical Information Systems and Remote Sensing:

Data processing and graphing:

Statistics:

Mapping, Home range and ranging behaviour analysis

Word processing:

Microsoft Access and Excel, $R$

Bibliography:

$R$, SPSS

Imaging and photo-editing:

Microsoft Word, Adobe Acrobat

Data presenting:

Endnote, Mendeley

Adobe Photoshop, Adobe Illustrator

Microsoft PowerPoint, Adobe Illustrator 


\section{Publications}

Marty PR, Hodges, K, Agil, M, Engelhardt, A (2014). Alpha male takeovers by immigrant males in crested macaques. American Journal of Physical Anthropology 153: 177-178

Dunkel LP, van Noordwijk MA, Marty P, Prasetyo E, Atmoko SSU, van Schaik CP (2011). Male Mating Strategies: A Comparison between Bornean and Sumatran Orangutans. Folia Primatologica 82: 337-338

Marty P, Cadilek M, Dunkel L, Heistermann M, Weingrill T (2009). Glucocorticoid and Androgen Levels in Flanged and Unflanged Wild Bornean Orang-Utans. Folia Primatologica 80:165-165

Cadilek M, Marty P, Dunkel L, Heistermann M, Weingrill T (2009). Female Behaviour and Stress Levels in Response to Interactions with Males in Bornean Orang-Utans (Pongo pygmaeus wurmbii). Folia Primatologica 80:153-153

Weingrill T, Cadilek M, Marty P, Heistermann M (2009). Faecal Glucocorticoid Levels of Zoo and Wild Bornean Orang-Utans: How Stressed Are Orang-Utans in Captivity? Folia Primatologica 80:148-149

\section{In revision:}

Marty PR, Hodges K, Agil M, Engelhardt A. Cost and benefit dependent migrating strategies in male crested macaques (Macaca nigra). Animal Behaviour

Marty PR, Hodges K, Agil M, Engelhardt A. Alpha male replacements and delayed dispersal in male crested macaques (Macaca nigra). American Journal of Primatology

Marty PR, van Noordwijk MA, Heistermann M, Willems EP, Dunkel L, van Schaik CP, Cadilek M, Agil M, Weingrill T. New Endocrinological Implications for Male Bimaturism in Wild Bornean Orangutans. American Journal of Primatology

\section{In preparation:}

Marty PR, Hodges K, Heistermann M, Agil M, Engelhardt A. Hormonal correlates of immigrations in male crested macaques (Macaca nigra)

Dunkel LP, van Noordwijk MA, Marty PR, Prasetyo E, Atmoko Utami SS, van Schaik CP: Flanged male mating strategies and the benefit of arrested development: A comparison between Sumatran and Bornean orangutans

\section{Acknowledged contribution:}

Arora N, van Noordwijk MA, Ackermann C, et al. (2012). Parentage-based pedigree reconstruction reveals female matrilineal clusters and male-biased dispersal in nongregarious Asian great apes, the Bornean orang-utans (Pongo pygmaeus). Molecular ecology 21: 3352-62, for GIS data analyses 


\section{Conference attended}

- $\quad$ German Zoological Society, Göttingen, 2014,

- International Primatology Society, Hanoi, 2014,

(oral presentation)

- American Association of Physical Anthropologists, $83^{\text {rd }}$ annual meeting, Calgary 2014,

- $\quad$ X Göttinger Freilandtage 2013

- VII Göttinger Freilandtage 2009

- European Federation for Primatology, $3^{\text {rd }}$ International Congress, Zurich (2009).

(Poster presentation)

\section{Relevant Jobs}

November - December 2010: $\quad$ Research assistant at the Anthropological Institute and Museum University of Zurich, GIS work on home ranges/travel lengths/movement behaviours of Bornean orangutans

September 2010-May 2011: $\quad$ Guide for zoological tours at the Zoo Zurich

Pascal Marty 
I hereby declare that I have written this thesis entitled "Male migrations and alpha male takeovers in crested macaques, Macaca nigra" independently and with no other aids or sources than quoted

Pascal Marty 